\title{
EXBELT: expelling belt restraints from psychogeriatric nursing homes
}

Citation for published version (APA):

Gulpers, M. J. M. (2013). EXBELT: expelling belt restraints from psychogeriatric nursing homes. [Doctoral Thesis, Maastricht University]. Datawyse / Universitaire Pers Maastricht. https://doi.org/10.26481/dis.20130419mg

Document status and date:

Published: 01/01/2013

DOI:

10.26481/dis.20130419mg

Document Version:

Publisher's PDF, also known as Version of record

\section{Please check the document version of this publication:}

- A submitted manuscript is the version of the article upon submission and before peer-review. There can be important differences between the submitted version and the official published version of record.

People interested in the research are advised to contact the author for the final version of the publication, or visit the DOI to the publisher's website.

- The final author version and the galley proof are versions of the publication after peer review.

- The final published version features the final layout of the paper including the volume, issue and page numbers.

Link to publication

\footnotetext{
General rights rights.

- You may freely distribute the URL identifying the publication in the public portal. please follow below link for the End User Agreement:

www.umlib.nl/taverne-license

Take down policy

If you believe that this document breaches copyright please contact us at:

repository@maastrichtuniversity.nl

providing details and we will investigate your claim.
}

Copyright and moral rights for the publications made accessible in the public portal are retained by the authors and/or other copyright owners and it is a condition of accessing publications that users recognise and abide by the legal requirements associated with these

- Users may download and print one copy of any publication from the public portal for the purpose of private study or research.

- You may not further distribute the material or use it for any profit-making activity or commercial gain

If the publication is distributed under the terms of Article $25 \mathrm{fa}$ of the Dutch Copyright Act, indicated by the "Taverne" license above, 


\section{EXBELT: expelling belt restraints from psychogeriatric nursing homes}

Mathieu Joseph Maria Gulpers 
The research presented in this thesis was conducted at the School for Public Health and Primary Care: CAPHRI, Department of Health Services Research (HSR), of Maastricht University. CAPHRI participates in the Netherlands School of Primary Care Research CaRe. CAPHRI was classified as 'excellent' by the external evaluation committee of leading international experts that reviewed CAPHRI in December 2010.

ISBN 9789461592231

(c) 2013, Math JM Gulpers,

Email: m.gulpers@zw.unimaas.nl

Maastricht University, Faculty of Health, Medicine and Life Sciences, Department of Health Service Research, School for Public Health and Primary Care (Caphri), PO Box 616, 6200 MD, Maastricht, The Netherlands

Photography: Erick Van Heugten

Cover design: Oburon Design (Robert Nijboer), www.oburon.nl Lay-out and printing: Datawyse / Universitaire Pers Maastricht 


\title{
EXBELT: expelling belt restraints from psychogeriatric nursing homes
}

\author{
PROEFSCHRIFT \\ ter verkrijging van de graad van doctor \\ aan de Universiteit Maastricht, \\ op gezag van de Rector Magnificus, \\ Prof. dr. L.L.G. Soete, \\ volgens het besluit van het College van Decanen, \\ in het openbaar te verdedigen \\ op vrijdag 19 april 2013 om 16.00 uur \\ door \\ Mathieu Joseph Maria Gulpers
}

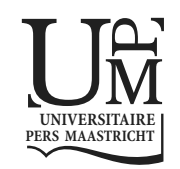




\section{Promotores}

Prof. dr. J.P.H. Hamers

Prof. dr. E Capezuti (NYU)

\section{Copromotores}

Dr. E van Rossum

Dr. M.H.C. Bleijlevens

\section{Beoordelingscommissie}

Prof. dr. F.R.J. Verhey (voorzitter)

Prof. dr. E.J.A. Scherder (VU)

Prof. dr. J.M.G.A. Schols

Prof. dr. M.J. Schuurmans (UMCU)

Prof. dr. N. de Vries

ZonMw - The Netherlands Organization for Health Research and Development (grant number 8140.0006), MeanderGroep Zuid Limburg, the School for Public Health and Primary Care (Caphri), and the Maastricht University are gratefully acknowledged for funding the studies in this thesis. 


\section{Contents}

$\begin{array}{lll}\text { Chapter } 1 \text { General introduction } & 7\end{array}$

$\begin{array}{lll}\text { Chapter } 2 & \text { Belt restraint reduction in } & 15\end{array}$

nursing homes:

Design of a quasi-experimental study

Published in BMC Geriatrics. 2010;10: 11

Chapter 3 Belt restraint reduction in nursing homes:

Effects of a multi-component intervention program

(EXBELT)

Published in Journal of the American Geriatrics Society.

2011;59: 2029-2036

Chapter 4 Preventing belt restraint use in newly admitted

residents in nursing homes: A quasi-experimental study

Published in International Journal of Nursing Studies

2012:1007-1013

Chapter 5 Process Evaluation of a multi-component intervention

program (EXBELT) to reduce belt restraints in nursing homes

Accept for publication 5 March 2013 in Journal of the American Medical Directors Association

Chapter 6 Reduction of belt restraint use: Long-term effects of the EXBELT intervention

Published in Journal of the American Geriatrics Society. 2013;61: 107-112

Chapter 7 General discussion

Summary 105

Nederlandse samenvatting

Dankwoord

About the author

List of publications 

Chapter 1

General introduction 


\section{General introduction}

The routine use of physical restraints in nursing homes must be reduced. This is the basic proposition of the studies presented in this thesis.

The use of physical restraints is highly prevalent in psychogeriatric nursing home care. Psychogeriatric nursing homes in the Netherlands provide longterm care to mainly very frail, older adults, of which $85 \%$ suffer from dementia. ${ }^{1}$ Of the estimated 235,000 people with dementia in the Netherlands, about 40,000 reside in psychogeriatric nursing homes. ${ }^{2}$ It is expected that the number of people with dementia in the Netherlands will increase to 400,000 by $2050,{ }^{3}$ thus, it is likely that those institutionalized will increase proportionately.

The most common types of dementia are Alzheimer's disease (approximately 70\%), vascular dementia (16\%), frontotemporal dementia, and Lewy body dementia. ${ }^{2}$ Dementia is a progressive brain disorder that gradually results in care dependence. About $70 \%$ of the people with dementia live at home with support from family, friends, or home care. However, as the disease progresses, admission to a nursing home often becomes necessary. ${ }^{2}$

Care in Dutch nursing homes is mostly provided by the nursing staff members with qualification levels of basic nursing aides, nursing assistants, certified nursing assistants (about 87\%), and registered nurses. The other members of the multidisciplinary team are, for example, physicians, physiotherapists, occupational therapists, and psychologists. ${ }^{4}$

Physical restraints are defined as any limitations in an individual's freedom of movement by the use of devices. ${ }^{5}$ The most commonly used devices for physical restraints are (wheel) chairs with a locked table, full enclosure bedrails, or belts tied to a (wheel) chair or bed. Belt restraints are devices used around the waist to secure a patient on a bed or in a (wheel) chair. Belts are one of the most restrictive types of physical restraints. ${ }^{6,7}$ The prevalence of physical restraint use in nursing homes is between $15 \%$ and $66 \%$ internationally. ${ }^{8-10}$ Recent measurements show that restraints are applied to about $57 \%$ of the residents in Dutch psychogeriatric nursing homes; the self-reported prevalence of belt restraint use is $10 \%$ to $14 \% .^{11-13}$ The most common reason $(90 \%)$ for the use of restraints is to prevent falls. ${ }^{14,} 15$ In addition, physical restraints are used to prevent wandering, to manage agitation, and reduce aggression. ${ }^{16}$

However, physical restraints' use is ineffective in fall prevention and sometimes is even harmful. Although they are used to enhance residents' safety and, mostly, to prevent falls and fall-related injuries, various studies conclude that restraints' use is ineffective in this way. ${ }^{9}, 14,17-19$ Mobility and cognition decrease, while care dependency and risk of falls increase in residents who are managed using physical restraints. ${ }^{20,21}$ Restraint use can contribute to disturb- 
ances of balance and coordination and the loss of muscle strength and endurance. ${ }^{14,15,22-24}$ Furthermore, the use of physical restraints has various other negative physical, psychological, and social consequences for the residents, such as incontinence, pressure ulcers, depression, aggression, discomfort, demoralization, and mortality. 22, 25, 2627

In short, physical restraints are used frequently in nursing home practice despite empirical evidence discounting their effectiveness and safety. This is especially for restrictive measures such as belt restraints. The question is how can these physical restraints be reduced effectively?

In the last decennium several efforts have been done by international research groups to develop effective restraint reduction programs. ${ }^{28-33}$ The majority of these programs consist of educational programs for staff, consultation by expert nurses, and a combination of educational programs with expert consultation. ${ }^{8,28,29,31-40}$ A recent review ${ }^{41}$ shows that in addition to education and consultation, other interventions such as guidance, information program for family members of the residents, policy change, and availability of alternative interventions have been used. ${ }^{32,33,41-44}$ However, in general the results of these interventions were rather disappointing and ranged from no reduction effects to some with short-term, small effects. ${ }^{8,17,29,31-34,45}$ A summary of these studies support the argument that the effects of education and consultation on the reduction of restraint use is not clear. If there is a positive effect, mostly it is a preventive effect in newly admitted residents, instead of a reduction of the use of physical restraints. ${ }^{28,32,36}$ These interventions reduce restraint use however, there lack of any long-term reduction has significant consequences for frail older adults residing in nursing homes.

\section{Research on restraint reduction by the Maastricht group}

Our research group at Maastricht University started their studies on physical restraints in 1999, with a study on the prevalence of physical restraints in psychogeriatric nursing homes. 5 This study showed that restraint use was highly prevalent (49\%) and that full-enclosure bedrails, belts, and (wheel) chairs with locked tables were the most frequently used restraints. Most disturbing was that that $91 \%$ of all restraints were used as a routine measure and had been used for at least the last three months. The most commonly cited reason for using restraints was to prevent falls (80\%). ${ }^{9,46}$

Based on this study, we decided to develop an approach aiming to reduce physical restraints and to prevent the use of new restraint measures in nursing home residents. The approach was derived from a study with promising results in the USA ${ }^{45}$ and consisted of a combination of education and consultation by a 
nurse specialist. The intervention was introduced on nursing home wards and evaluated using a cluster randomized trial. ${ }^{29}$ The results of this approach were rather disappointing; we were neither able to demonstrate a reduction of restraint use nor the prevention of new restraints. However, the study also resulted in clear indications for the further development of an approach to reduce restraints, such as the need for a clear policy on restraint use, a culture change in attitudes of nursing home staff regarding about the use of physical restraints and more involvement of multidisciplinary staff and residents' relatives. Furthermore, this study revealed new and rather unexpected findings regarding the association between organizational characteristics and the use of physical restraints. Organizational characteristics (workload, experienced social support from colleagues and supervisors provided to nursing staff, the percentage of registered nurses on staff, and the rate of sickness absence) were not associated with physical restraint use. ${ }^{47}$ At the same time, we studied the attitudes and opinions regarding restraint use in nursing home staff 7, 18, 24 in order to get valuable information to further develop a new restraint reduction approach.

These studies have resulted in an improved intervention, named EXBELT (expelling belts), focusing primarily on restrictive restraints such as belts, and secondarily on other measures, such as bedrails. EXBELT consist of a policy change, an educational program, expert consultation, and the availability of alternative interventions. The intervention was introduced at 1 nursing home ward where belt use was highly prevalent: at baseline, belts were used in 12 of 30 residents. After 3 and 9 months' follow-up, only 1 belt was still in use. This reduction did not result in an increase of other restrictive physical restraint use, fall-related injuries, or psychoactive drug use. ${ }^{46}$ Although this study indicated the feasibility of the implementation of the EXBELT approach, no conclusions could be drawn about its efficacy; this small study did not employ a controlled design. It was necessary to evaluate the effects of the EXBELT approach in a large and controlled study.

\section{Aims and outline of the thesis}

The overall aim of this thesis is to evaluate the effects and feasibility of the EXBELT intervention to reduce and prevent the use of belt restraints. The main research questions in this thesis are:

1. Does a multi-component intervention (EXBELT) result in the reduction and prevention of the use of belts and other types of physical restraints on residents in psychogeriatric nursing homes in the Netherlands?

2. Does belt elimination result in an increase in falls and fall-related injuries? 
3. Does the effect of EXBELT persist in the long-term for belt and other physical restraint use?

4. To what extent is the EXBELT intervention program feasible?

\section{Outline}

Chapter 2 describes the design of a quasi-experimental study, exploring the effects and feasibility of the EXBELT program.

Chapter 3 reports on EXBELT's effectiveness in reducing belt and other restraint usage, and on falls and fall-related injuries.

Chapter 4 presents the preventive effect of EXBELT on belt restraint use in newly admitted residents of psychogeriatric nursing homes.

Chapter 5 reports the findings of the process evaluation and contains six main components: fidelity, dose delivered, dose received (satisfaction and exposure), reach, and barriers.

Chapter 6 describes effects of the EXBELT on belt and other physical restraint use 24 months after baseline.

Finally, Chapter 7 contains a general discussion and presents the main findings of this thesis, in addition to some theoretical and methodological considerations of the previous studies, and gives suggestions regarding the implications and challenges for future research and clinical practice. 


\section{References}

[1] Schols JMGA, Van der Schriek - van Weel C. Day care for demented elderly in a dairy farm setting. J Am Med Dir Assoc. 2006;456 - 459.

[2] Alzheimer's Association. Alzheimer's disease facts and figures. . Alzheimers Dement 2010. 2010: 36.

[3] CBS. Kerncijfers van de bevolkingsprognoses 2008-2050. Centraal Burreau voor de Statistiek (CBS). 2008.

[4] te Boekhorst S, Willemse B, Depla MF, Eefsting JA, Pot SM. Working in group living homes for older people with dementia: the effects on job satisfaction and burnout and the role of job characteristics. International Psychogeriatric Association. 2008;20:5: 13.

[5] Hantikainen V. Physical restraint: a descriptive study in Swiss nursing homes. Nursing Ethics. 1998; 5: 330-346.

[6] Halfens RJG, Meijers JMM, Neyens JCL, Offermans MPW. Rapportage resultaten Landelijke Prevalentiemeting Zorgproblemen 2007. Maastricht: Universiteit Maastricht; Onderzoeksinstituut Caphri, Department of Healt Care and Nursing Sciences, 2007.

[7] Hamers JP, Meyer G, Kopke S, Lindenmann R, Groven R, Huizing AR. Attitudes of Dutch, German and Swiss nursing staff towards physical restraint use in nursing home residents, a crosssectional study. Int J Nurs Stud. 2009;46: 248-255.

[8] Capezuti E, Wagner LM, Brush BL, Boltz M, Renz S, Talerico KA. Consequences of an intervention to reduce restrictive side rail use in nursing homes. Journal of the American Geriatrics Society. 2007;55: 334-341.

[9] Hamers JP, Gulpers MJ, Strik W. Use of physical restraints with cognitively impaired nursing home residents. Journal of Advanced Nursing. 2004;45: 246-251.

[10] Meyer G, Kopke S, Haastert B, Muhlhauser I. Restraint use among nursing home residents: cross-sectional study and prospective cohort study. Journal of Clinical Nursing. 2009;18: 981990.

[11] Halfens R, Meesterberends E, Meijers J, et al. Landelijke Prevalentiemeting Zorgproblemen 2011. 2011.

[12] Halfens RJG, Meijers JMM, Neyens JCL, Offermans MPW. Rapportage resultaten Landelijke Prevalentiemeting Zorgproblemen 2008. Maastricht: Universiteit Maastricht; Onderzoeksinstituut Caphri, Department of Healt Care and Nursing Sciences, 2008.

[13] IGZ. Zorg voor vrijheid: terugdringen van vrijheidsbeperkende maatregelen kan en moet. Den Haag: IGZ, 2008.

[14] Capezuti E. Minimizing the use of restrictive devices in dementia patients at risk for falling. Nursing Clinics of North America. 2004;39: 625-647.

[15] Werner P. Perceptions regarding the use of physical restraints with elderly persons: comparison of Israeli health care nurses and social workers. Journal of Interprofessional Care. 2002;16: 59-68.

[16] Evans D, FitzGerald M. Reasons for physically restraining patients and residents: a systematic review and content analysis. International journal of nursing studies. 2002;39: 735-743.

[17] Capezuti E, Maislin G, Strumpf N, Evans LK. Side rail use and bed-related fall outcomes among nursing home residents. Journal of the American Geriatrics Society. 2002;50: 90-96.

[18] Hamers JP, Huizing AR. Why do we use physical restraints in the elderly? Z Gerontol Geriatr. 2005;38: 19-25.

[19] Neufeld RR, Libow LS, Foley WJ, Dunbar JM, Cohen C, Breuer B. Restraint reduction reduces serious injuries among nursing home residents. Journal of the American Geriatrics Society. 1999;47: 1202-1207.

[20] Castle NG, Engberg J. The health consequences of using physical restraints in nursing homes. Med Care. 2009;47: 1164-1173. 
[21] Engberg J, Castle NG, McCaffrey D. Physical restraint initiation in nursing homes and subsequent resident health. The Gerontologist. 2008;48: 442-452.

[22] Evans D, Wood J, Lambert L. Patient injury and physical restraint devices: a systematic review. Journal of Advanced Nursing. 2003;41: 274-282.

[23] Hamers JP, Huizing AR. The use of physical restraints in elderly people: nurses' attitudes. . Abstractbook 18th world congress of the international association of gerontology. 2005b.

[24] Hamers JP, Huizing AR, Lindenmann HP. Measuring nurses' attitudes regarding physical restraint use. Proceedings of the Abstractbook 60th Annual Scientific Meeting of the Gerontological Society of America. 2007: 1.

[25] Castle NG, Mor V. Physical restraints in nursing homes: a review of the literature since the Nursing Home Reform Act of 1987. Med Care Res Rev. 1998;55: 139-170; discussion 171-136.

[26] Miles SH, Irvine P. Deaths caused by physical restraints. The Gerontologist. 1992;32: 762-766.

[27] IGZ. Circulaire 2000-11, maatregelen bij ongelukken door het gebruik van de Zweedse band. Den Haag: IGZ, 2008.

[28] Huizing AR, Hamers JP, Gulpers MJ, Berger MP. Short-term effects of an educational intervention on physical restraint use: a cluster randomized trial. BMC Geriatr. 2006;6: 17.

[29] Huizing AR, Hamers JP, Gulpers MJ, Berger MP. A cluster-randomized trial of an educational intervention to reduce the use of physical restraints with psychogeriatric nursing home residents. J Am Geriatr Soc. 2009;57: 1139-1148.

[30] Mion LC. Physical restraint in critical care settings: will they go away? Geriatric Nursing. 2008;29: 421-423.

[31] Pellfolk TJ, Gustafson Y, Bucht G, Karlsson S. Effects of a restraint minimization program on staff knowledge, attitudes, and practice: a cluster randomized trial. J Am Geriatr Soc. 2010;58: 62-69.

[32] Testad I, Aasland AM, Aarsland D. The effect of staff training on the use of restraint in dementia: a single-blind randomised controlled trial. International Journal of Geriatric Psychiatry. 2005;20: 587-590.

[33] Testad I, Ballard C, Bronnick K, Aarsland D. The effect of staff training on agitation and use of restraint in nursing home residents with dementia: a single-blind, randomized controlled trial. J Clin Psychiatry. 2010;71: 80-86.

[34] Huizing AR, Hamers JP, Gulpers MJ, Berger MP. Preventing the use of physical restraints on residents newly admitted to psycho-geriatric nursing home wards: a cluster-randomized trial. Int J Nurs Stud. 2009;46: 459-469.

[35] Koczy P, Becker C, Rapp K, et al. Effectiveness of a multifactorial intervention to reduce physical restraints in nursing home residents. J Am Geriatr Soc. 2011;59: 333-339.

[36] Kuske B, Luck T, Hanns S, et al. Training in dementia care: a cluster-randomized controlled trial of a training program for nursing home staff in Germany. International Psychogeriatrics. 2009;21: 295-308.

[37] Lai CKY, Chan MH, Szeto SSL, et al. A retrospective study on the outcomes of a collaborative restraint reduction project by a residential home for older people and a hospital-based community geriatric assessment service. Hong Kong Nursing Journal. 2006;42: 23-30.

[38] Mac Dermaid L, Byrne C. Restraint reduction education. Canadian Nursing Home. 2006;17: 10 14.

[39] Milke DL, Kendall TS, Neumann I, Wark CF, Knopp A. A longitudinal evaluation of restraint reduction within a multi-site, multi-model Canadian continuing care organization. Canadian Journal of Aging. 2008;27: 35-43.

[40] Wagner LM, Capezuti E, Brush B, Boltz M, Renz S, Talerico KA. Description of an advanced practice nursing consultative model to reduce restrictive siderail use in nursing homes. $R e$ search in Nursing and Health. 2007;30: 131-140.

[41] Mohler R, Richter T, Kopke S, Meyer G. Interventions for preventing and reducing the use of physical restraints in long-term geriatric care. Cochrane Database Syst Rev. 2011: CD007546. 
[42] Gulpers MJ, Bleijlevens MH, Ambergen T, Capezuti E, van Rossum E, Hamers JP. Belt restraint reduction in nursing homes: effects of a multicomponent intervention program. J Am Geriatr Soc. 2011;59: 2029-2036.

[43] Gulpers MJ, Bleijlevens MH, van Rossum E, Capezuti E, Hamers JP. Belt restraint reduction in nursing homes: design of a quasi-experimental study. BMC Geriatr. 2010;10: 11.

[44] Haut A, Kopke S, Gerlach A, Muhlhauser I, Haastert B, Meyer G. Evaluation of an evidencebased guidance on the reduction of physical restraints in nursing homes: a clusterrandomised controlled trial [ISRCTN34974819]. BMC Geriatr. 2009;9: 42.

[45] Evans LK, Strumpf NE, Allen-Taylor SL, Capezuti E, Maislin G, Jacobsen B. A clinical trial to reduce restraints in nursing homes. Journal of the American Geriatrics Society. 1997;45: 675681.

[46] Hamers JPH, Gulpers MJM. Reducing physical restraints in nursing homes: results of a pilot study. Journal of Nutrition, Health \& Aging 2009;suppl.: S17.

[47] Huizing AR, Hamers JP, de Jonge J, Candel M, Berger MP. Organisational determinants of the use of physical restraints: a multilevel approach. Soc Sci Med. 2007;65: 924-933. 


\section{Chapter 2}

\section{Belt restraint reduction in}

nursing homes:

Design of a quasi-experimental study

Math J M Gulpers, Michel H C Bleijlevens, Erik van Rossum, Elizabeth Capezuti, Jan P H Hamers

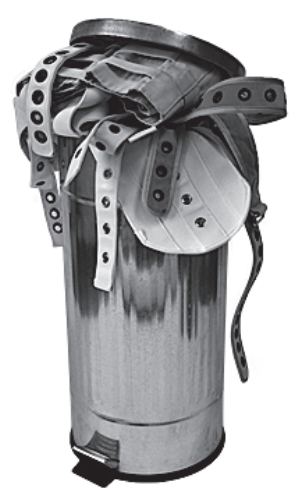

Published in BMC Geriatrics. 2010;10: 11 


\begin{abstract}
Background: The use of physical restraints still is common practice in the nursing home care. Since physical restraints have been shown to be an ineffective and sometimes even hazardous measure, interventions are needed to reduce their usage. Several attempts have been made to reduce the use of physical restraints. Most studies used educational approaches and introduced a nurse specialist as a consultant. However, the success rate of these interventions has been inconsistent. We developed a new multi-component intervention (EXBELT) comprising an educational intervention for nursing home staff in combination with a policy change (belt use is prohibited by the nursing home management), availability of a nurse specialist and nursing home manager as consultants, and availability of alternative interventions. The first aim of this study is to further develop and test the effectiveness of EXBELT on belt restraint reduction in Dutch psychogeriatric nursing homes. However, the reduction of belts should not result in an increase of other restrictive restraints (such as a chair with locked tray table) or psychoactive drug use. The overall aim is an effective and feasible intervention that can be employed on a large scale in Dutch nursing homes.
\end{abstract}

Methods and design: Effects of EXBELT will be studied in a quasiexperimental longitudinal study design. Alongside the effect evaluation, a process evaluation will be carried out in order to further develop EXBELT. Data regarding age, gender, use of physical restraints, the number of falls and fall related injuries, psychoactive drug use, and the use of alternative interventions will be collected at baseline and after four and eight months of follow-up. Data regarding the process evaluation will be gathered in a period of eight months between baseline and the last measurement. Furthermore, changing attitudes will become an important addition to the educational part of EXBELT.

Discussion: A quasi-experimental study is presented to investigate the effects of EXBELT on the use of belts on wards in psychogeriatric nursing homes. The study will be conducted in 26 wards in 13 psychogeriatric nursing homes. We selected the wards in a manner that contamination between control- and intervention group is prevented. 


\section{Background}

The use of physical restraints still is common practice in the nursing home care of older people with dementia. Physical restraints are defined as any limitation in an individual's freedom of movement ${ }^{1}$ and includes those worn by the person (belt, chest, and arm/leg), those attached to beds (full-enclosure bedrails) or chairs (locked table). Although reports of restraint prevalence internationally varies from 15 to $66 \%{ }^{2}, 3$, ranges of restraint prevalence in Dutch nursing homes is between 41 to $64 \% .{ }^{2}$ Recent prevalence measures in the Netherlands have shown that $10 \%$ to $14 \%$ of nursing home residents are restrained with belts. ${ }^{4,5}$

Staff report that physical restraints are used to prevent falls. ${ }^{6-8}$ The accumulating evidence that restraint reduction does not lead to an increased number of falls or fall-related injuries ${ }^{9-11}$ and that restraint use can result in falls and problems with balance and coordination $6,12,13$, call into question the continued use of these devices as "safety measures". Restraints have other known negative physical, psychological and social consequences for older persons. Both prolonged and short periods of physical restraint use are associated with pressure sores, loss of muscle strength and endurance, joint contractures, incontinence, demoralization, humiliation feelings of low self worth, depression, aggression and impaired social functioning. ${ }^{6,14,15}$ Evans and colleagues ${ }^{12}$ conducted a systematic review of physical restraint use in acute and residential health care facilities, and documented that the use of physical restraints (including belts), increases the risk of death, serious injury, as well as the length of hospital stay. Older adults report negative feelings about the restraint experience such as discomfort and indifference. ${ }^{16}$ The use of restraints may also indicate a failure to address the real needs of the residents. Since physical restraints have been shown to be an ineffective and sometimes even hazardous measure, interventions are needed to reduce their usage.

Several attempts have been made to reduce restraint use in clinical practice. ${ }^{17-}$ 22 Most interventions used educational approaches, aiming to improve nursing staff knowledge and confidence to avoid physical restraints and to use alternative measures that target the resident's underlying problems. 18, 19, 21, 22 These intensive training sessions were delivered to staff by a nurse specialist provided to the nursing home as a consultant from the study team. The success rate of these interventions differs between countries; a successful educational intervention in the USA ${ }^{18}$ proved to be ineffective in the Netherlands.19,23,24 It is unclear whether these contradictory results can be explained by cultural differences, differences in health care systems, or difference in educational level of 
nursing staff in nursing homes between the USA and the Netherlands. The results of a recent study among Dutch, German and Swiss nursing staff indicate that opinions and attitudes towards physical restraints hinder attempts to reduce restraint use. ${ }^{25}$ In this study, almost all nursing staff assessed the use of physical restraints in their clinical practice as appropriate. Moreover, Dutch nursing staff consistently assessed restraint measures as less restrictive than German and Swiss nursing staff and reported less discomfort in using restraints. ${ }^{25}$ Furthermore, this and other studies indicate that the availability of alternative interventions is essential for effective restraint reduction. 19, 23-25 For instance, in the study by Huizing and colleagues it was reported that the availability of some new and rather expensive alternative measures was limited. ${ }^{23}$ Finally, there are indications that legislation influences the use of restraints; the success of the educational intervention in the USA has also been supported by a nursing home law that led to national nursing home regulations (OBRA '87) that discourage restraint use. ${ }^{26,27}$ In the Netherlands, the secretary of state of the Ministry of Health, Welfare and Sports in 2009 has introduced a bill in Parliament ("Wet Zorg en Dwang") that regulates the use of physical restraints in people with dementia in general and belts in particular. According to this bill, the usage of belts to prevent falls will no longer be allowed. ${ }^{28}$ The proposed changes in legislation provide an opportunity to develop a multi-component intervention tailored to the Dutch nursing home environment that will assist facilities in meeting this new requirement.

Among restraints used in Dutch nursing homes, belts are the most restrictive measure 4, 19 therefore our intervention program, named EXBELT, primarily focuses on belt use reduction. ${ }^{25}$ The EXBELT intervention includes four components: (1) promotion of institutional policy change that discourages belt restraint use, (2) education, (3) consultation by a nurse specialist, and (4) development and availability of alternative interventions. Cultural differences in staff opinions is an important consideration for the development of effective interventions. The educational component (including strategies for changing attitudes) for nursing home staff (physicians, nurses, paramedical staff and psychologist) is based on the intervention developed by Evans and colleagues 18 and Huizing and colleagues ${ }^{19,23-25}$ that is customized for Dutch nursing home staff.

In 2007, EXBELT was developed and piloted in one nursing home ward. ${ }^{29}$ The results of this pilot study were very promising. At baseline, 12 belts in 30 residents were used. After one month follow up, no belt was used, but after three and nine months follow up 1 belt was used. This reduction in belt use did not result in either an increase in the number of falls and related injuries or the use 
of other restrictive measures such as chairs with a locked tray table or psychoactive medication. Belts were replaced with, resident-centered interventions, such as movement and balance training, lower beds, hip protectors, extra supervision and monitoring devices (video camera, sensor mat, and infrared alarm systems). The recent expansion of the pilot (in 2008) to other wards in the same nursing home has shown similar results. However, this home does not represent a typical Dutch facility since it is considered as 'best practice' regarding restraint reduction initiatives and research. Thus, further testing of the EXBELT intervention is needed on wards in other nursing homes prior to widespread dissemination.

\section{Study aim and research questions}

The first aim of this study is to further develop and test the effectiveness of a tailored multi-component intervention program (EXBELT) on belt restraint reduction in Dutch psychogeriatric nursing homes. However, the reduction of belts should not result in an increase of other restrictive restraints (such as a chair with locked tray table) or psychoactive drug use. The overall aim is an effective and feasible intervention that can be employed on a large scale in Dutch nursing homes. We translated the aims into the following eight specific research questions:

1. Does a tailored multi-component intervention (EXBELT) result in the reduction of belts in nursing homes?

2. Does EXBELT prevent the use of belts in newly admitted residents?

3. Does EXBELT reduce the use of other types of physical restraints?

4. Does belt elimination result in an increase of falls and fall related injuries?

5. What resident centered alternative interventions are used in EXBELT?

6. What is the opinion of nursing home staff, management and residents' relatives about EXBELT and the effectiveness of alternative interventions?

7. What are indicators for successful or unsuccessful implementation of EXBELT?

8. What improvements (related to content, organization and monitoring) are necessary to optimize the effect of EXBELT? 


\section{Methods}

\section{Design and sample}

Effects of EXBELT will be studied in a quasi-experimental longitudinal study design. Alongside the effect evaluation, a process evaluation will be carried out in order to further develop EXBELT. Figure 1 shows the design of the study presented. After contacting seven Dutch nursing home associations (networks of nursing homes) in order to assess whether they would be interested to participate in our study, four nursing home associations, located in three regions in the Netherlands (Zuid-Limburg, Midden Limburg/ Zuid-Oost Brabant en ZuidHolland) contacted the EXBELT research group to participate in the current study. To participate, the prevalence of belt use on psychogeriatric nursing home wards had to be at least $10 \%$. Wards are excluded if the unit is dedicated to residents with Korsakoff's, if far-reaching reorganizations and/or constructional renovations will be implemented, and if participating in other studies and/or projects aimed at the reduction of restrain use. The total study sample comprises four nursing home associations, 13 nursing homes with a total of 26 psychogeriatric wards. The 26 wards were assigned to either the intervention or control group. Assignment to either to intervention or control groups was carried out by the research team. Since no randomization took place, allocation was based on avoidance of contamination bias. Overlap of nursing home staff between the intervention and control wards was averted. In addition, based on the geographical location of the participating wards, wards from each of the four nursing associations that were situated closely together were allocated to the same group. The wards allocated to the control group will receive care as usual, while the wards allocated to the intervention group will receive the EXBELT program.

The management boards of the four participating nursing home associations agreed with the implementation of the EXBELT program. After allocation of the wards to intervention and control groups, written information about the study will be given to the residents' legal representatives, and written informed consent will be obtained from the legal representatives of the nursing home residents in order to include those residents in the study. Data will be collected at baseline (T1), and four (T2) and eight (T3) months after baseline.

The study design and protocol were approved by the Medical Ethics Committee of the University Hospital Maastricht and Maastricht University. In addition, local Ethical Committees of participating institutions have given their consent to the protocol and procedures. 


\section{Sample size considerations}

Sample size calculations are based on the primary outcome measure for residents: proportion of residents using a belt. We expect a reduction of $50 \%$ in belt use in the intervention group and no changes in use in the control group. Based on a significance level $\alpha$ of 0.05 (two sided) and a power of $60 \%, 216$ residents are needed in each group in the analyses. Taken into account an informed consent rate of $80 \%$ and a drop-out rate of $25 \%, 720$ psychogeriatric nursing home residents have to be selected at the start of the study.

\section{Intervention program}

EXBELT is a multi-component intervention that comprises a policy change, in combination with an educational intervention for nursing home staff and consultation by a nurse specialist, and the use and availability of alternative interventions. The four key components of EXBELT are:

1. Implementation of institutional policy change that prohibits belt restraint use including communication of the policy change to:

a. nursing home staff;

b. residents' relatives.

2. Intensive educational intervention program for nursing home staff (nursing home physicians, nurses, paramedical staff, psychologists and ward managers) that address changing staff attitudes. Key parts are:

a. focus on safely reducing belts with the understanding that nursing homes never can guarantee no falls or related injuries;

b. taught by a nurse specialist during three small-scale meetings, each lasting three hours, over a three week period;

c. small-scale meetings attended by nursing home staff from different wards;

d. a 90-minute educational session directed toward all nursing home staff of each intervention ward after the three small-scale meetings were delivered;

e. one specific module focused on strategies for changing attitudes such as shifting perspectives. ${ }^{30,31}$

3. Consultation:

a. the nurse specialist who delivered the educational program will provide on-site consultation to individual nurses on the intervention wards regarding challenges in reducing restraints for specific resident cases ${ }^{18}$; 
b. a nursing home manager and the Netherlands Health Care Inspectorate (IGZ) will be available as a consultant to nursing home managers and clinical staff for individual cases, as needed;

c. representatives of the nursing staffs, product developers, and the research team will discuss problem cases in a creative session.

4. Development and availability of alternative interventions:

a. directors of the involved nursing homes will provide resident centered alternative interventions available including hip protectors, infrared systems, balance training, exercise, special pillows and lower beds;

b. the nurse specialist stimulates en facilitates decision-making regarding alternative interventions by multidisciplinary team;

c. the nurse specialist encourages the use of alternative interventions.

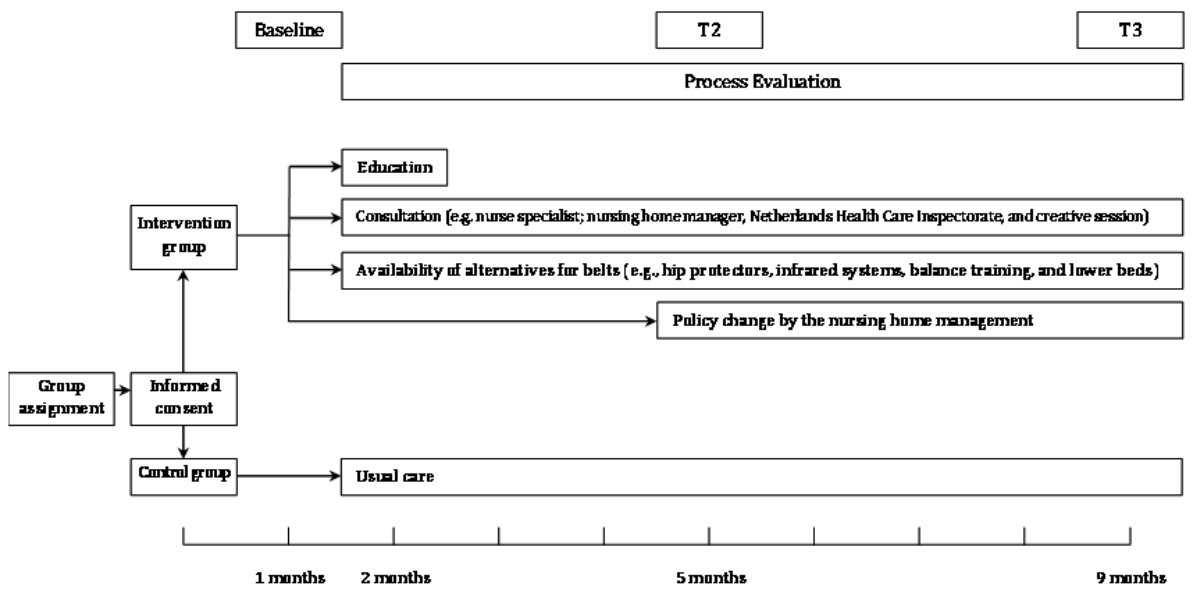

Figure 1. Study Design

\section{Measures}

\section{Effect evaluation}

The primary outcome measure of the effect evaluation is the use of belts. Belt use will be measured at baseline, T2 and T3 using the observation tool developed by Huizing and colleagues. 19, 23, 24 Belts per resident will be recorded as present or absent. The use of belts will be measured by a single trained observer, who is blinded to the group assignment, on four times during a 24-hour period (morning, afternoon, evening and night). The day each of the participating wards is visited will be unannounced in order to prevent any artificial removal of belts by nursing home staff. 
Secondary outcome measures include other types of physical restraints (e.g. bilateral full-enclosure bedrails, deep or overturned chairs, chairs with a locked tray table, chairs on a board), psychoactive drug use, number of falls and fallrelated injuries, the use of alternative interventions, cognitive level, activities of daily living (ADL)-status, ADL-dependency, and mobility. Physical restraint use will be measured at baseline, T2 and T3 using the same observation tool to measure the usage of belts developed by Huizing and colleagues. 19, 23, 24 Types of physical restraints per resident will be recorded as present or absent. The day each of the participating wards is visited will be unannounced in order to prevent any artificial removal of physical restraints by nursing home staff. Data on psychoactive drug use will be collected at baseline, T2 and T3 using the residents' medical records. Falls and fall-related injuries will be recorded retrospectively (three months preceding each of the three measurements, using the register of falls that Dutch nursing homes are required to maintain. ${ }^{32}$ The use of alternative interventions used will be monitored continuously, using a report chart (addressing type of intervention) that will be filled out by the nursing staff. Data concerning cognitive level, activities of daily living (ADL)-status, ADL-dependency, and mobility will be collected only for those residents who are restrained by a belt. Cognitive status will be measured using the Cognitive Performance Scale: 33 ADL-status will be measured using the ADL Selfperformance Hierarchy; ${ }^{34}$ ADL dependency will be measured using the Barthel index; ${ }^{35}$ and mobility will be measured using a mobility scale developed from MDS items. ${ }^{24}$ Agitation will be measured using the Cohen-Mansfield Agitation Index-short form. ${ }^{36,37}$ In addition, socio-demographic characteristics will be assessed at baseline, T2 and T3 for all residents participating in the study: age and gender.

\section{Process evaluation}

For conducting the process evaluation, other samples will be recruited in comparison with the effect evaluation. Depending on the study question, residents' relatives, nursing home staff, educators (nurse specialists), nursing home management, and the Netherlands Health Care Inspectorate (IGZ) will be invited to participate in different parts of the process evaluation.

The process evaluation will monitor the content and feasibility of the intervention program. Data regarding the process evaluation will be gathered regarding the eight month period between baseline and T3. First, to investigate the opinion of nursing home staff, the nursing home management and the residents' relatives about EXBELT and the effectiveness of alternative interventions, structured interviews will be used. Second, intervention fidelity, including the 
dose delivered, and dose received ${ }^{38}$, will be obtained by conducting interviews with nursing home staff, nursing home management, educators and consultants. In addition, checklists and observation forms will be used to document fidelity of the intervention across nursing home units assigned to the intervention group. Finally, to examine the influence of the EXBELT on attitudes and opinions regarding restraint use, we will measure attitudes of nursing home staff using the MAQ ${ }^{25}$ at baseline, after the education program and at the end of the project.

\section{Data analysis}

Comparability between the intervention and control groups will be assessed at baseline to check for differences between the two groups on socio-demographic characteristics (age and gender). Outcomes at T2 and T3 will be compared between the intervention and control groups by both univariate and multivariate techniques. Data resulting from the effect evaluation will be primarily analyzed according to the intention-to-treat principle, i.e., including all participants with valid data, regardless of whether they remained in the setting which they were measured at baseline. Subsequently, the results of the intention-to-treat analysis will be compared with the results of a per-protocol analysis, to assess whether protocol deviations have caused bias. In all analyses effect estimates will be adjusted for baseline differences. Dropouts and losses-to-follow up will be described. Data resulting from the process evaluation will mainly be analyzed by means of descriptive techniques.

\section{Study progress}

In November 2008 the Medical Ethics Committee of the University Hospital Maastricht and Maastricht University has approved the study design and protocols. In December 2008 we started the selection of the nursing homes. The informed consent procedure began in February 2009. Representatives of the residents received written information and were asked to give written informed consent for the use of personal data on the residents in the study.

Baseline measurements followed in February and March and the implementation of EXBELT was started in March and April. The last follow up measurements are planned for the end of 2009 (effect evaluation) and early 2010 (process evaluation). Analyses of the data and dissemination of results are planned for 2010. 


\section{Discussion}

This paper presents the design of a quasi-experimental study, which aims to explore the effect and feasibility of an intervention program (EXBELT) that aims to reduce the use of belts in Dutch psychogeriatric nursing homes. Some methodological and practical drawbacks, concerning the current design, exist. However, under the current circumstances it is the most feasible method the assess data on the effectiveness of the intervention program. 


\section{References}

[1] Hantikainen V. Physical restraint: a descriptive study in Swiss nursing homes. Nursing Ethics. 1998;5: 330-346.

[2] Hamers JP, Huizing AR. Why do we use physical restraints in the elderly? Zeitschrift für Gerontologie und Geriatrie. 2005;38: 19-25.

[3] Meyer G, Kopke S, Haastert B, et al. Restraint use among nursing home residents: crosssectional study and prospective cohort study. Journal of Clinical Nursing. 2009;18: 981-990.

[4] Halfens RJG, Meijers JMM, Neyens JCL, et al. Rapportage resultaten Landelijke Prevalentiemeting Zorgproblemen 2007. Maastricht: Universiteit Maastricht; Onderzoeksinstituut Caphri, Department of Healt Care and Nursing Sciences, 2007.

[5] IGZ. Zorg voor vrijheid: terugdringen van vrijheidsbeperkende maatregelen kan en moet. Den Haag: IGZ, 2008.

[6] Capezuti E. Minimizing the use of restrictive devices in dementia patients at risk for falling. Nursing Clinics of North America. 2004;39: 625-647.

[7] Hamers JP, Gulpers MJ, Strik W. Use of physical restraints with cognitively impaired nursing home residents. Journal of Advanced Nursing. 2004;45: 246-251.

[8] Werner P. Perceptions regarding the use of physical restraints with elderly persons: comparison of Israeli health care nurses and social workers. Journal of Interprofessional Care. 2002;16: 59-68.

[9] Capezuti E, Maislin G, Strumpf N, et al. Side rail use and bed-related fall outcomes among nursing home residents. Journal of the American Geriatrics Society. 2002;50: 90-96.

[10] Capezuti E, Strumpf NE, Evans LK, et al. The relationship between physical restraint removal and falls and injuries among nursing home residents. Journals of Gerontoly Series A: Biological Sciences and Medical Sciences. 1998;53: M47-52.

[11] Neufeld RR, Libow LS, Foley WJ, et al. Restraint reduction reduces serious injuries among nursing home residents. Journal of the American Geriatrics Society. 1999;47: 1202-1207.

[12] Evans D, Wood J, Lambert L. Patient injury and physical restraint devices: a systematic review. Journal of Advanced Nursing. 2003;41: 274-282.

[13] Kron M, Loy S, Sturm E, et al. Risk indicators for falls in institutionalized frail elderly. American Journal of Epidemiology. 2003;158: 645-653.

[14] Castle NG, Mor V. Physical restraints in nursing homes: a review of the literature since the Nursing Home Reform Act of 1987. Medical Care Research and Review. 1998;55: 139-170; discussion 171-136.

[15] Miles SH, Irvine P. Deaths caused by physical restraints. The Gerontologist. 1992;32: 762-766.

[16] Gallinagh R, Nevin R, McAleese L, et al. Perceptions of older people who have experienced physical restraint. British Journal of Nursing. 2001;10: 852-859.

[17] Capezuti E, Wagner LM, Brush BL, et al. Consequences of an intervention to reduce restrictive side rail use in nursing homes. Journal of the American Geriatrics Society. 2007;55: 334-341.

[18] Evans LK, Strumpf NE, Allen-Taylor SL, et al. A clinical trial to reduce restraints in nursing homes. Journal of the American Geriatrics Society. 1997;45: 675-681.

[19] Huizing AR, Hamers JP, Gulpers MJ, et al. Short-term effects of an educational intervention on physical restraint use: a cluster randomized trial. BMC Geriatrics. 2006;6: 17.

[20] Koczy P, Klie T, Kron M, et al. Effektivität einer multifaktoriellen Intervention zur Reduktion von körpernaher Fixierung bei demenzerkrankten Heimbewohnern: Ziele und Studiendesign einer prospektiven clusterrandomisierten Interventionsstudie. Zeitschrift für Gerontologie und Geriatrie. 2005;38: 33-39.

[21] Testad I, Aasland AM, Aarsland D. The effect of staff training on the use of restraint in dementia: a single-blind randomised controlled trial. International Journal of Geriatric Psychiatry. 2005;20: 587-590. 
[22] Wagner LM, Capezuti E, Brush B, et al. Description of an advanced practice nursing consultative model to reduce restrictive siderail use in nursing homes. Research in Nursing and Health. 2007;30: 131-140.

[23] Huizing AR, Hamers JP, Gulpers MJ, et al. A cluster-randomized trial of an educational intervention to reduce the use of physical restraints with psychogeriatric nursing home residents. Journal of the American Geriatrics Society. 2009a;57: 1139-1148.

[24] Huizing AR, Hamers JP, Gulpers MJ, et al. Preventing the use of physical restraints on residents newly admitted to psycho-geriatric nursing home wards: a cluster-randomized trial. International Journal of Nursing Studies. 2009b;46: 459-469.

[25] Hamers JP, Meyer G, Kopke S, et al. Attitudes of Dutch, German and Swiss nursing staff towards physical restraint use in nursing home residents, a cross-sectional study. International Journal of Nursing Studies. 2009;46: 248-255.

[26] Dunn KS. The effect of physical restraints on fall rates in older adults who are institutionalized. Journal of Gerontological Nursing. 2001;27: 40-48.

[27] Marek KD, Rantz MJ, Fagin CM, et al. OBRA '87: has it resulted in better quality of care? Journal of Gerontological Nursing. 1996;22: 28-36.

[28] Klink A, Bussemaker J. Fixatie en separatie. Ministerie van Volksgezondheid, Welzijn en Sport, 2008.

[29] Hamers JPH, Gulpers MJM. Reducing physical restraints in nursing homes: results of a pilot study. Journal of Nutrition, Health \& Aging 2009;suppl.: S17.

[30] Bartholomew LK, Parcel GS, Kok G, et al. Planning Health Promotion Programs : An Intervention Mapping Approach. Hoboken: John Wiley \& Sons, 2006.

[31] Janz NK, Becker MH, Stretcher VJ. The Heatlh Belief Model. In: Glanz K, Rimer BK, Lewis FM, eds. Health behavior and health education: theory, research \& practice, 3rd ed edn. Hoboken: John Wiley \& Sons, 2002.

[32] Arcares. Registration of incidents and near accidents in nursing homes and old peoples' homes. Utrecht: Arcares, 2002.

[33] Morris JN, Fries BE, Mehr DR, et al. MDS Cognitive Performance Scale. Journal of Gerontology. 1994;49: M174-182.

[34] Morris JN, Fries BE, Morris SA. Scaling ADLs within the MDS. Journals of Gerontology Series A: Biological Sciences and Medical Sciences. 1999;54: M546-553.

[35] Mahoney FI, Barthel DW. Functional Evaluation: the Barthel Index. Maryland State Medical Journal. 1965;14: 61-65.

[36] Cohen-Mansfield J, Billig N. Agitated behaviors in the elderly. I: A conceptual review. Journal of the American Geriatrics Society. 1986;34: 711-721.

[37] De Jonghe JF, Kat MG. Factor structure and validity of the Dutch version of the CohenMansfield Agitation Inventory (CMAI-D). Journal of the American Geriatrics Society. 1996;44: 888-889.

[38] Saunders RP, Evans MH, Joshi P. Developing a process-evaluation plan for assessing health promotion program implementation: a how-to guide. Health Promotion Practice. 2005;6: 134147. 



\section{Chapter 3 \\ Belt restraint reduction in \\ nursing homes: \\ Effects of a multi-component intervention program (EXBELT)}

Math J M Gulpers, Michel H C Bleijlevens,

Ton Ambergen, Elizabeth Capezuti, Erik van Rossum, Jan P H Hamers

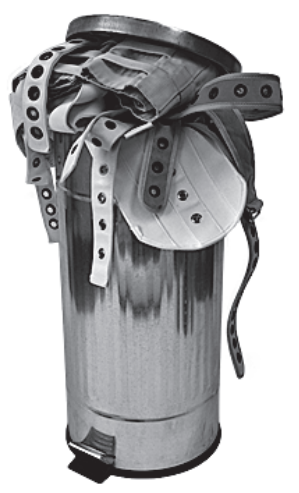

Published in Journal of the American Geriatrics Society. 2011;59: 2029-2036 


\begin{abstract}
Objectives: To test the effects of a multi-component intervention program to reduce the use of belt restraints in psychogeriatric nursing homes.
\end{abstract}

Design: A quasi-experimental longitudinal design. Study duration was 8 months.

Setting: Twenty-six psychogeriatric nursing home wards in 13 Dutch nursing homes were assigned to intervention or control groups.

Participants: Seven hundred fourteen residents were selected for participation. Legal representatives of 520 residents agreed on participation; complete data are available for 405 residents.

Intervention: The intervention program included four major components: promotion of institutional policy change that discourages use of belt restraint, nursing home staff education, consultation by a nurse specialist aimed at nursing home staff and availability of alternative interventions.

Measurements: The primary outcome measure was the frequency of belt restraint use. Secondary outcomes included other types of physical restraints, psychoactive drug use, falls and fall-related injuries. These data were collected at baseline, and after 4 and 8 months. A trained, blinded observer measured the use of belts and other physical restraints types four times during a 24-hour period.

Results: The intervention resulted in a $50 \%$ decrease in belt use (odds ratio = $.48 ; 95 \%$ confidence interval $=0.28-0.81$ ); $\mathrm{P}=.005$ ). No increase occurred in the use of other types of restraints. No marked differences between the groups were found regarding psychoactive drugs, falls and fall-related injuries.

Conclusion: A multicomponent intervention program EXBELT led to a substantial reduction in use of belts, full-enclosure bedrails and sleep suits, without increasing the use of other physical restraints, psychoactive drugs, or falls and fall-related injuries. 


\section{Introduction}

Approximately 25 million people worldwide have dementia and this number will likely increase to approximately 81 million people by 2040.1,2 In the Netherlands approximately 235,000 people have dementia with nearly 40,000 of those residing in psychogeriatric nursing homes. ${ }^{3}$ Psychogeriatric nursing homes provide long-term care to mainly very frail, older adults with psychogeriatric disorders, especially people suffering from dementia. ${ }^{4}$ The use of physical restraints, defined as any limitation in an individual's freedom of movement, ${ }^{5}$ is still common practice in nursing home care for residents with dementia. In the Netherlands $10 \%$ to $14 \%$ of nursing home residents with psychogeriatric disorders are restrained with belts.6,7 Depending on varying definitions and reporting methods, the prevalence of physical restraint use is between $15 \%$ to $66 \%$ internationally. ${ }^{8,9}$ These definitions usually include devices worn by the person that they cannot easily remove, including belts (materials attached to the waist), sleep suits (clothing that deters a person from undressing), and special sheet (a fitted sheet that includes a coat and encloses a mattress) as well as devices attached to furniture (e.g., full-enclosure bedrails or (wheel)chairs with a locked tray table).

Although physical restraint use is not associated with a decrease in falls or fall-related injuries, these devices continue to be used to prevent falls. ${ }^{10-14}$ Because physical restraint use can contribute to problems with balance and coordination as well as falls, 10,15,16 the question arises as to why there remains a persistent perception of physical restraints as "safety measures." The use of physical restraints results in greater risk of sustaining serious injury or death. ${ }^{15}$ Other known negative consequences of restraint use are, for example; pressure ulcers, loss of muscle strength and endurance, incontinence, and aggression. ${ }^{10,17,18}$ In addition, older adults report negative feelings about experiences with physical restraints, such as discomfort and demoralization. ${ }^{19}$ The use of physical restraints may also indicate a failure of staff to recognize and deal with the underlying causes of fall risk for these restrained residents. Evidence that the use of restraint is often an ineffective fall prevention strategy and can potentially increase risk of other untoward effects related to immobility supports the pursuit of effective alternative interventions to reduce their routine usage.

Several studies have reported findings from restraint reduction intervention programs. ${ }^{20-25}$ The most frequently used intervention is staff education. These educational programs typically focus on improving staff knowledge about the negative aspects of restraint use, assessment of restraint risk factors, and the decision-making process for implementing alternative non-restraint measures that specifically target the resident's underlying problems. ${ }^{21,22,24,25} \mathrm{~A}$ successful educational-consultation intervention in the United States ${ }^{21}$ proved 
to be ineffective when modified for use in other countries.22,26-29 A study in three European countries (the Netherlands, Germany and Switzerland) indicated that nursing staff have different attitudes and opinions regarding the use of physical restraints. These findings underscore the importance of employing more adapted, culturally sensitive interventions to reduce restraint use in nursing homes in these countries. ${ }^{30}$ Also, these findings, similar to others, indicate that education regarding alternatives is not sufficient. The availability of alternative interventions for meeting underlying needs is essential to eliminating restraint use.22,26,27,30 Finally, legislation and related regulatory mandates that have changed individual nursing home restraint policies have also been shown to decrease restraint use. For example, in the United States, the introduction of the Nursing Home Reform Act (OBRA '87) regulating the use of physical restraints led to a drastic reduction in their use. ${ }^{31,32}$

Based on these observations, a multi-component intervention, Expelling Belts (EXBELT) was developed. Because belts are the most restrictive physical restraint measure used in the Netherlands, ${ }^{22,33}$ EXBELT primarily focuses on these devices although the principles apply to all physical restraints. ${ }^{30} \mathrm{~A}$ pilot version was first implemented in one nursing home ward ( $\mathrm{n}=30$ residents) resulted in a reduction from 12 to no belts over a single month following the intervention and only one belt at 3 and 9 months following the intervention. ${ }^{34}$ Expansion to the other four wards in the same nursing home showed similar results. The pilot intervention included four components: institutional policy change discouraging use of belt restraints, nursing home staff education, consultation by a nurse specialist aimed at nursing home staff, and availability of alternative interventions. The main aim of the current study was to test the effectiveness of EXBELT on reducing belt restraint usage in psychogeriatric nursing home care. Our three specific research questions were:

1. Does a customized multi-component intervention (EXBELT) result in a reduction of belt use in nursing homes?

2. Does EXBELT reduce the use of other types of physical restraints and psychoactive drug use?

3. Does belt elimination result in an increase in falls and fall-related injuries?

\section{Methods}

\section{Design and Sample}

Data were obtained in a quasi-experimental longitudinal study with 8 months of follow-up. The study design is described in detail elsewhere. ${ }^{35}$ We recruited 26 psychogeriatric wards from 13 nursing homes from various regions in the 
Netherlands with at least a $10 \%$ prevalence in use of belts. Belt use was defined as the restraining of a resident by a belt at least once per day. Wards were excluded if they only provided care to residents with Korsakoff syndrome, if they were undergoing extensive reorganization and/or constructional renovations, or if they were already participating in other restraint reduction projects.

Because of the geographical location of participating wards, overlap with regard to the nursing home staff could be expected. To avoid contamination bias, wards from nursing homes that were situated in close proximity were assigned to the same group. Because randomization according to ward or home was not feasible, the research team assigned wards and homes to the intervention (receiving the EXBELT intervention) or control (receiving care as usual) group. Six nursing homes (15 wards, 403 residents) were assigned to the intervention group and seven (11 wards, 311 residents) to the control group. Sample size calculations indicated that 216 psychogeriatric nursing home residents per group were needed to detect a targeted $50 \%$ reduction of belt use in the intervention group (alpha .05 two-sided). Based on an expected informed consent rate of $80 \%$ and a drop-out rate of $25 \%$ during eight months of follow-up, the 714 eligible residents at baseline appeared adequate to test the aims.

\section{Ethical Considerations}

Because none of the potential participants were cognitively able to provide consent, written informed consent was obtained from the legal representatives of the residents after allocation of the wards to intervention and control groups. The medical ethics committee of the University Hospital Maastricht and Maastricht University and the ethical committees from four nursing home associations that represent the 13 nursing homes approved the study design and protocol.

\section{Intervention program}

The implementation process of the EXBELT intervention program was an important aspect of this study, particularly in terms of the ordering of interventions and the length of time periods between each one. Therefore, extensive collaboration between the research team and the nursing home managers was necessary.

EXBELT comprises four key components:

1. Implementation of an institutional policy change, which was implemented 4 months after baseline, including: 
a. Prohibition of both the use of belt restraint for newly-admitted residents and initiating belt restraint use for already admitted residents as well as the overall reduction of current use of belt restraint.

b. Written and oral communication regarding the forthcoming policy change provided by the nursing home management to all members of nursing home staff and to residents' relatives during the first 4 months of the study following baseline. The policy change was announced to nursing home staff and legal representatives of the residents in a formal letter and announcements in internal newspapers and in group meetings aimed at the legal representatives of the residents.

c. Oral communication regarding the policy change provided by the nurse specialists during the educational program to the nursing home staff (second month after baseline).

2. Education: An intensive educational intervention program providing information about physical restraints and fall prevention; the negative aspects of physical restraint use; staff attitudes towards physical restraint use; how to make decisions regarding alternative interventions, and the use of resident-centered interventions. Two nurse specialists (registered nurses with extensive experience in physical restraint reduction) delivered this educational program to all 15 intervention wards during a 3-week period (one session per week) which was started 1 month after baseline. The educational program was offered to the nursing home staff (physician, nurses, paramedical staff, psychologist, and ward manager). Each meeting lasted approximately 3 hours during nursing home staff's working hours. In addition, a 90-minute educational session, summarizing the content of the 9 hours of education, was provided separately to those members of the nursing staff who could not attend the program sessions.

3. Consultation: The two nurse specialists who delivered the educational program also provided on-site consultation from the start of the educational program (Month 2) to the second post-test (T2) (Month 8) to individual nurses on the intervention wards regarding challenges in reducing restraints. ${ }^{21}$ The nurse specialists were available on demand, with each ward receiving at least two consultations. A nurse from each of the intervention wards and one of the nurse specialists analyzed specific resident cases and discussed possible solutions for reducing restraints. A nursing home manager and a representative from the Netherlands Health Care Inspectorate (IGZ, the regulatory body for monitoring quality and safety in the Netherlands nursing homes) were also available for consultation with nursing home managers and clinical staff if needed in individual cases.

4. Availability of alternative interventions: nursing home managers in the intervention group provided resident-centered alternative interventions, 
such as hip protectors, infrared alarm systems, balance training, exercise, special pillows and adjustable low-height beds. Alternative interventions were available 1 month after baseline onward. The choice for alternative intervention resources to be purchased was made based on experience of the pilot EXBELT project and requests from staff members of the intervention wards. Extra costs were limited because requirements were mostly adaptations of planned purchases; for example, if beds had to be replaced anyway, those additional beds could be adjustable low-height ones. Nursing home staff suggested possible alternative interventions in consultation with resident's relatives. The nurse specialist who provided on-site consultation facilitated decision-making regarding alternative interventions and encouraged the use of alternative interventions.

The fidelity of how the teaching and consultation were delivered was ensured by providing the nurse specialists with a script for the educational program. The principal researchers (MG, MB) served as the intervention supervisors to monitor the fidelity of the intervention components. Copies of consultation notes and other logs maintained by the nurse specialists were reviewed during monthly meetings of the principal researchers with both nurse specialists. These sessions provided feedback to the nurse specialists on their performance, generated potential strategies to improve the diffusion of the interventions and made certain that the two nurse specialists delivered the interventions consistently.

\section{Measurements}

The primary outcome measure was belt restraint use; this was measured at baseline (T1), and after 4 (T2) and 8 (T3) months, using an observation tool developed previously.22, 26, 27 The interrater reliability was found to be perfect (kappa $=1.0)$. A single trained observer, blinded to group assignment, recorded belt use as present or absent four times during a 24-hour period (morning, afternoon, evening and night). The day and timing of measurements was unannounced in order to prevent any temporary removal of belts.

Secondary outcome measures included all other types of physical restraints (e.g., (wheel)chair with a locked tray table, special sheet, full-enclosure bedrails, chair on a board (chair whose legs are fixed to a board), deep and/or overturned (wheel) chairs, sleep suits), use of at least one psychoactive medication (antipsychotic, antidepressant, tranquillizers, and hypnotic medication ${ }^{36}$ ), and falls and fall-related injuries (e.g. hematomas, bruises, lacerations, joint dislocations, and fractures). Use of other types of physical restraint simultaneously with belt use was recorded as present or absent, using the same observation tool. Data on psychoactive drug use were collected from the residents' 
medical records. Falls and fall-related injuries were recorded using an incident reporting system, that Dutch nursing homes are required to maintain. ${ }^{37}$

\section{Data analysis}

Data from residents was used and analyzed according to the intention-to-treat principle. Only complete data sets were analyzed. Differences at baseline between the intervention and control groups with regard to belt use, psychoactive drug use, falls and residents' characteristics (age and gender) were investigated. Chi-square tests were used for categorical variables and generalized estimating equations (GEE) techniques were used to estimate the effect on the main outcome variable (belts use) while adjusting for baseline characteristics and dependence between measurements (age, gender, psychoactive drug use, falls and nursing home). SPSS software version 15 and STATA 11 was used to perform these analyses (SPSS, Inc., Chicago, IL. Results are presented according to odds ratio (Ors) and with 95\% confidence intervals (CIs).

\section{Results}

Seven hundred fourteen residents were eligible for participation in this study. Informed consent was obtained from legal representatives of 520 residents who were allocated to either the intervention (319 residents from 15 wards in 6 nursing homes) or control group (201 residents from 11 wards in 7 nursing homes). After 8 months of follow-up, 22\% $(n=69)$ of the residents had dropped out in the intervention group and 23\% $(n=46)$ from the control group. Reasons for drop-outs were similar in both groups and mostly due to death (Figure 1). Complete data were available (all three measurements) for 405 residents and only these sets were included in the analyses. The total number of residents in the control group which could be included in the analyses was less than the number of residents needed according to the sample size calculations. There were no significant differences in baseline characteristics between the residents who completed all measurements and those who dropped out during follow-up, with the exception of sex (more male residents dropped out). Table 1 shows the baseline characteristics of the study groups. Baseline belt restraint use, sex, and falls in the preceding 3 months did not differ between the two groups. The mean age in the control group was somewhat higher (84.4 versus 82.1 years, $\mathrm{P}=.001$ ). 


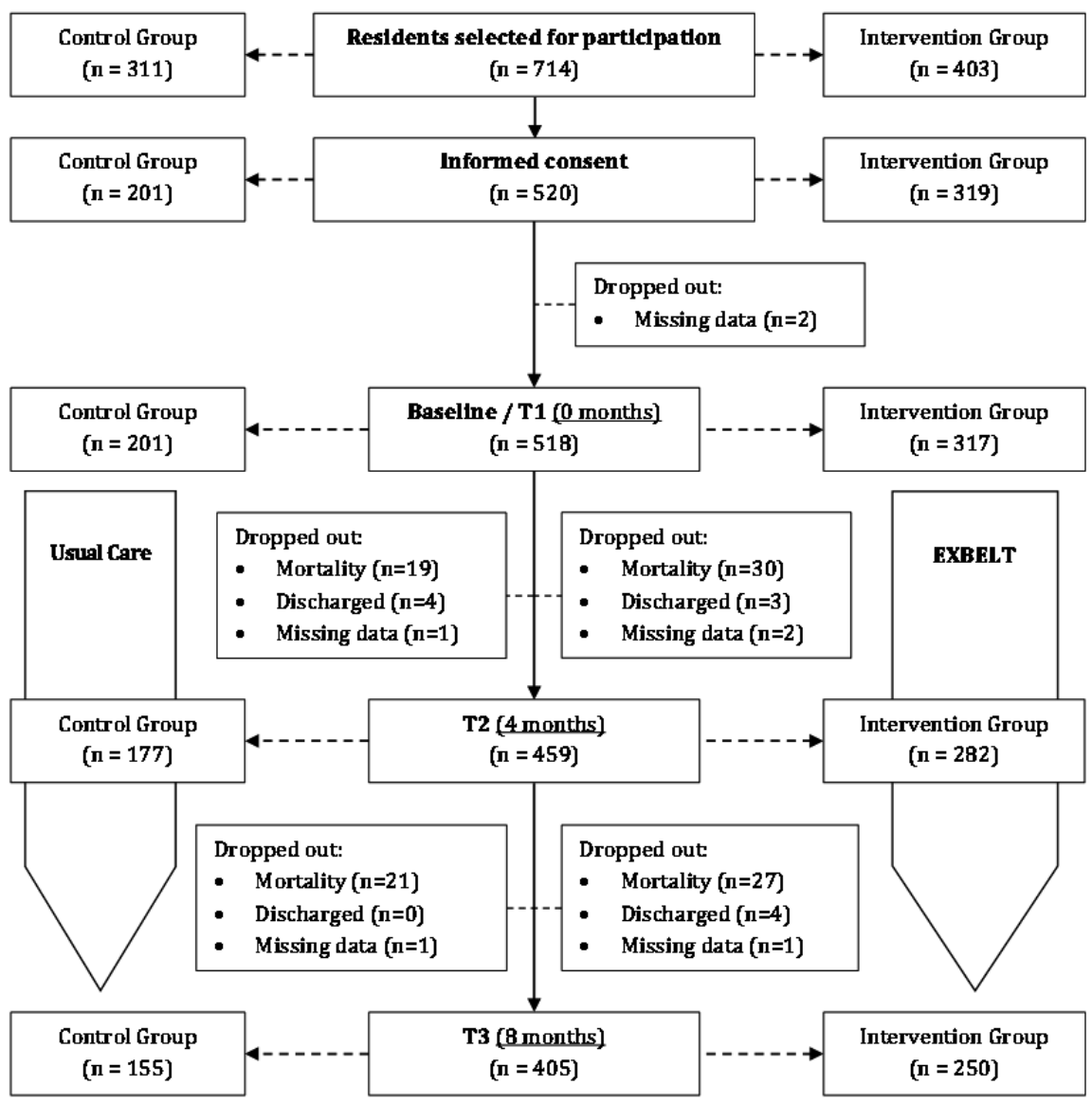

Figure 1. Flow Chart of Residents

Table 1. Background Characteristics and Outcome Measures at Baseline

\begin{tabular}{llll}
\hline & Control group & Intervention group & \\
\cline { 2 - 3 } Measured variables & $(\mathrm{n}=155)$ & $(\mathrm{n}=250)$ & $\mathrm{p}$-value \\
\hline Background characteristics & $120(77)$ & $176(70)$ & .12 \\
$\quad$ Female, n (\%) & $84.4 \pm 6.2$ & $82.1 \pm 8.1$ & .001 \\
$\quad$ Age, mean $\pm \mathrm{SD}^{*}$ & & & .70 \\
Outcome measures & $29(19)$ & $43(17)$ & .63 \\
$\quad$ Belt restraints, n (\%) & $25(16)$ & $45(18)$ & .15 \\
$\quad$ Falls, n (\%) & $105(68)$ & $186(74)$ & \\
$\quad$ Psychoactive drug use, n (\%) & & \\
\hline
\end{tabular}

*SD = Standard Deviation 


\section{Use of belt restraints}

At baseline, belts were used for $19 \%$ of the residents in the control group and $17 \%$ in the intervention group $(\mathrm{P}=.70)$. At $\mathrm{T} 2$ the use of belts had slightly decreased in both groups (Table 2 and Figure 2). Between T1 (17\%) and T3 (9\%) belt use had decreased by nearly $50 \%$ in the intervention group, whereas the proportion of residents using belts in the control group was similar to baseline. The adjusted difference between both groups was significant, $\mathrm{P}=.01$. GEE analysis showed a significant difference between the intervention and control groups regarding the use of belts (OR $=.48 ; 95 \%$ CI $(.28-.81) ; \mathrm{P}=.005)$. The reduction of belts use can mainly be attributed to a reduction of belts in (wheel)chairs. There was no difference in the use of belt restraints in bed (\%) between the groups at any of the three measurements (Table 2).

\section{Use of other physical restraints}

Table 2 shows a statistically significant unadjusted difference between the groups at T3 with regard to the number of residents who were restrained with any kind of physical restraint. Following the intervention, more restraints were used in the control group at T3 (69\%) than in the intervention group (54\%), (P $=.003)$. The greatest differences between the groups were found in the use of full-enclosure bedrails and sleep suits at $\mathrm{T} 2(\mathrm{P}=.009$ and $\mathrm{P}=.02$, respectively) and T3 ( $\mathrm{P}=.001$ and $\mathrm{P}=.006$, respectively) in favor of less usage in the intervention group (Table 2 ).

\section{Psychoactive drug use, falls and fall-related injuries}

At baseline, fewer residents used psychoactive drugs in the control group than in the intervention group (68\% versus $74 \% ; \mathrm{P}=.15)$. Over time there was a small (6\%) decrease in the intervention group, whereas the control group hardly changed (Table 2). At T3 there were no differences between groups.

No significant differences were found between the groups at baseline, T2, and T3 regarding the number of residents who fell or sustained a fall or fall-related injuries (including fractures). Belt elimination did not result in an increase of falls, or in fall-related injuries (including fractures). The use of belts had stopped at T3 for 25 residents in the intervention group. This group $(n=25)$ had, five falls and four fall-related injuries (including 2 fractures) at baseline and six falls, including four injurious falls (with two fractures) at T3. 

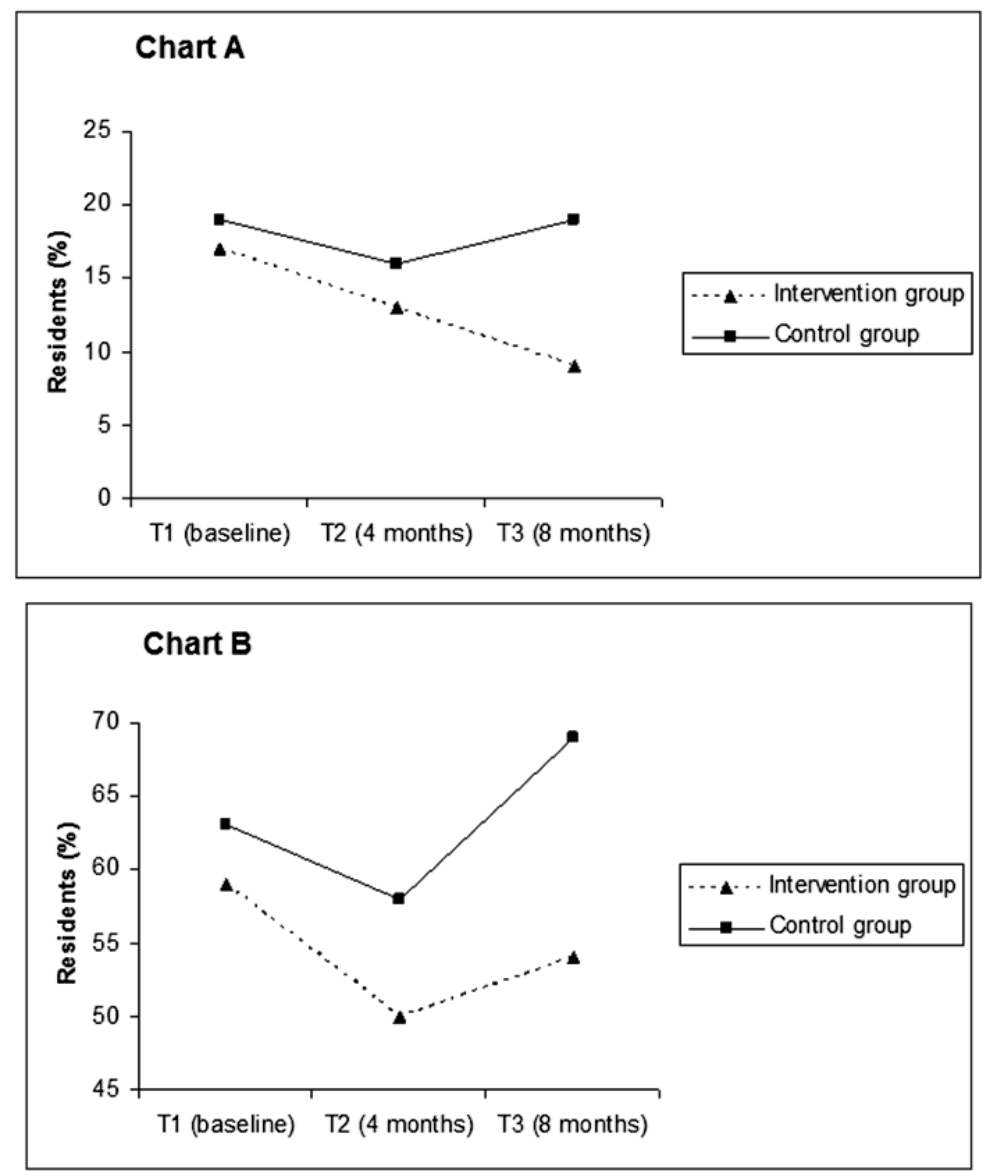

Figure 2. Changes in the Use of Belt Restraints (A), and of at Least One Physical Restraint Device (B) in psychogeriatric nursing home residents according to group over time $n=405$ )

\section{Availability and Use of Alternative Interventions}

For almost $50 \%$ of the residents, in whom the usage of belt restraints was stopped, no alternative interventions were reported. Alternative interventions which were reported most often included sensor mats (21\%) and low-heightadjustable beds (12\%). 
Table 2. Effects on Primary and Secondary Outcome Measures at Baseline and after 4 and 8 Months

\begin{tabular}{|c|c|c|c|c|c|c|c|c|c|}
\hline \multirow[b]{4}{*}{ Outcome Measure } & \multicolumn{9}{|c|}{ Follow-up period } \\
\hline & \multicolumn{3}{|c|}{ T1 (baseline) } & \multicolumn{3}{|l|}{$\mathrm{T} 2$} & \multicolumn{3}{|l|}{ T3 } \\
\hline & \multirow{2}{*}{$\begin{array}{l}\text { Control } \\
\%\end{array}$} & \multicolumn{2}{|l|}{ Intervention } & \multirow{2}{*}{$\begin{array}{l}\text { Control } \\
\%\end{array}$} & \multicolumn{2}{|l|}{ Intervention } & \multirow{2}{*}{$\begin{array}{l}\text { Control } \\
\%\end{array}$} & \multicolumn{2}{|l|}{ Intervention } \\
\hline & & $\%$ & $\mathrm{p}$-value & & $\%$ & $\mathrm{p}$-value & & $\%$ & p-value \\
\hline \multicolumn{10}{|l|}{ Primary* } \\
\hline Belt restraints & 19 & 17 & .70 & 16 & 13 & .45 & 19 & 9 & .005 \\
\hline (Wheel)chair & 16 & 14 & .56 & 14 & 11 & .31 & 17 & 8 & .004 \\
\hline Bed & 6 & 6 & .93 & 4 & 4 & .95 & 3 & 3 & .81 \\
\hline \multicolumn{10}{|l|}{ Secondary* } \\
\hline $\begin{array}{l}\text { (Wheel)chair with a } \\
\text { locked table }\end{array}$ & 14 & 10 & .27 & 13 & 10 & .31 & 12 & 7 & .13 \\
\hline Special sheet & 5 & 8 & .22 & 3 & 5 & .27 & 4 & 5 & .66 \\
\hline $\begin{array}{l}\text { Full enclosure } \\
\text { bedrails }\end{array}$ & 59 & 52 & .13 & 58 & 45 & .009 & 63 & 46 & .001 \\
\hline Chair on a board & 1 & 2 & .27 & 1 & 1 & .73 & 1 & 0 & .73 \\
\hline $\begin{array}{l}\text { Deep and/or over- } \\
\text { turned (wheel) chair }\end{array}$ & 9 & 8 & .61 & 14 & 12 & .60 & 14 & 14 & .96 \\
\hline Sleep suits & 8 & 7 & .72 & 11 & 5 & .02 & 10 & 4 & .006 \\
\hline $\begin{array}{l}\text { At least one physical } \\
\text { restraint device }\end{array}$ & 63 & 59 & .45 & 64 & 54 & .06 & 69 & 54 & .003 \\
\hline Falls & 16 & 18 & .75 & 14 & 20 & .10 & 16 & 16 & .98 \\
\hline Fall related injuries & 10 & 8 & .56 & 8 & 10 & .44 & 11 & 10 & .66 \\
\hline Fall related fractures & 1 & 2 & .40 & 0 & 1 & .26 & 1 & 3 & .32 \\
\hline $\begin{array}{l}\text { Psychoactive drug } \\
\text { use }\end{array}$ & 68 & 74 & .15 & 72 & 72 & .93 & 70 & 68 & .79 \\
\hline
\end{tabular}

* Effects were assessed by means of chi-square analyses

\section{Discussion}

The multi-component intervention program EXBELT was effective in reducing the use of belt restraints. In previous studies aiming to reduce the use of physical restraints, intervention strategies were mainly delivered by staff education programs, ${ }^{22,24,28,29,38,39}$ combined in some studies with consultancy from a nurse specialist. 20,21,25-27 Evidence for the success of this approach is moderate and inconsistent. $20,21,24,26-29,35,38-40$ Reported positive effects are mainly related to short-term effects in terms of prevention of restraint initiation, not reduction of use. Recent studies about overall physical restraint use confirm that education alone is not enough to reduce the use of physical restraints. ${ }^{39,41}$ In the current study, the effects on the first post-test (T2) were comparable with those in other studies that only used an educational intervention. ${ }^{21,22,28,38}$ At that moment, 
only the educational part of the intervention was completely implemented. The consultation activities of the nurse specialists increased after the educational part of the program. Between T2 and T3 they visited the intervention wards at least twice, but between baseline and $\mathrm{T} 2$ we found a non-significant reduction in belt use and other physical restraints in both groups. The reduction of belt restraint use in both groups may be the result of much media attention in the Netherlands and extra attention by the Dutch government to the reduction of belt use in nursing homes at the beginning of the current study because of fatal accidents and serious injuries resulting from belt restraints use.

In the light of the inconsistent findings with regard to the effectiveness of educational programs, in some studies combined with consultancy from a nurse specialist, the literature provides clear evidence that additional actions are necessary to achieve more effective reduction of physical restraints. The first is to focus on certain restraints, preferably the most restrictive restraints such as belt restraints. ${ }^{20}$ The second is to organize targeted institutions' policy on reducing restraints. ${ }^{42}$ Finally, there are clear indications that an independent measurement is preferable to achieve reliable determination of physical restraint use, including determination of effectiveness of policies and interventions for restraint reduction. The effectiveness of auditing nursing homes in Australia is a clear illustration. ${ }^{43}$ In other countries (e.g., USA, Denmark), a policy change (stricter legislation, OBRA '87) led to a significant reduction in some physical restraint usage. There are strong indications that the introduction of this stricter legislation reinforced the positive effects of education in the United States. $^{31,32}$ Apart from the fact that the policy change described in the current study concerns no change in legislation, it is largely comparable with the introduction of OBRA '87 in the United States. ${ }^{44}$ In the current study, two additional components were added to the EXBELT intervention protocol: institutional policy change regarding belt use, and the availability of resident-centered alternatives interventions. ${ }^{35}$ In the intervention wards the management of the nursing homes implemented the policy change shortly after T2. This policy change seems to make an important contribution to the success of the EXBELT intervention.

Belt restraint reduction and use of alternative interventions of individual residents was discussed with legal representatives of the resident, physician, nurse and ward manager. No alternative interventions were employed in $50 \%$ of all residents for whom belt restraint were removed in the intervention group. It seems that using belt restraints in these residents had become more common than necessary. The implementation of the EXBELT intervention thus made 
clear that there was not need for using belt restraints or any alternatives for belt restraints in these residents.

Although most of the significant difference in belt use between the control and intervention group at $\mathrm{T} 3$ can be attributed to a reduction in use of belts in (wheel)chairs, a statistically significant reduction in the use of other physical restraints in general was also found in the intervention group, especially fullenclosure bedrails and sleep suits. The use of belts in bed was the same for the intervention and control groups at each of the three measurements and decreased in both groups, from $6 \%$ to $3 \%$ during the study. At the same time, the use of full-enclosure bedrails increased in the control group, and decreased in the intervention group. The decision process regarding the use of new physical restraints during the night depended on which physical restraint type was to be used; for example, regarding belt restraint use, current practice is that the night head nurse contacts a physician for an order. Meanwhile, decisions about fullenclosure bedrails on the spot and then discuss the next day with the physician. This may contribute to the preference at night for using less restrictive physical restraints, such as full-enclosure bedrails although education about the use and availability of alternative interventions to prevent bed-related falls may explain the decrease in use of these bedrails in the intervention group. With the use of adjustable low-height beds, for example, it is not necessary to use bedrails. The proportion of residents who used any kind of psychoactive drug was unchanged in either group. With regard to falls and fall-related injuries, this study confirmed previous findings: a reduction of physical restraint usage, in particular, belts, did not lead to an increase of falls and injurious falls. ${ }^{11,45}$ These results should be interpreted with caution because the number of participants available for analyses in the control group did not meet sample size calculations.

A quasi-experimental design was used to assign wards to the two study groups. For example, the nursing homes in one of two groups were assigned according to practical considerations, such as geographic location, for efficiency in conducting the training programs and taking measurements. This lack of randomization may have introduced selection bias. In research on complex interventions, the proper implementation and execution of the intervention is crucial, but often underestimated. Therefore, the introduction of the EXBELT program was monitored carefully. No large problems or obstacles were encountered during its implementation. Another question is whether the effects of EXBELT continued after the study. It often has been reported that short-term benefits disappear over a longer time period. The results at T3 provide a positive indication of the potential long-term continuity of benefits, although this requires further research. The study was limited to psychogeriatric nursing homes, and 
thus, it is not clear whether these results can be obtained in other healthcare settings or in other target groups, or for what reason belts and other restraints were used and where and when falls occurred investigated.

In conclusion, this study shows that decreasing the use of belts and other physical restraints in nursing homes is attainable without an increase of psychoactive drug use, falls and fall-related injuries. The success of the intervention lies in the combination of all components of EXBELT, including the education program, which provides the foundation for the all other interventions. In addition, the comprehensiveness of planning and supervision of program implementation and the intensive communication and spirit of cooperation among all those who participated in the program is important. Further research is important to explore whether the EXBELT intervention is applicable to other countries, healthcare settings, and target groups. In addition, the dose-effect response as well as the long-term effects of the EXBELT intervention need further exploration. 


\section{References}

[1] Wimo A, Winblad B, Aguero-Torres $\mathrm{H}$ et al. The magnitude of dementia occurrence in the world. Alzheimer Dis Assoc Disord 2003;17: 63-67.

[2] Ferri CP, Prince M, Brayne C et al. Global prevalence of dementia: a Delphi consensus study. Lancet 2005;366: 2112-2117.

[3] Nederland A. Cijfers en feiten over dementie. 2010.

[4] Schols JMGA. Daycare for demented elderly in a dairy farm setting. J Am Med Dir Assoc 2006.

[5] Hantikainen V. Physical restraint: a descriptive study in Swiss nursing homes. Nurs Ethics 1998; : 330-346.

[6] Halfens RJG, Meijers JMM, Neyens JCL et al. Rapportage resultaten Landelijke Prevalentiemeting Zorgproblemen 2008. Maastricht: Universiteit Maastricht; Onderzoeksinstituut Caphri, Department of Healt Care and Nursing Sciences, 2008.

[7] IGZ. Zorg voor vrijheid: terugdringen van vrijheidsbeperkende maatregelen kan en moet. Den Haag: IGZ, 2008.

[8] Hamers JP, Huizing AR. Why do we use physical restraints in the elderly? Z Gerontol Geriatr 2005;38: 19-25.

[9] Meyer G, Kopke S, Haastert B et al. Restraint use among nursing home residents: crosssectional study and prospective cohort study. J Clin Nurs 2009;18: 981-990.

[10] Capezuti E. Minimizing the use of restrictive devices in dementia patients at risk for falling. Nurs Clin North Am 2004;39: 625-647.

[11] Capezuti E, Maislin G, Strumpf $\mathrm{N}$ et al. Side rail use and bed-related fall outcomes among nursing home residents. J Am Geriatr Soc 2002;50: 90-96.

[12] Hamers JP, Gulpers MJ, Strik W. Use of physical restraints with cognitively impaired nursing home residents. J Adv Nurs 2004;45: 246-251.

[13] Neufeld RR, Libow LS, Foley WJ et al. Restraint reduction reduces serious injuries among nursing home residents. J Am Geriatr Soc 1999;47: 1202-1207.

[14] Werner P. Perceptions regarding the use of physical restraints with elderly persons: comparison of Israeli health care nurses and social workers. J Interprof Care 2002;16: 59-68.

[15] Evans D, Wood J, Lambert L. Patient injury and physical restraint devices: a systematic review. J Adv Nurs 2003;41: 274-282.

[16] Kron M, Loy S, Sturm E et al. Risk indicators for falls in institutionalized frail elderly. Am J Epidemiol 2003;158: 645-653.

[17] Castle NG, Mor V. Physical restraints in nursing homes: a review of the literature since the Nursing Home Reform Act of 1987. Med Care Res Rev 1998;55: 139-170; discussion 171-136.

[18] Miles SH, Irvine P. Deaths caused by physical restraints. Gerontologist 1992;32: 762-766.

[19] Gallinagh R, Nevin R, McAleese L et al. Perceptions of older people who have experienced physical restraint. Br J Nurs 2001;10: 852-859.

[20] Capezuti E, Wagner LM, Brush BL et al. Consequences of an intervention to reduce restrictive side rail use in nursing homes. J Am Geriatr Soc 2007;55: 334-341.

[21] Evans LK, Strumpf NE, Allen-Taylor SL et al. A clinical trial to reduce restraints in nursing homes. J Am Geriatr Soc 1997;45: 675-681.

[22] Huizing AR, Hamers JP, Gulpers MJ et al. Short-term effects of an educational intervention on physical restraint use: a cluster randomized trial. BMC Geriatr 2006;6: 17.

[23] Koczy P, Klie T, Kron M et al. Effektivität einer multifaktoriellen Intervention zur Reduktion von körpernaher Fixierung bei demenzerkrankten Heimbewohnern: Ziele und Studiendesign einer prospektiven clusterrandomisierten Interventionsstudie. Z Gerontol Geriatr 2005;38: 33-39.

[24] Testad I, Aasland AM, Aarsland D. The effect of staff training on the use of restraint in dementia: a single-blind randomised controlled trial. Int J Geriatr Psychiatry 2005;20: 587-590. 
[25] Wagner LM, Capezuti E, Brush B et al. Description of an advanced practice nursing consultative model to reduce restrictive siderail use in nursing homes. Res Nurs Health 2007;30: 131140.

[26] Huizing AR, Hamers JP, Gulpers MJ et al. A cluster-randomized trial of an educational intervention to reduce the use of physical restraints with psychogeriatric nursing home residents. J Am Geriatr Soc 2009a;57: 1139-1148.

[27] Huizing AR, Hamers JP, Gulpers MJ et al. Preventing the use of physical restraints on residents newly admitted to psycho-geriatric nursing home wards: a cluster-randomized trial. Int J Nurs Stud 2009b;46: 459-469.

[28] Lai CKY, Chan MH, Szeto SSL et al. A retrospective study on the outcomes of a collaborative restraint reduction project by a residential home for older people and a hospital-based community geriatric assessment service. Hong Kong Nursing Journal 2006;42: 23-30.

[29] Dermaid LM, Byrne C. Restraint reduction education. Can Nurs Home 2006;17: 10-14.

[30] Hamers JP, Meyer G, Kopke S et al. Attitudes of Dutch, German and Swiss nursing staff towards physical restraint use in nursing home residents, a cross-sectional study. Int J Nurs Stud 2009;46: 248-255.

[31] Dunn KS. The effect of physical restraints on fall rates in older adults who are institutionalized. J Gerontol Nurs 2001;27: 40-48.

[32] Marek KD, Rantz MJ, Fagin CM et al. OBRA '87: has it resulted in better quality of care? J Gerontol Nurs 1996;22: 28-36.

[33] Halfens RJG, Meijers JMM, Neyens JCL et al. Rapportage resultaten Landelijke Prevalentiemeting Zorgproblemen 2007. Maastricht: Universiteit Maastricht; Onderzoeksinstituut Caphri, Department of Healt Care and Nursing Sciences, 2007.

[34] Hamers JPH, Gulpers MJM. Reducing physical restraints in nursing homes: results of a pilot study. J Nutr Health Aging 2009;suppl.: S17.

[35] Gulpers MJ, Bleijlevens MH, van Rossum E et al. Belt restraint reduction in nursing homes: design of a quasi-experimental study. BMC Geriatr 2010;10: 11.

[36] Rehnquist J. Ministerie van Volksgezondheid en Human Services; Psychotrope medicatie in verpleeghuizen. 2001.

[37] Arcares. Registration of incidents and near accidents in nursing homes and old peoples' homes. Utrecht: Arcares, 2002.

[38] Kuske B, Luck T, Hanns S et al. Training in dementia care: a cluster-randomized controlled trial of a training program for nursing home staff in Germany. Int Psychogeriatr 2009;21: 295308.

[39] Milke DL, Kendall TS, Neumann I et al. A longitudinal evaluation of restraint reduction within a multi-site, multi-model Canadian continuing care organization. Can J Aging 2008;27: 35-43.

[40] Pellfolk T], Gustafson Y, Bucht G et al. Effects of a restraint minimization program on staff knowledge, attitudes, and practice: a cluster randomized trial. J Am Geriatr Soc 2010;58: 6269.

[41] Testad I, Ballard C, Bronnick K et al. The effect of staff training on agitation and use of restraint in nursing home residents with dementia: a single-blind, randomized controlled trial. J Clin Psychiatry 2010;71: 80-86.

[42] Baier RR, Butterfield K, Harris Y et al. Aiming for star performance: the relationship between setting targets and improved nursing home quality of care. J Am Med Dir Assoc 2008;9: 594598.

[43] Timmins J. Compliance with best practice: implementing the best available evidence in the use of physical restraint in residential aged care. Int J Evid Based Healthc 2008;6: 345-350.

[44] Dunbar JM, Neufeld RR, Libow LS et al. Taking charge. The role of nursing administrators in removing restraints. J Nurs Adm 1997;27: 42-48. 
[45] Capezuti E, Strumpf NE, Evans LK et al. The relationship between physical restraint removal and falls and injuries among nursing home residents. J Gerontol A Biol Sci Med Sci 1998;53: M47-52. 


\section{Chapter 4}

\section{Preventing belt restraint use in newly admitted residents in nursing homes:}

A quasi-experimental study

Math J M Gulpers, Michel H C Bleijlevens, Elizabeth Capezuti, Erik van Rossum, Ton Ambergen, Jan P H Hamers

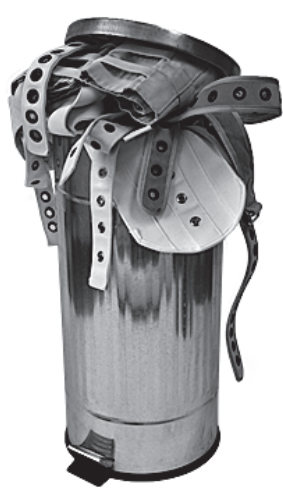

Published in International Journal of Nursing Studies 2012:1007-1013 


\begin{abstract}
Background: Physical restraints are commonly used in psychogeriatric nursing home residents despite reports of negative consequences. Most research has focused on restraint reduction without addressing methods to prevent initiation of restraints in nursing homes. EXBELT has been found to decrease belt restraint use but should also be evaluated for its use in preventing restraints.
\end{abstract}

Objective: To investigate the effectiveness of the EXBELT intervention to prevent the use of belt restraints on psychogeriatric residents newly admitted to nursing homes.

Design: Quasi-experimental study design.

Setting: Twenty-six nursing home wards from thirteen Dutch nursing homes.

Participants: Newly admitted residents $(n=104)$ during a four month period.

Interventions: Fifteen wards (intervention group) implemented the EXBELT intervention, which consisted of four components: a policy change, education, consultation and the availability of alternative interventions.

Methods: Data on the use of belt restraints, other types of physical restraints, falls and fall-related injuries and psychoactive drug use were collected at T2 (4 months) and T3 (8 months) after baseline (T1) for those resident who were newly admitted after baseline and before T2 (4 months). Physical restraint use data were collected by a trained, blinded observer four times during a 24-hour period.

Results: A total of 104 residents were newly admitted after baseline (T1) and before T2. Of those, 82 were present on T2 and T3. Informed consent was obtained from legal representatives of 49 out of the 82 residents. In the control group ( $\mathrm{n}=20$ ), 15\% and 20\% used belts at T2 (4 months) and T3 ( 8 months) respectively. In the intervention group $(n=29)$, these proportions were $3 \%$ and $0 \%$, respectively (OR $=0.08 ; 95 \%$ CI $(0.01-0.76) ; \mathrm{p}=0.03)$. There was no increase in the intervention group in the use of other physical restraints, falls and fallrelated injuries or psychoactive drug use.

Conclusion: The EXBELT intervention effectively seems to prevent the use of belt restraints in newly admitted residents in psychogeriatric nursing homes. 


\section{What is already known about the topic?}

- Physical restraints are often used in psychogeriatric nursing homes. Belt restraints is one of the most restrictive forms of physical restraint currently in use in nursing homes.

- Safety perceptions of nursing home staff result in physical restraint use in order to prevent falls, although many negative physical, psychological and social consequences of restraint use have been reported.

- The most frequently used multi-component intervention in studies aimed at reducing restraint use is that of education and consultation. The results of these studies are conflicting: some reported positive effects, while others found no effect.

\section{What this paper adds}

- This study focused on preventing belt restraint use in newly admitted residents as compared to reducing belt usage among already admitted residents.

- The EXBELT intervention includes a policy change, education, consultation and the availability of alternative interventions.

- EXBELT seems to be effective in preventing the use of belt restraints in newly admitted residents; no increase occurred in the intervention group in the use of other physical restraints, falls and fall-related injuries or psychoactive drug use. 


\section{Introduction}

Of the estimated 235,000 people suffering from dementia in the Netherlands, about 40,000 reside in psychogeriatric nursing homes. ${ }^{1}$ Psychogeriatric nursing homes are institutions providing nursing care 24 hours a day, assistance with activities of daily living and mobility, psychosocial and personal care, paramedical care, such as physiotherapy and occupational therapy, as well as room and board. ${ }^{2}$ They mainly serve very frail, older adults with psychogeriatric disorders, especially people with dementia, that affect autonomous personal care, mobility, continence, and cognitive functioning. ${ }^{3}$ Physical restraints are often used in this population; estimates range from $15 \%$ to $66 \%$. ${ }^{4-6}$ The large variance in prevalence estimates can be explained by the usage of different definitions of physical restraint use (e.g. in some studies bedrails were excluded as a physical restraint measure) and differences in data collection methods (resident observations versus questionnaires to nursing home staff about restraint use), next to differences in national restraint policies and characteristics of nursing homes and their residents.

Poor mobility, high dependency and impaired cognitive status are the strongest predictors of restraint usage. 5, 7-10 Several studies demonstrated that in almost all cases, physical restraints are used as safety measures 5, 8,11, mainly to prevent falls (more than 90\% ). 5, 8, 12 Other uses include the prevention of wandering, the control of restless and aggressive behaviour and maintenance of a resident's position while seated in a chair. ${ }^{8,9,13-15}$ In nursing homes physical restraints in most cases are used for more than three months and as a routine measure. ${ }^{5}$ It seems that it is difficult to remove physical restraints once they are deployed. Many negative physical, psychological and social consequences of restraint use have been reported, such as problems with balance and coordination, incontinence, demoralisation, depression, aggression and impaired social functioning. The use of restraints may even increase the risk of serious injury and death. ${ }^{16-19}$ In the light of the accumulating evidence regarding the adverse consequences of physical restraint use, their use should be recognized as inappropriate. ${ }^{5,20-22}$ In addition, physical restaints usage affects human rights which should enable us live full lives with maximum dignity and respect. ${ }^{23}$

Knowing that the use of physical restraints has been shown to be ineffective and sometimes even hazardous, attention must be focused on interventions that can effectively reduce current usage as well as prevent initiation of restraints in newly admitted residents. Up until now, however, attention has mainly focused on the reduction of physical restraint reduction use. Only one study ${ }^{24}$ reported on the prevention of physical restraint use in newly admitted residents. In this study, an educational program combined with consultation provided by a nursing specialist did not prevent the use of physical restraints in 
newly admitted residents to psychogeriatric nursing home wards. ${ }^{24}$ Most studies that aim to reduce restraint use also have mostly used education and consultation interventions. In studies that aimed to reduce restraint use, in general the most frequently used interventions were also education and consultation. The results of these studies are conflicting: some reported positive effects ${ }^{25,26}$, while others found no effect. 6, 25, 27 Recent studies confirmed that education alone is not enough to ensure a reduction in the use of restraints. ${ }^{27-29}$ The availability of alternative interventions seems to be an important additional prerequisite for eliminating restraint use. ${ }^{30-33}$ In some countries such as Denmark, Scotland and the US belt restraint use is only permitted under strict conditions. ${ }^{34}$ These measures seem to have contributed to a reduction in restraint use in these countries. ${ }^{35-38}$ However, the challenge of finding the ideal combination of interventions to avert the use of physical restraints from clinical practice still remains. 34

Based on the outcomes and implications from previous studies we developed a comprehensive strategy called the EXBELT intervention to reduce and prevent initiation of the use of belt restraints. The strategy includes a policy change, education, consultation and the availability of alternative interventions. The implementation of the EXBELT intervention resulted in a $50 \%$ reduction in belt use (odds ratio $=0.48,95 \%$ confidence interval $=0.28-0.81 ; \mathrm{P}=.005$ ). ${ }^{39}$ The aim of the present study was to examine the effect of EXBELT intervention on the prevention of belt restraint use in newly admitted residents of psychogeriatric nursing home wards.

\section{Methods}

\section{Design and sample}

The present study is part of the quasi-experimental study which focused on the reduction of belt restraint usage in residents with dementia who reside in psychogeriatric nursing homes. ${ }^{39}, 40$ In this study we employed a quasiexperimental longitudinal study with 8 month follow-up to examine the effect of a multi-component intervention program on reduction and prevention of belt restraints in two different samples: (1) residents living in as nursing homes and (2) newly residents admitted.

The present study focuses primarily on the prevention of belt restraints in newly admitted residents. A total of 104 residents were newly admitted after baseline (T1) and before the T2 measurement ( 4 months after baseline). Only residents who were newly admitted after baseline (T1) and before the T2 measurement and were present at both the T2 and T3 (8 months after baseline) 
measurement were included. In order to participate, the prevalence of belt restraint use on the psychogeriatric nursing home ward had to be at least $10 \%$. Belt use was defined as the use of any type of belt restraint applied to the waist at least once a day. Wards were excluded for participation if they were restricted to residents with Korsakoff's, if wards were undergoing administrative reorganization and/or construction renovations, and if they were participating in other projects and/or studies aimed at restraint use. A total of 26 psychogeriatric wards from 13 nursing homes throughout various regions in the Netherlands were recruited for the study. A total of 6 nursing homes (15 wards) were allocated to the EXBELT intervention group and 7 nursing homes (11 wards) were allocated to the control group (which received care as usual). In order to avoid contamination bias from nursing homes that were situated in close proximity, these were assigned to the same group by the research team. In addition, nursing homes in close proximity were also assigned to the same group in order to keep the study feasible and avoid excessive travel time for the nurse specialists who delivered the educational and consult part of the intervention. Randomization was not feasible by the introduction of the intervention in different parts of the Netherlands with limited nursing staff available $(n=2)$ and travel distances of more than 200 kilometres. We tried to minimize the travel distances as much as possible. This also accounts for the nursing home staff who participated in the educational program. The study design is described in more detail elsewhere (Gulpers et al., 2010).

\section{Intervention}

The EXBELT intervention was delivered to the 15 wards in the intervention group during the four months following baseline data collection (T1). The EXBELT intervention comprises four key components; institutional policy change, education, consultation and the availability of alternative interventions : 40

- The institutional policy change discourages the use of belt restraints: Written and oral communication with all members of the nursing home staff and with the relatives of residents about a reduction in the current use of belts and the prohibition of belt restraint use on newly admitted residents.

- An educational program was delivered to members of the nursing home staff (physician, nurses, paramedical staff, psychologist, and ward manager) by a nursing specialist. The content of the training program was: fall prevention, (negative) aspects of physical restraints, attitudes, decision making and the use of resident-centred alternatives. This program consisted of three 3-hour sessions over a period of 3 weeks. An additional 90minute educational session summarising the content was provided to staff 
members of the intervention wards who could not attend the educational program.

- Consultation: Two nursing specialists provided on-site consultations with individual nurses on the intervention wards regarding the challenges of reducing and preventing restraint use. A nursing home director was also available for individual consultations with nursing home managers and clinical staff.

- Alternative interventions: Alternative interventions were discussed with the multidisciplinary team and with the representatives of the residents. Managers purchased resident-centred alternative interventions such as hip protectors, infrared alarm systems, balance training, exercise, special pillows and adjustable low-height beds.

\section{Measures}

In our study, physical restraints were defined as any limitation on an individual's freedom of movement by using measures or equipment such as belts (materials attached to the waist) tied to a chair or bed, full-enclosure bedrails and (wheel) chairs with a locked tray table. ${ }^{14}$ The use of belt restraints (primary outcome) and other physical restraints (secondary outcomes) was measured per resident using an observation tool developed by Huizing et al. (2006). The interrater reliability was found to be perfect (kappa $=1.0$ ). ${ }^{6}$ Restraints were simultaneously recorded as present or absent by trained observers who were blinded to the group assignment.

The days and times of observations were not announced to the wards to prevent any temporary removal of belts. ${ }^{25,40}$ Observations were made four times during a 24-hour period (morning, afternoon, evening and night). Falls and fall-related injuries (e.g. haematomas, bruises, lacerations, joint dislocations and fractures) over the previous 3 months were recorded using an incident reporting system that Dutch nursing homes are required to maintain. ${ }^{41}$ Data on psychoactive drug use (antipsychotics, antidepressants, tranquillisers and hypnotic medication) were collected from the residents' medical records.

\section{Ethical considerations}

Aggregated, restraint use prevalence was collected without resident-identifiers. Since none of the newly admitted participants were cognitively able to provide informed consent, written informed consent was obtained to collect additional demographic data, data on falls, fall-related injuries, and psychoactive drug use, from the legal representatives of the residents. The study design and protocol were approved by both the Medical Ethics Committee of the University Hospital 
Maastricht and Maastricht University, as well as by the local Ethical Committees of participating nursing home associations.

\section{Data collection and analysis}

Data for this study were collected 4 months (T2) and 8 months (T3) following baseline. The residents for whom we obtained complete data at both T2 and T3 were used and analyzed according to the intention-to-treat principle. We used Fisher's exact test for the categorical variables. Statistical Package for the Social Sciences (SPSS) software version 17.0 was used to perform these analyses. In addition, generalized estimating equation (GEE) techniques were employed to estimate the effect on the main outcome variable (belt restraint use). The GEE analysis accounts for clustering within homes and wards as well as serial correlation (across time points) within residents. We adjusted for baseline characteristics and dependence in the measurements (age, psychoactive drug use and falls) A difference between groups was deemed not due to chance if $p \leq 0.05$.

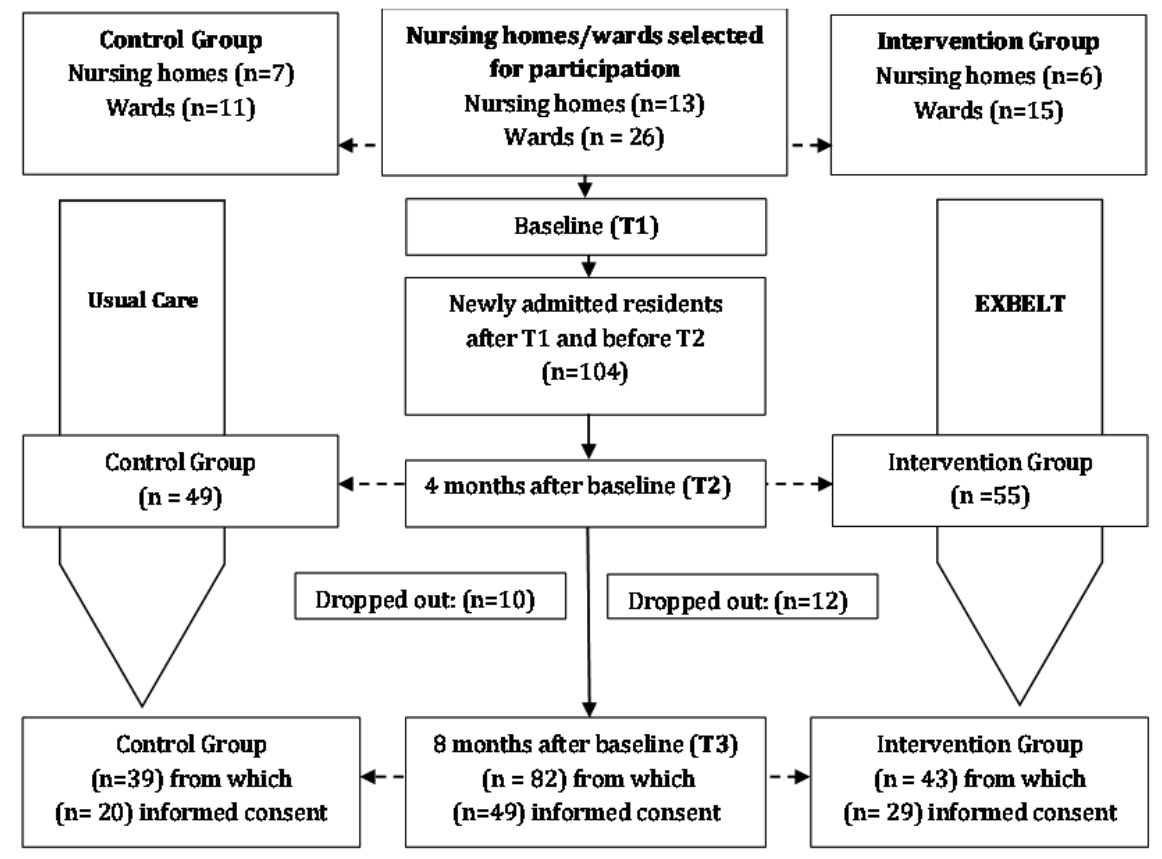

Figure 1. Flow chart, newly admitted residents, informed consent group 


\section{Results}

For restraint use prevalence we included all residents newly admitted after baseline (T1) that were also present at both post-intervention data collection periods (T2 and T3; $n=82$ control group $n=39$ and intervention group $n=43$ ). We collected only observational data regarding physical restraint use from this group.

For 49 residents out of 82 , we obtained informed consent from their legal representatives. For these 49 residents, additional information (demographic characteristics, falls, fall-related injuries and psychoactive drug) was available for both post-intervention measurements (T2 and T3) (see Figure 1). No differences were found between the control $(n=20)$ and intervention group $(n=29)$ in terms of demographic characteristics, sex, recent falls and fall-related injuries or psychoactive drug use at (T2), except age; residents in the intervention group were older $(\mathrm{p}=0.03)$.

Table 1. Background characteristics and outcome measures upon admission $(n=49)$

\begin{tabular}{llll}
\hline & Control group & Intervention group & \\
\cline { 2 - 3 } Measured variables & $(\mathrm{n}=20)$ & $(\mathrm{n}=29)$ & p-value \\
\hline Background characteristics & $14(70)$ & $18(62)$ & 0.76 \\
$\quad$ Female, $\mathrm{n}(\%)$ & $82 \pm 6.6$ & $85.9 \pm 5.1$ & 0.03 \\
$\quad$ Age, mean $\pm \mathrm{SD}^{*}$ & & & \\
Outcome measures & $3(15)$ & $1(3.4)$ & 0.29 \\
$\quad$ Belt restraints, n (\%) & $8(40)$ & $11(37.9)$ & 1.00 \\
$\quad$ Falls, n (\%) & $2(10)$ & $7(24)$ & 0.28 \\
$\quad$ Fall related injuries, $\mathrm{n}(\%)$ & $14(70)$ & $22(76)$ & 0.75 \\
$\quad$ Psychoactive drug use, $\mathrm{n}(\%)$ & &
\end{tabular}

\section{Belt restraint use}

Among the 82 newly admitted residents an increase in the use of belt restraints was observed in those residing in the control ward $(n=39)$ from $8 \%$ at T2 to $13 \%$ at $\mathrm{T} 3$, whereas belt use in the intervention group $(\mathrm{n}=43)$ was $2 \%$ at both T2 and T3 (13\% versus 2\%, p=0.07 at T3) (Table 2).

The subgroup of 49 newly admitted residents with informed consent received belt restraints more often in the control group than in the intervention group (at T2 15\% vs. 3\%, p=0.29) although it was not until T3 that this difference became statistically significant (20\% vs. $0 \%, \mathrm{p}=0.02)$ (Figure 2). The GEE model, adjusting for baseline characteristics, confirmed this finding $(\mathrm{OR}=0.08$; 95\% CI (0.01 - 0.76); $\mathrm{p}=0.03)$. 


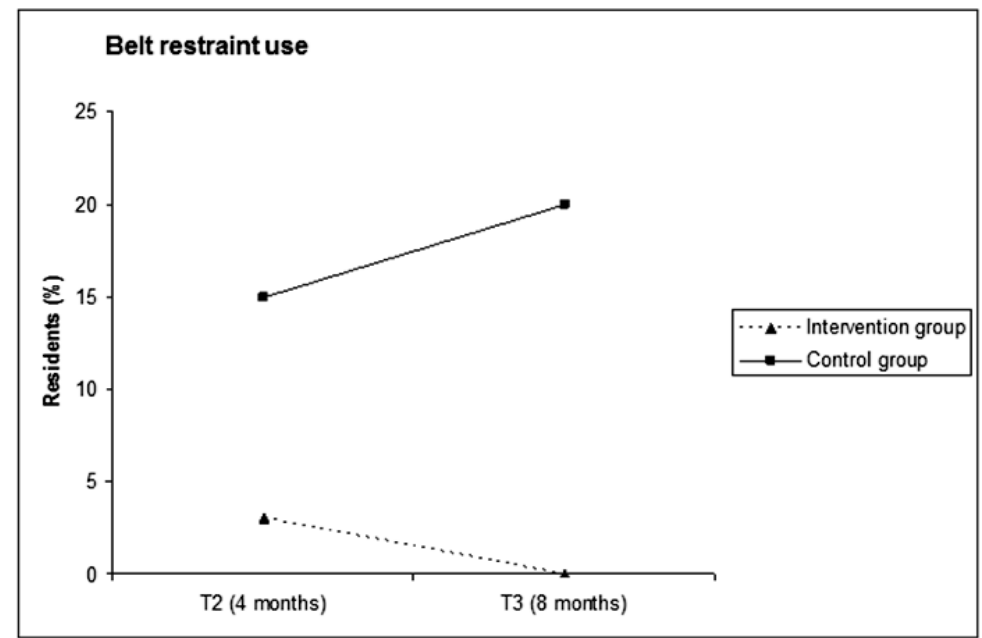

Figure 2. Belt restraint use in newly admitted residents $(n=49)$ (Difference of proportions in control and intervention group is 0.16 (95\%CI: 0.01-0.32)

\section{Physical restraint use}

As can be seen in Tables 2 and 3, increases in the use of all restraining measures were found in the control group compared to a decrease in the use of these measures in the intervention group. However, these differences proved not to be statistically significant.

\section{Falls and psychoactive drug use}

Falls, fall-related injuries and the use of psychoactive drugs did not change among those in the intervention group over time. The number of fallers decreased in the control group between T2 and T3 (from 40\% to 20\%). Despite this reduction in the number of falls, the percentage of fall-related injuries $(10 \%$ at $\mathrm{T} 2$ and $\mathrm{T} 3)$ did not change in the control group. No significant differences in falls, fall-related injuries or psychoactive drug use were observed between the two groups at the two post-intervention points (T2 and T3; Table 3). 
Table 2. Differences between the intervention and control groups in the use of physical restraints (n=82, complete data)

\begin{tabular}{|c|c|c|c|c|c|c|}
\hline \multirow[b]{2}{*}{ Outcome measures } & \multicolumn{3}{|c|}{ First post-test after 4 months (T2) } & \multicolumn{3}{|c|}{ Second post-test after 8 months (T3) } \\
\hline & $\begin{array}{l}\text { Control } \\
(\mathrm{n}=39)\end{array}$ & $\begin{array}{l}\text { Intervention } \\
(\mathrm{n}=43)\end{array}$ & $\mathrm{p}$-value & $\begin{array}{l}\text { Control } \\
(n=39)\end{array}$ & $\begin{array}{l}\text { Intervention } \\
(\mathrm{n}=43)\end{array}$ & $\mathrm{p}$-value \\
\hline \multicolumn{7}{|l|}{ Primary* } \\
\hline Belt restraints, $\mathrm{n}(\%)$ & $3(8)$ & $1(2)$ & 0.34 & $5(13)$ & $1(2)$ & 0.10 \\
\hline \multicolumn{7}{|l|}{ Secondary* } \\
\hline $\begin{array}{l}\text { (Wheel)chair with a locked } \\
\text { table, } \mathrm{n}(\%)\end{array}$ & $2(5)$ & $1(2)$ & 0.60 & $3(8)$ & 0 & 0.10 \\
\hline Fully enclosed bedrails, n (\%) & $10(26)$ & $11(26)$ & 1.00 & $12(31)$ & $8(19)$ & 0.30 \\
\hline $\begin{array}{l}\text { Deep and/or overturned } \\
\text { (wheel)chair, } \mathrm{n}(\%)\end{array}$ & $1(3)$ & $3(7)$ & 0.62 & $2(5)$ & $1(2)$ & 0.60 \\
\hline Sleep suits, n (\%) & $2(5)$ & $2(5)$ & 1.00 & $4(10)$ & $1(2)$ & 0.19 \\
\hline $\begin{array}{l}\text { At least one physical restraint } \\
\text { device, } n(\%)\end{array}$ & $12(31)$ & $13(30)$ & 1.00 & $14(36)$ & $9(21)$ & 0.15 \\
\hline
\end{tabular}

* Effects were assessed by means of Fisher's exact tests

Table 3. Differences between the intervention and control groups in the use of physical restraints, falls and psychoactive drug use in newly admitted residents $(n=49$, complete data and informed consent)

\begin{tabular}{|c|c|c|c|c|c|c|}
\hline \multirow[b]{2}{*}{ Outcome measures } & \multicolumn{3}{|c|}{ First post-test after 4 months (T2) } & \multicolumn{3}{|c|}{ Second post-test after 8 months (T3) } \\
\hline & $\begin{array}{l}\text { Control } \\
(\mathrm{n}=20)\end{array}$ & $\begin{array}{l}\text { Intervention } \\
(\mathrm{n}=29)\end{array}$ & p-value & $\begin{array}{l}\text { Control } \\
(\mathrm{n}=20)\end{array}$ & $\begin{array}{l}\text { Intervention } \\
(\mathrm{n}=29)\end{array}$ & p-value \\
\hline \multicolumn{7}{|l|}{$\overline{\text { Primary* }}$} \\
\hline Belt restraints, $\mathrm{n}(\%)$ & $3(15)$ & $1(3)$ & 0.29 & $4(20)$ & $0(0)$ & 0.02 \\
\hline \multicolumn{7}{|l|}{ Secondary* } \\
\hline $\begin{array}{l}\text { (Wheel)chair with a locked } \\
\text { table, } n(\%)\end{array}$ & $1(5)$ & $0(0)$ & 0.41 & $2(10)$ & $0(0)$ & 0.16 \\
\hline Fully enclosed bedrails, n (\%) & $3(15)$ & $7(24)$ & 0.50 & $5(25)$ & $5(17)$ & 0.72 \\
\hline $\begin{array}{l}\text { Deep and/or overturned } \\
\text { (wheel)chair, } \mathrm{n}(\%)\end{array}$ & $0(0)$ & $2(7)$ & 0.51 & $0(0)$ & $1(3)$ & 1.00 \\
\hline Sleep suits, n (\%) & $2(10)$ & $2(7)$ & 1.00 & $3(15)$ & $1(3)$ & 0.29 \\
\hline $\begin{array}{l}\text { At least one physical restraint } \\
\text { measure, } \mathrm{n}(\%)\end{array}$ & $5(25)$ & $8(28)$ & 1.00 & $6(30)$ & $6(21)$ & 0.51 \\
\hline Falls, n (\%) & $8(40)$ & $11(38)$ & 1.00 & $4(20)$ & $10(35)$ & 0.34 \\
\hline Fall-related injuries, n (\%) & $2(10)$ & $7(24)$ & 0.28 & $2(10)$ & $4(14)$ & 1.00 \\
\hline Fall-related fractures, $\mathrm{n}(\%)$ & - & - & - & - & - & - \\
\hline Psychoactive drug use, n (\%) & $14(70)$ & $22(76)$ & 0.75 & $13(65)$ & $21(72)$ & 0.75 \\
\hline
\end{tabular}

* Effects were assessed by means of Fisher's exact tests 


\section{Discussion}

Our study indicates that the EXBELT intervention prevented belt restraint use in newly admitted psychogeriatric nursing home residents. We also found a trend that the EXBELT intervention can prevent the use of other physical restraints. Not using belt restraints did not lead to any adverse effects such as an increase in psychoactive drug use, falls or fall-related injuries. These results are in line with the effects of the EXBELT intervention in the larger study among already admitted residents. ${ }^{39}$ That study also showed that a statistically significant decrease in the use of belts and other physical restraints in nursing homes is attainable without causing an increase in psychoactive drug use, falls or fallrelated injuries. 39

The integrated EXBELT approach substantially contributed to the prevention of restraint use. Although education in combination with consultation showed conflicting outcomes in previous studies, these are necessary components of the more comprehensive EXBELT intervention. Education is one of the indispensable elements of any implementation strategy, but additional approaches are often necessary. ${ }^{42}$ However, we believe that the strength of the EXBELT approach is in the combination of its components (institutional policy change, education, consultation and the availability of resident-centred alternative interventions); they all seem necessary aspects for preventing belt restraint. Education informs staff of why and how to minimize restraint use, the consultant reinforces these concepts by demonstrating how to apply alternatives in resident situations. Therefore, it is important that alternative devices, instead of physical restraints, are available and easily accessible to staff. The policy change supports and clarifies what is expected of staff. It also provides a clear message to residents' relatives regarding the facilities' in regard to restraint use.

Following baseline, implementation of the multi-component intervention began with education. The change of policy, consultation and availability of alternative interventions were implemented before the second data collection period (T3). At the first post-test (T2) the intervention was starting to work, differences in restraint use were found between the intervention and control groups, but this trend was more robust at the second post-test (T3) once the intervention had been fully implemented. This indicates again that the combination of all elements of the EXBELT intervention is required to prevent initiation of restraints in newly admitted residents.

Our study had some limitations. Although we collected observation data on restraint use at both time points (T2 and T3) for 82 newly admitted residents; legal representatives gave approval for participation for only $60 \%(n=49)$ of these residents. This limited our ability to evaluate the demographic character- 
istics, falls, fall-related injuries and psychoactive drugs data for $40 \%$ of the newly admitted residents. Furthermore, we have no data on demographic characteristics and physical restraint use of all newly admitted residents who were only present at one measurement (T2 or T3). Therefore we were unable to assess the impact of sample selection bias which may have implications for the generalizability of the findings. The number of newly admitted residents was not large. The requirement of informed consent further reduced the size of the sample and the power of the study. Consequently, we have to be careful in interpreting our results. However, we still think that our results show a convincing preventive EXBELT trend. Thirdly, a quasi-experimental design was used. In order to avoid contamination bias and excessive travel time, randomization by ward or home was not feasible. For that reason assignment to either the intervention or control groups was done by the research team. Nevertheless, both resident populations were broadly similar. Fourthly, newly admitted residents did not use belt restraints before admission to the nursing home; further information was not available about other types of restraint use before admission. Using physical restraints before admission may impact the use of restraints after admission. Finally, it has often been reported that short-term benefits disappear over time. Between baseline (T1) and the first post-test (T2) (a period of 4 months), the average length of stay of newly admitted residents was 2 months. There was a period of 4 months between T2 and T3. The results at T3 that represent residents with an average stay of 6 months after admission provide a positive indication of the potential long-term effects of the EXBELT intervention to prevent belt restraint and other types of physical restraint use in the newly admitted residents.

\section{Conclusion}

The prevention of belt restraint and other types of physical restraint use in newly admitted residents in nursing homes seems to be attainable without causing an increase in psychoactive drug use, falls and fall-related injuries. In view of the small sample size and modest follow-up period, it would be desirable to conduct additional studies using larger samples to explore long-term effects of EXBELT on the use of physical restraints on newly admitted residents. 


\section{References}

[1] Alzheimer's Association. Alzheimer's disease facts and figures. Alzheimers Dement 2010. 2010: 36.

[2] Ribbe MW, Ljunggren G, Steel K, et al. Nursing homes in 10 nations: a comparison between countries and settings. Age and ageing. 1997;26 Suppl 2: 3-12.

[3] Schols JMGA, Van der Schriek - van Weel C. Day care for demented elderly in a dairy farm setting. J Am Med Dir Assoc. 2006;456 - 459.

[4] Capezuti E, Taylor J, Brown H, et al. Challenges to implementing an APN-facilitated falls management program in long-term care. Applied Nursing Research. 2007;20: 2-9.

[5] Hamers JP, Gulpers MJ, Strik W. Use of physical restraints with cognitively impaired nursing home residents. Journal of Advanced Nursing. 2004;45: 246-251.

[6] Huizing AR, Hamers JP, Gulpers MJ, et al. Short-term effects of an educational intervention on physical restraint use: a cluster randomized trial. BMC Geriatr. 2006;6: 17.

[7] Burton LC, German PS, Rovner BW, et al. Physical restraint use and cognitive decline among nursing home residents. J Am Geriatr Soc. 1992;40: 811-816.

[8] Capezuti E. Minimizing the use of restrictive devices in dementia patients at risk for falling. Nursing Clinics of North America. 2004;39: 625-647.

[9] Gallinagh R, Nevin R, Mc Ilroy D, et al. The use of physical restraints as a safety measure in the care of older people in four rehabilitation wards: findings from an exploratory study. Int J Nurs Stud. 2002;39: 147-156.

[10] Sullivan-Marx EM, Strumpf NE, Evans LK, et al. Initiation of physical restraint in nursing home residents following restraint reduction efforts. Research in Nursing and Health. 1999;22: 369379.

[11] Werner P. Perceptions regarding the use of physical restraints with elderly persons: comparison of Israeli health care nurses and social workers. Journal of Interprofessional Care. 2002;16: 59-68.

[12] Werner P, Mendelsson G. Nursing staff members' intentions to use physical restraints with older people: testing the theory of reasoned action. J Adv Nurs. 2001;35: 784-791.

[13] Castle NG, Fogel B, Mor V. Risk factors for physical restraint use in nursing homes: pre- and post-implementation of the Nursing Home Reform Act. Gerontologist. 1997;37: 737-747.

[14] Hantikainen V. Physical restraint: a descriptive study in Swiss nursing homes. Nursing Ethics. 1998;5: 330-346.

[15] Ryden MB, Feldt KS, Oh HL, et al. Relationships between aggressive behavior in cognitively impaired nursing home residents and use of restraints, psychoactive drugs, and secured units. Arch Psychiatr Nurs. 1999;13: 170-178.

[16] Evans D, Wood J, Lambert L. Patient injury and physical restraint devices: a systematic review. Journal of Advanced Nursing. 2003;41: 274-282.

[17] Healey F, Oliver D, Milne A, et al. The effect of bedrails on falls and injury: a systematic review of clinical studies. Age Ageing. 2008;37: 368-378.

[18] Miles SH, Irvine P. Deaths caused by physical restraints. The Gerontologist. 1992;32: 762-766.

[19] Mohler R, Richter T, Kopke S, et al. Interventions for preventing and reducing the use of physical restraints in long-term geriatric care. Cochrane Database Syst Rev. 2011: CD007546.

[20] Hamers JPH, Gulpers MJM. Reducing physical restraints in nursing homes: results of a pilot study. Journal of Nutrition, Health \& Aging 2009;suppl.: S17.

[21] Meyer G, Kopke S, Haastert B, et al. Restraint use among nursing home residents: crosssectional study and prospective cohort study. Journal of Clinical Nursing. 2009;18: 981-990.

[22] Sullivan-Marx. Achieving restraint-free care of acutely confused older adults. Journal of Gerontological Nursing. 20014

[23] Hughes R. Human rights and restraints. Br J Hosp Med (Lond). 2008;69: 494-495. 
[24] Huizing AR, Hamers JP, Gulpers MJ, et al. Preventing the use of physical restraints on residents newly admitted to psycho-geriatric nursing home wards: a cluster-randomized trial. Int J Nurs Stud. 2009;46: 459-469.

[25] Evans LK, Strumpf NE, Allen-Taylor SL, et al. A clinical trial to reduce restraints in nursing homes. Journal of the American Geriatrics Society. 1997;45: 675-681.

[26] Testad I, Aasland AM, Aarsland D. The effect of staff training on the use of restraint in dementia: a single-blind randomised controlled trial. International Journal of Geriatric Psychiatry. 2005;20: 587-590.

[27] Testad I, Ballard C, Bronnick K, et al. The effect of staff training on agitation and use of restraint in nursing home residents with dementia: a single-blind, randomized controlled trial. $J$ Clin Psychiatry. 2010;71: 80-86.

[28] Huizing AR, Hamers JP, Gulpers MJ, et al. A cluster-randomized trial of an educational intervention to reduce the use of physical restraints with psychogeriatric nursing home residents. $J$ Am Geriatr Soc. 2009;57: 1139-1148.

[29] Pellfolk TJ, Gustafson Y, Bucht G, et al. Effects of a restraint minimization program on staff knowledge, attitudes, and practice: a cluster randomized trial. J Am Geriatr Soc. 2010;58: 6269.

[30] Becker C, Kron M, Lindemann U, et al. Effectiveness of a multifaceted intervention on falls in nursing home residents. J Am Geriatr Soc. 2003;51: 306-313.

[31] Capezuti E, Talerico KA, Cochran I, et al. Individualized interventions to prevent bed-related falls and reduce siderail use. Journal of Gerontological Nursing. 1999;25: 26-34; quiz 52-23.

[32] Freeman MA. Motion device: an alternative to physical restraints. Geriatr Nurs. 2004;25: 175.

[33] Hoffman SB, Powell-Cope G, MacClellan L, et al. BedSAFE. A bed safety project for frail older adults. J Gerontol Nurs. 2003;29: 34-42.

[34] Hamers JP, Huizing AR. Why do we use physical restraints in the elderly? Z Gerontol Geriatr. 2005;38: 19-25.

[35] Bower FL, McCullough CS, Timmons ME. A synthesis of what we know about the use of physical restraints and seclusion with patients in psychiatric and acute care settings: 2003 update. Online J Knowl Synth Nurs. 2003;10: 1.

[36] Castle NG. The use of physical restraints in nursing homes: pre- and post-Nursing Home Reform Act. J Health Soc Policy. 1998;9: 71-89.

[37] Castle NG. Nursing homes with persistent deficiency citations for physical restraint use. Med Care. 2002;40: 868-878.

[38] Dunn KS. The effect of physical restraints on fall rates in older adults who are institutionalized. Journal of Gerontological Nursing. 2001;27: 40-48.

[39] Gulpers MJ, Bleijlevens MH, Ambergen T, et al. Belt restraint reduction in nursing homes: effects of a multicomponent intervention program. J Am Geriatr Soc. 2011;59: 2029-2036.

[40] Gulpers MJ, Bleijlevens MH, van Rossum E, et al. Belt restraint reduction in nursing homes: design of a quasi-experimental study. BMC Geriatr. 2010;10: 11.

[41] Arcares. Registration of incidents and near accidents in nursing homes and old peoples' homes. Utrecht: Arcares, 2002.

[42] Grol R. The implementation of change in clinical practice. 2005. 



\section{Chapter 5}

\section{Process Evaluation of a multi-component intervention program (EXBELT) to reduce belt restraints in nursing homes}

Michel HC Bleijlevens; Math JM Gulpers; Elizabeth Capezuti;

Erik van Rossum; Jan PH Hamers

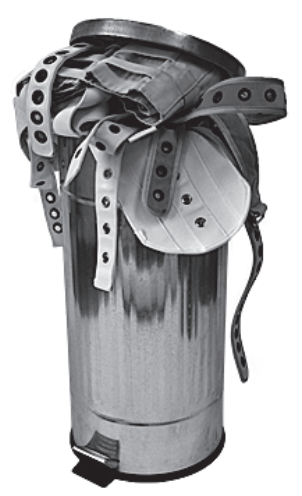

Accept for publication 5 March 2013 in Journal of the American Medical Directors Association 


\begin{abstract}
Objective: The current study describes the process evaluation of a multicomponent intervention program (EXBELT) to reduce the use of belt restraints in psychogeriatric nursing homes. The aim was to assess the feasibility and ascertain suggestions for optimization of the EXBELT program.
\end{abstract}

Design: A descriptive study comprising longitudinal elements.

Setting: Fifteen psychogeriatric nursing home wards in 6 Dutch nursing homes.

Participants: The study population consisted of 4 different groups of participants who took part in the intervention arm of the quasi-experimental study examining the effectiveness of EXBELT: Nursing home staff who attended the final session of the educational program; 2 nurse specialists who delivered the educational program and did the consultations; 4 groups of delegates representing the nursing home associations were the EXBELT program was implemented and; the relatives of those residents in the intervention group who were restrained with a belt at the start of the study.

Measurements: Both quantitative and qualitative data were collected from the study population. Data were assessed by means of self-administered questionnaires, recording forms, group interviews, telephone interviews, and monthly meetings.

Results: The EXBELT study was largely performed according to protocol and very well received by nursing home staff as well as resident's relatives. Suggestions to improve the EXBELT program include the addition of examples of how to communicate about the policy change, improving the reach of the intended target population, adding more case-based learning strategies, and embedding the available consultants more proactively.

Conclusion: The implementation of EXBELT was highly successful in the current research population and is likely to be feasible in psychogeriatric nursing homes in general. 


\section{Introduction}

More than 3 decades of research on the use of physical restraints in nursing homes has informed us of the prevalence, determinants and adverse consequences of physical restraint as well as effective interventions to reduce and prevent their usage ${ }^{1-10}$. The prevalence of physical restraints varies widely in nursing homes; from $4 \%$ to $85 \%{ }^{11-14}$. These large differences may be the result of dissimilarities in regulations/legislation regarding restraint use among countries, as well as different study populations, diverse methodological approaches, and varied definitions of physical restraint 12,14 . There is clear evidence that the use of physical restraints causes negative health outcomes for nursing home residents $10,15,16$. These range from agitation, dependency in activities of daily living and walking, pressure ulcers, contractures, behavior problems and falls, to sustaining serious injuries and even death ${ }^{15-19}$. Nevertheless, the use of these devices is still common practice in many countries 10,11,13, 14, $20,21$.

Several programs have been developed to reduce and prevent the use of physical restraints $22-31$. The multi-component EXBELT program, which aims to reduce restrictive belt restraint use, is an example of such a program 25,32 . A quasi-experimental longitudinal study evaluating the effectiveness of the EXBELT program demonstrated a 50\% reduction of belt restraints in psychogeriatric nursing homes with no increase in falls, fall-related injuries or psychoactive drug use ${ }^{32}$. In addition, the EXBELT program turned out to be effective in preventing the use of belt restraints in newly admitted residents ${ }^{33}$. A detailed process evaluation was performed to assess what components of the EXBELT program were implemented successfully and how the program could be optimized. A process evaluation reveals information, which may facilitate the understanding of the relationship among the various components of a program and how this affects the program. Given the rising complexity of interventions researchers are increasingly interested in the extent to which all components of a program are actually implemented and what program components can explain the success or ineffectiveness of an intervention ${ }^{34,35}$. Saunders' and colleagues' 35 framework for designing process evaluations addresses the following factors: fidelity, dose delivered (completeness), dose received (exposure and satisfaction), reach, and barriers. We used this framework to conduct a process evaluation to evaluate the feasibility of the EXBELT program and how to improve the program for dissemination. The research questions for this process evaluation are:

- Were all EXBELT components delivered (dose delivered)? 
- $\quad$ To what extent was the EXBELT program implemented as planned (fidelity)?

- To what extent did nursing home staff and residents' relatives interact, were receptive to, and/or used materials or recommended resources (dose received - exposure)?

- What were the opinions of the nursing home staff, nurse specialists, and resident's relatives regarding different components of EXBELT (dose received - satisfaction) and how can the program be improved?

- What proportion of the target audience attended the educational part of the EXBELT program (Reach)?

- To what extent were problems experienced while implementing EXBELT (barriers)?

The current study does not report on the effects of the EXBELT program on attitudes and opinions of nursing home staff regarding physical restraint use which were measured with the MAQ before, during, and after the implementation of the EXBELT program ${ }^{25}$.

\section{Methods}

\section{Study design and population}

The EXBELT process evaluation is a descriptive study comprising longitudinal elements in which quantitative as well as qualitative data were gathered. The study population consisted of 4 different groups of participants who were part of the intervention arm of the quasi-experimental study examining the effectiveness of EXBELT 25, 32:

- Nursing home staff who attended the final session of the educational program;

- Two nurse specialists who delivered the educational program and did the consultations;

- Four groups of delegates representing the nursing home associations where the EXBELT program was implemented and;

- The relatives of those residents in the intervention group who were restrained with a belt at the start of the study.

\section{Intervention}

The multi-component EXBELT program comprises 4 key components; institutional policy change, education, consultation and the availability of alternative interventions: the implementation of an institutional policy change 4 months 
after baseline that prohibits initiation of belt restraints for both newly-admitted and current residents, and encourages reduction of belt restraints. In the Netherlands the current Psychiatric Hospitals Compulsory Admissions Act (BOPZ) does not prohibit the use of physical restraints in nursing home residents. However, physical restraints may only be used when there is a danger to the resident. Thus, the decision to use physical restraints is left to the institution. For that reason we introduced a policy change implemented by the nursing home management. This policy change was communicated by nursing home management to all members of nursing home staff and to residents' relatives (i.e. formal letter, internal newsletters, and meetings).

An educational program, consisting of three 3-hour sessions over a period of 3 weeks, that was delivered by 2 nurse specialists (registered nurses with extensive experience in physical restraint reduction) to nursing home staff of all intervention wards. These sessions included content addressing the negative aspects of physical restraint use, fall prevention, and the use of residentcentered alternative interventions. After session 1 and 2, participants completed problem-based assignments to supplement the sessions. Each ward was represented by 12 nursing home staff members including at least one physician, physical therapist, occupational therapist, psychologist, ward manager, and 7 nurses.

On-site consultation was provided by the same 2 nurse specialists who delivered the educational program. In addition, both a nursing home director and a representative from the Dutch Health Care Inspectorate (IGZ, which is the regulatory body for monitoring quality and safety in Dutch nursing homes) were also available for consultation.

Alternative interventions were made available by the nursing home directors. These included resident-centered alternative interventions, such as hip protectors, infrared alarm systems, balance training exercise, special pillows and adjustable low-height beds.

\section{Data collection}

Both quantitative and qualitative data were collected from the study population. The nursing home staff evaluated the educational program with a selfadministered questionnaire (Q). The nurse specialists maintained attendance lists (AL) for all educational sessions they delivered. In addition, they maintained notes of the consultation visits on recording forms (RF1). The delivery of the educational program and the consultation activities by the nurse specialists were discussed with the principal researchers during monthly meetings that were also documented (M). The nursing home staff recorded all alternative interventions they applied on a second recording form (RF2). The delegates 
from the 4 nursing home associations shared their impression of the intervention program in a structured group interview (INT1) after the intervention period. Finally, a structured telephone interview (INT2) was used to capture the experiences of the residents' relatives with the intervention program. All these tools included questions based on the main components for process evaluations: Dose delivered (completeness), fidelity, dose received (exposure), dose received (satisfaction), reach, and barriers ${ }^{34,35}$. Table 1 shows how these components were operationalized and measured in the current process evaluation.

Table 1. Components of EXBELT process evaluation and measurement instruments

\begin{tabular}{|c|c|c|c|c|c|c|c|}
\hline \multirow[b]{2}{*}{ Component and operationalization } & \multicolumn{7}{|c|}{ Measurement Instruments } \\
\hline & INT1* & INT2* & $\mathrm{Q}^{*}$ & RF1* & RF2* & $\mathrm{M}^{*}$ & $\mathrm{AL}^{*}$ \\
\hline \multicolumn{8}{|l|}{ Dose delivered } \\
\hline $\begin{array}{l}\text { Proportion of components of the EXBELT program } \\
\text { that is actually delivered and the extent to which all } \\
\text { intended content is covered (completeness) and } \\
\text { methods were used. }\end{array}$ & & $\mathrm{x}$ & $\mathrm{x}$ & $\mathrm{x}$ & $\mathrm{x}$ & $\mathrm{x}$ & \\
\hline
\end{tabular}

\section{Fidelity}

$\begin{array}{lllllllllll}\text { Extent to which the EXBELT program was imple- } & \mathrm{x} & \mathrm{x} & \mathrm{x} & \mathrm{x} & \mathrm{x} & \mathrm{x}\end{array}$ mented as planned

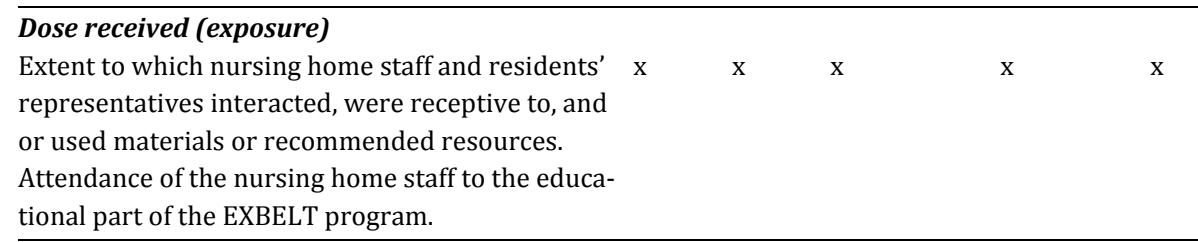

\section{Dose received (satisfaction)}

Satisfaction of nursing home staff and resident's $\quad x \quad$ x $\quad$ x

representatives regarding different part of the

EXBELT program

\section{Reach}

Proportion of the intended target population who

attended the educational program

\section{Barriers}

The extent to which problems were encountered $\quad x \quad$ x $\quad x$ while implementing the EXBELT program

* INT1 = structured face to face interviews; INT2 = structured telephone interviews; $Q$ = selfadministered questionnaires; RF1 = recording forms (consultation notes and other logs); RF2 = recording forms regarding alternative interventions; $M=$ monthly meetings; $A L=$ attendance list

Dose delivered relates to the amount of components of the EXBELT program that is actually delivered. The program was considered to be implemented completely if 1) the institutional policy change was announced and put into practice; 2) the educational program was delivered to the nursing home staff; 
3) the 2 nurse specialists, nursing home director and representative from the Dutch Health Care Inspectorate were available for on-site consultation; and 4) alternative interventions were made available. Actual delivery of the components was measured by means of recording forms (RF1 and RF2), selfadministered questionnaires (Q), as well as structured group (INT1) and telephone interviews (INT2).

Fidelity refers to the quality of the implementation of the intervention. It is operationalized as the extent to which the EXBELT program was implemented consistently with the preconceived plan. The concept of fidelity is strongly related but goes beyond the concept of dose delivered as it provides us with indepth information about the actual implementation of the EXBELT components according to the protocol. In addition, there is overlap with the concept of reach as we are interested in the proportion of the target population that was reached and whether this was according to protocol. The fidelity of how the teaching and consultation were delivered was ensured by providing the nurse specialists with a script. This script included a detailed description of all topics that should be addressed during the educational program. The principal researchers served as the intervention supervisors in order to monitor the fidelity of these intervention components. Copies of consultation notes (RF1), attendance lists (AL) and other logs maintained by the nurse specialists were reviewed during monthly meetings (M) of the principal researchers with both nurse specialists. These sessions provided feedback to the nurse specialists on their performance, generated potential strategies to improve the diffusion of the interventions, and made certain that the 2 nurse specialists delivered the interventions consistently.

Dose received in terms of exposure reflects to the extent of engagement of nursing home staff with the EXBELT program. It provides insight into the extent to which nursing home staff was receptive to, interacted with, and/or used materials or recommended resources. First the extent to which nursing home staff was familiar with the policy change was measured ( $Q$ and INT2). Second, the extent to which the participants of the educational program completed their assignments after the first 2 sessions and whether they perceived that the content of the educational program was useful in daily practice was monitored (Q). Finally, the number of requested consultations (RF1) and the use of alternative interventions (RF2) were documented with recording forms by nursing staff (RF2).

Dose received regarding satisfaction is related to the nursing home staff's and residents' relatives' satisfaction with the EXBELT program. Satisfaction with the educational program of the participating nursing home staff was assessed by means of a self-administered questionnaire with a 5-point Likert scale (ranging from strongly disagree to strongly agree) (Q). For example, par- 
ticipants were asked to determine the extent to which the content and teaching methods of the educational program met their goals for learning how to effectively reduce restraint use. The opinion of the participants regarding the educational program was further assessed by means of open ended questions regarding the strengths and weaknesses and suggested areas for improvement of the educational program (Q). In addition, they were asked whether they intended to recommend this training to a colleague and to rate both the overall educational program and the performance of the instructor (one of the nurse specialists) (Q). Satisfaction with the overall intervention was assessed through structured face-to-face interviews with the 4 groups of delegates representing the nursing home associations (INT1). During these interviews the experiences with the EXBELT program were discussed as well as suggestions for further development and optimization of the intervention. Information regarding the satisfaction of the relatives of the residents with the EXBELT program was gathered through structured telephone interviews (INT2). Relatives were asked how satisfied they were with the EXBELT program and the information they received about the program, as well as the extent to which they were involved in the decision process concerning the use of belt restraints.

Reach refers to the proportion of the intended target audience that participated in the educational part of the intervention. It is measured by attendance of the nursing home staff to the 3 sessions of the educational program (AL).

Barriers were evaluated through asking nursing home staff (educational program), nurse specialists (consultation), nursing home staff's delegations and residents' relatives (implementation EXBELT program) for experiences (INT1, INT2, Q).

\section{Analysis}

Quantitative data were analyzed by means of descriptive statistics. In order to analyze the qualitative data (i.e. the answers to open questions) an iterative process was conducted, in which several rounds of analysis, evaluation, and adaptions took place. A codebook was created using an open coding approach, in which the categories are derived from the data at hand without preconceived categories (conventional content analyses). The emerging categories were used to identify relevant themes and patterns ${ }^{36}$. The group interviews and discussion with the delegates representing the 4 nursing home associations, and the monthly meetings with the nurse specialists were analyzed by the principal researchers. 


\section{Ethical considerations}

The Medical Ethics Committee of Maastricht University / University Hospital Maastricht approved the current process evaluation as part of a larger quasiexperimental study ${ }^{25,32}$. Participation in the study was voluntary for all participants.

\section{Results}

\section{Participants}

A total of 162 nursing home staff members participated in the educational program. Of these, 145 attended the final meeting with 143 completing the selfadministered program evaluation questionnaire (Q). These 143 participated in the process evaluation as well as two nurse specialists and 4 groups of delegates representing each of the nursing home associations. For each of the 4 nursing home associations the group of delegates included a nursing home director, ward manager, nursing home physician, psychologist, physical therapist, occupational therapist and nurse. Finally, relatives of the 38 surviving residents in the intervention group agreed to participate. Table 1 provides a summary of each of the following components of the feasibility evaluation and sources of data.

\section{Dose delivered}

The completeness measure shows that all 4 intervention components were actually delivered to all intervention wards. The structured group interviews (INT1) revealed that the policy change was implemented by the management boards of all 4 nursing home associations. The policy change was communicated to nursing home staff via an internal facility newsletter $(n=4)$ and to residents' relatives in both a newsletter and in on-site group meetings facilitated by the nursing home management $(n=4)$. Both the self-administered questionnaires (Q) and the monthly meetings with the principal researchers (M) revealed that the educational program was delivered completely. Finally, consultation visits (RF1) and use of alternative interventions (RF2) documentation as well as the results from the structured group interviews with nursing home staff (INT1) demonstrate that both consultants and alternative interventions were readily available 


\section{Fidelity}

Although all management boards implemented the new policy, the structured group interviews (INT1) revealed that only 2 boards actually confirmed the implementation of the policy change by means of a formal letter to the nursing home staff and the relatives of the residents. In those cases a formal letter was sent, it was sent respectively 1 and 2 months too late according to protocol. The monthly meetings with the 2 nurse specialists (M) revealed no protocol deviations regarding the delivery of the content of the educational program; all key topics were addressed. The attendance lists (AL) documented that the 15 training groups included staff members from different wards and the composition was largely according to protocol (93\%). In 6 groups there was no occupational therapist represented, in 4 groups no nursing home physician representative, in 1 group no ward manager, and in 1 group a nurse was lacking. According to the protocol a total of 180 nursing home staff members (12 per group) were expected to attend the educational program. However, 162 nursing home staff members participated with an average of 11 participants per group since some nursing home physicians, paramedical staff, and psychologists work on multiple wards.

According to the delegates representing the 4 participating nursing home associations (INT1) both consultants (2 nurse specialists, a nursing home director and a representative from the Dutch Health Care Inspectorate) as well as resident-centered alternative interventions, were available during the total length of the study ( 9 months).

\section{Dose received (exposure)}

A total of $76 \%$ of the nursing home staff who attended the educational program reported to have been informed of the forthcoming policy change before the start of the educational program. In addition, all residents' relatives $(100 \%)$ included in this process evaluation reported to have been informed about the policy change. Most of them (79\%) received this information personally from a nurse. Regarding their participation during the educational program, the selfadministered questionnaires (Q) revealed that most (85\%) of participants completed at least one of two educational assignments.

The consultation notes maintained by the nurse specialists showed that they had been consulted in 9 cases during the first 4 months of the study (on average less than one consult per ward). During the next 5 months the nurse specialists proactively visited all wards at least two times to engage the staff and solicit consultations. Both the available nursing home director and representative from the Dutch Health Care Inspectorate were not consulted, however, the 
manager contacted his colleagues in each of the 4 nursing home associations every 2 months in order to offer any support.

The recording forms recording the use of alternatives (RF2) revealed that in more than half of the cases in which a belt was removed no alternative interventions were introduced. The most frequently used alternative interventions were infrared barrier alarm systems (21\%) and adjustable low-height beds $(12 \%)$.

\section{Dose received (satisfaction)}

Overall, the educational program was evaluated positively by the 143 participants. Nearly all participants (96\%) reported that the educational program met their learning needs including the level of the educational content (76\%) and the duration of the program (75\%). Participants were asked to identify strengths and weaknesses of the program. Fifty-three participants considered the content describing the rationale of the EXBELT program, especially the consequences of physical restraint use, $(n=38)$ to be the most useful. They felt that the educational objectives were clearly communicated $(n=27)$ and appreciated the opportunity to discuss the use of physical restraint with other clinicians in a group $(n=27)$. Some participants suggested that the educational program could have been delivered in less time by reducing the number of sessions $(n=13)$ and providing more examples from clinical practice $(n=8)$. Most $(n=79)$ made no suggestions for improvement and almost all participants (96\%) would recommend the educational program to one of their colleagues. The educational program was rated by participating nursing home staff members with an average score of $7.6(S D \pm 1.1$ ) on scale ranging from 1 to 10 with higher scores indicating better quality. The results from the structured telephone interviews showed that most of the 38 resident's relatives (76\%) did not agree with the use of belt restraints, but thought it was necessary prior to the EXBELT project. Thirty-two (84\%) were satisfied with the information they received about the EXBELT program and 30 (78\%) were satisfied with the policy change. The majority of the relatives (79\%) stated that they were extensively involved in the decision making process regarding belt restraint removal, which they appreciated.

\section{Reach}

A total of 162 nursing home staff members attended at least one of the 3 sessions of the educational program. Of these 137 attended all 3 sessions (85\%) with an overall attendance per session of 93\%. For the individual sessions this was $97 \%$ (session 1), 94\% (session 2) and 90\% (session 3). 


\section{Barriers}

Only 3 specific barriers regarding the feasibility and implementation of the EXBELT program were indicated during the current process evaluation. First, the preferred resident-centered alternative interventions were not immediately available in 4 of the 15 intervention wards. It was recommended that alternative interventions should be available from the start of the intervention. Second, the nursing home staff enthusiastically embraced restraint reduction; however, they attempted to remove all physical restraints at the same time without carefully considering each individual decision. This resulted in some potentially dangerous situations which placed residents at risk for injury, however no residents were injured. The third barrier mentioned concerns an organizational issue. Due to the brief period of time between getting involved in the EXBELT study and actually starting the EXBELT program, there was little time available to plan the educational program. Also, the time interval between the educational sessions was reported to be too short.

\section{Discussion}

The current process evaluation reveals that all 4 main components of the EXBELT program were completely implemented at the 15 intervention wards that participated in the quasi-experimental longitudinal study assessing the effectiveness of EXBELT 25, 32. Both the nursing home staff members who participated in the educational program and the residents' relatives were highly satisfied with the EXBELT program. The attendance rates of the educational program were also high ( $85 \%$ of the participants attended all 3 sessions). The high overall satisfaction is supported by the relatively few reported barriers. One of the barriers mentioned (enthusiasm of nursing home staff) confirms the positive engagement of the nursing home staff that is jointly responsible for reducing the number of residents restrained with a belt. One of the key components of the EXBELT program concerned the introduction of an institutional policy change, suggesting that leadership has a decisive role in restraint reduction. For this reason it was of the utmost importance that both nursing home directors and ward managers communicated about the policy change, participated in the educational program and made alternative interventions available in order to make clear that they supported this policy change.

Nevertheless, the implementation of all EXBELT components was not entirely according to protocol. First, although different measures confirm that the policy change was announced in different ways, a confirmation by means of a formal letter from the management board to staff and the resident's relatives 
was introduced too late $(n=2)$ or was never sent $(n=2)$. Secondly, the number of nursing staff members participating in the educational program did not match the pre-planned number of participants (on average 11 instead of 12 participants). Finally, according to the delegates representing the 4 nursing home associations both consultants and alternative interventions were available during the complete implementation period. However, nursing home staff members from 4 wards $(27 \%)$ stated that the resident-centered alternative interventions were not immediately available during the first period after the start of the intervention. Also, few consultations were requested. Thus, the nursing home staff as well as the management board had to overcome internal barriers before they requested support from a consultant (e.g. nurse specialist and nursing home director). This is important since the proportion of residents restrained with a belt was still $13 \%$ four months after the introduction of the EXBELT program. It is possible that nursing staff first wanted to solve those cases by themselves, or they were not sufficiently aware of the possibility to request a consultation.

Some specifics areas of the intervention may need to be fine-tuned. The results indicate that participants want less emphasis on lectures and individual assignments and more focus on case-based group discussion during the educational program. Although not all did carry out the assignments, the results of these assignments can be useful as starting point for the group discussions. The nurse specialist facilitating these discussions of actual case scenarios will likely improve the decision-making skills of the participants as well as their intraprofessional communication skills. Also, by observing how the consultant can provide constructive advice, the staff may be more likely to seek consultation. The study found that increases in consultation also resulted in safe removal of restraints. The opportunity to consult a nurse specialist helped in those cases in which a belt cannot be simply removed. The multidisciplinary team found that an experienced person was able to guide them through the decision to employ possible solutions. In $50 \%$ of cases in which a belt was removed, no alternative intervention was introduced. In these cases it could be questioned for what reason belt usage was initiated and whether the usage was evaluated over time. Again, the consultant reviewing these cases helped the staff to question their passivity in not questioning cases of prolonged restraint. The process evaluation revealed that although a majority of the residents' relatives do not agree with belt restraint use, they did not question the use in their relative. The relative thus acquired the nursing home staff view that restraints could prevent dangerous situations and adverse consequences such as falls. Since this is no longer considered true ${ }^{16,17}$, this project helped nursing home staff inform the resident's relatives that there are more humane measures to provide safety and involve them in the decision making process. The high level (79\%) of relatives 
involvement in the decision making process underscores the importance of engaging relatives in this process.

The current process evaluation has some limitations. First, dose delivered and fidelity were mainly measured based on data directly collected from those who were responsible for the implementation of the EXBELT program. No measurements were used and/or available to test these elements in a more objective manner, for example through independent observations. Secondly, several authors suggest important outcome measures which should be part of a process evaluation $34,35,37$. In the current study not all of these concepts are used (e.g. recruitment and context). Nevertheless, we think that we collected enough data on the other elements (dose delivered, fidelity, dose received, reach, and barriers) to indicate the feasibility of the program and to inform further dissemination of this multi-component intervention. Finally, we were unfortunately not able to collect the nursing home resident's experience due to their cognitive status.

To our knowledge only one other study has reported the outcomes of a process evaluation for an intervention program aimed at the reduction of physical restraint use ${ }^{38}$. Both our study and the study conducted by Köpke and colleagues used the framework of Saunders and colleagues ${ }^{35}$. A thorough comparison between both studies is not possible since only few data were reported. Both studies revealed organizational issues as an important barrier, however, our study focused on primarily research-related issues that would not likely effect implementation in practice.

\section{Conclusion}

The EXBELT study was largely performed according to protocol and very well received by nursing home staff as well as resident's relatives. The results of the current study show that the implementation of the EXBELT study was highly successful in our research and is likely to be feasible in psychogeriatric nursing home populations in general. However, the implementation of the intervention could be optimized by 1) introducing examples of how nursing homes can communicate the policy change (sample letters and standardized text for internal newsletters), 2) improving the reach of the intended target population by requiring key figures to attend the educational program, 3) intensifying the educational sessions by shortening the duration of the individual sessions, 4) adding more case-based learning experiences to the educational program, and 5) embedding the available consultants in a more proactive way. 
Relevance to clinical practice

The results from the current study as well as the detailed program evaluation 32 reveals that the EXBELT program is both feasible and effective in order to reduce the use of belt restraints in a structured and safe manner. Since the use of physical restraints continues to be a problem in nursing home practice and the need for feasible and effective interventions is evident ${ }^{10}$, the widespread implementation of the EXBELT program in nursing homes should be recommended and emphasized. 


\section{References}

[1] Capezuti E, Brush BL, Won RM, et al. Least restrictive or least understood?: waist restraints, provider practices, and risk of harm. Journal of Aging \& Social Policy 2008;20: 305-322.

[2] Capezuti E, Strumpf NE, Evans LK, et al. The relationship between physical restraint removal and falls and injuries among nursing home residents. Journals of Gerontoly Series A: Biological Sciences and Medical Sciences 1998;53: M47-52.

[3] Capezuti E, Wagner LM, Brush BL, et al. Consequences of an intervention to reduce restrictive side rail use in nursing homes. Journal of the American Geriatrics Society 2007;55: 334-341.

[4] Castle NG. The use of physical restraints in nursing homes: pre- and post-Nursing Home Reform Act. J Health Soc Policy 1998;9: 71-89.

[5] Evans D, FitzGerald M. Reasons for physically restraining patients and residents: a systematic review and content analysis. International journal of nursing studies 2002;39: 735-743.

[6] Evans LK, Cotter VT. Avoiding restraints in patients with dementia: understanding, prevention, and management are the keys. American Journal of Nursing 2008;108: 40-50.

[7] Hamers JP, Huizing AR. Why do we use physical restraints in the elderly? Z Gerontol Geriatr 2005;38: 19-25.

[8] Huizing AR, Hamers JP, de Jonge J, et al. Organisational determinants of the use of physical restraints: a multilevel approach. Soc Sci Med 2007;65: 924-933.

[9] Huizing AR, Hamers JP, Gulpers MJ, et al. Short-term effects of an educational intervention on physical restraint use: a cluster randomized trial. BMC Geriatr 2006;6: 17.

[10] Möhler R, Richter T, Köpke S, et al. Interventions for preventing and reducing the use of physical restraints in long-term geriatric care. Cochrane Database Syst Rev 2011: CD007546.

[11] Feng Z, Hirdes JP, Smith TF, et al. Use of physical restraints and antipsychotic medications in nursing homes: a cross-national study. International Journal of Geriatric Psychiatry 2009;24: 1110-1118.

[12] Gastmans C, Milisen K. Use of physical restraint in nursing homes: clinical-ethical considerations. J Med Ethics 2006;32: 148-152.

[13] Hamers JP, Gulpers MJ, Strik W. Use of physical restraints with cognitively impaired nursing home residents. Journal of Advanced Nursing 2004;45: 246-251.

[14] Meyer G, Köpke S, Haastert B, et al. Restraint use among nursing home residents: crosssectional study and prospective cohort study. Journal of Clinical Nursing 2009;18: 981-990.

[15] Castle NG, Engberg J. The health consequences of using physical restraints in nursing homes. Med Care 2009;47: 1164-1173.

[16] Evans D, Wood J, Lambert L. Patient injury and physical restraint devices: a systematic review. Journal of Advanced Nursing 2003;41: 274-282.

[17] Capezuti E. Minimizing the use of restrictive devices in dementia patients at risk for falling. Nursing Clinics of North America 2004;39: 625-647.

[18] Miles SH, Irvine P. Deaths caused by physical restraints. The Gerontologist 1992;32: 762-766.

[19] Tinetti ME, Liu WL, Ginter SF. Mechanical restraint use and fall-related injuries among residents of skilled nursing facilities. Ann Intern Med 1992;116: 369-374.

[20] Saarnio R, Isola A, Laukkala H. The use of physical restraint in institutional care of older people in Finland: nurses' individual, communal and alternative modes of action. Journal of Clinical Nursing 2009;18: 132-140.

[21] Heinze C, Dassen T, Grittner U. Use of physical restraints in nursing homes and hospitals and related factors: a cross-sectional study. Journal of clinical nursing 2012;21: 1033-1040.

[22] Ejaz FK, Folmar SJ, Kaufmann M, et al. Restraint reduction: can it be achieved? The Gerontologist 1994;34: 694-699.

[23] Evans D, Wood J, Lambert L. A review of physical restraint minimization in the acute and residential care settings. Journal of advanced nursing 2002;40: 616-625. 
[24] Evans LK, Strumpf NE, Allen-Taylor SL, et al. A clinical trial to reduce restraints in nursing homes. Journal of the American Geriatrics Society 1997;45: 675-681.

[25] Gulpers MJ, Bleijlevens MH, van Rossum E, et al. Belt restraint reduction in nursing homes: design of a quasi-experimental study. BMC Geriatr 2010;10: 11.

[26] Haut A, Köpke S, Gerlach A, et al. Evaluation of an evidence-based guidance on the reduction of physical restraints in nursing homes: a cluster-randomised controlled trial [ISRCTN3497 4819]. BMC Geriatr 2009;9: 42.

[27] Huizing AR, Hamers JP, Gulpers MJ, et al. A cluster-randomized trial of an educational intervention to reduce the use of physical restraints with psychogeriatric nursing home residents. $J$ Am Geriatr Soc 2009;57: 1139-1148.

[28] Koczy P, Becker C, Rapp K, et al. Effectiveness of a multifactorial intervention to reduce physical restraints in nursing home residents. J Am Geriatr Soc 2011;59: 333-339.

[29] Pellfolk TJ, Gustafson Y, Bucht G, et al. Effects of a restraint minimization program on staff knowledge, attitudes, and practice: a cluster randomized trial. J Am Geriatr Soc 2010;58: 6269.

[30] Testad I, Aasland AM, Aarsland D. The effect of staff training on the use of restraint in dementia: a single-blind randomised controlled trial. International Journal of Geriatric Psychiatry 2005;20: 587-590.

[31] Testad I, Ballard C, Bronnick K, et al. The effect of staff training on agitation and use of restraint in nursing home residents with dementia: a single-blind, randomized controlled trial. $J$ Clin Psychiatry 2010;71: 80-86.

[32] Gulpers MJ, Bleijlevens MH, Ambergen T, et al. Belt restraint reduction in nursing homes: effects of a multicomponent intervention program. J Am Geriatr Soc 2011;59: 2029-2036.

[33] Gulpers MJM, Bleijlevens MHC, Capezuti E, et al. Preventing belt restraint use in newly admitted residents in nursing homes: A quasi-experimental study. Int J Nurs Stud 2012: http://dx.doi.org/10.1016/j.ijnurstu.2012.1007.1013.

[34] Linnan L, Steckler A. Process Evaluation for Public Health Interventions and Research: An Overview. In: Linnan L, Steckler A, eds. Process Evaluation for Public Health Interventions and Research. San Francisco: Jossey-Bass, 2002, pp. 1-23.

[35] Saunders RP, Evans MH, Joshi P. Developing a process-evaluation plan for assessing health promotion program implementation: a how-to guide. Health Promotion Practice 2005;6: 134147.

[36] Hsieh HF, Shannon SE. Three approaches to qualitative content analysis. Qual Health Res 2005;15: 1277-1288.

[37] Hasson H. Systematic evaluation of implementation fidelity of complex interventions in health and social care. Implement Sci 2010;5: 67.

[38] Köpke S, Mühlhauser I, Gerlach A, et al. Effect of a guideline-based multicomponent intervention on use of physical restraints in nursing homes: a randomized controlled trial. JAMA : the journal of the American Medical Association 2012;307: 2177-2184. 



\section{Chapter 6}

\section{Reduction of belt restraint use: Long-term effects of the EXBELT intervention}

Math J M Gulpers, Michel H C Bleijlevens,

Ton Ambergen, Elizabeth Capezuti, Erik van Rossum, Jan P H Hamers

Published in Journal of the American Geriatrics Society. 2013;61: 107-112

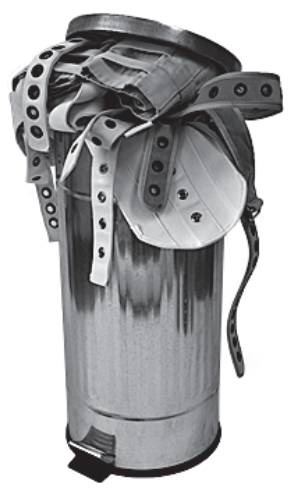




\begin{abstract}
Objectives: The EXBELT intervention program, aimed at reduction of belt restraint use, was found to be effective immediately after implementation. The present study aims to assess the long-term effects after 24 months.
\end{abstract}

Design: A quasi-experimental longitudinal design.

Setting: Thirteen nursing homes; seven were assigned to the control and six to the intervention group.

Participants: The study population consists of two groups: 1) A panel group $(n=225)$, comprised of residents who were present at both baseline and 24 months after baseline, and 2) a survey group ( $n=689)$, comprised of all residents who were present 24 months after baseline. The survey group includes the panel group.

Intervention: EXBELT included four components: a policy change, an educational program, consultation, and availability of alternative interventions.

Measurements: The use of belt restraints 24 months after baseline was the primary outcome measure. Secondary outcomes included other types of physical restraints. Data were collected by an independent observer four times during a 24-hour period.

Results: EXBELT resulted in a 65\% decrease in belt use between baseline and 24 months after baseline in the panel group (odds ratio $=(\mathrm{OR}=0.35,95 \%$ confidence interval $(0.13-0.93) ; \mathrm{p}=.036)$. In the survey group the proportion of residents using belts was $13 \%$ in the control and $3 \%$ in the intervention group $(\mathrm{p}<.001) 24$ months after baseline. The use of the most restrictive types of restraints was significantly lower in the intervention group compared to the control group in both the panel and the survey group.

Conclusion: The EXBELT intervention is associated with long-term minimization of belt restraint usage among older nursing home residents compared to the control group. A multi-component intervention including institutional policy change, education, consultation, and the availability of alternative interventions demonstrates an enduring effect for successful restraint reduction. 


\section{Introduction}

Several studies have shown that the use of physical restraints has negative consequences, such as physical decline, incontinence, pressure ulcers, depression, agitation, and aggression. ${ }^{1-4}$ Therefore, a reduction in the use of these restraints in (psychogeriatric) nursing homes is recommended by professional associations and governmental agencies..$^{5-8}$ Psychogeriatric nursing homes in the Netherlands provide long-term care to mainly very frail older adults suffering from dementia and who are not able to independently perform their own activities of daily living. ${ }^{9}$ A minimum of 20 residents usually reside on a ward. Nursing home staff has differentiated tasks including medical and personal care for residents. 10 The EXBELT intervention was developed based on recommendations from previous studies. It resulted in a multi-component intervention targeting reduction of belt restraints. ${ }^{11-14}$ EXBELT includes four key components: policy change, education, consultation, and availability of alternative interventions. ${ }^{11,} 15$ Evaluation of the EXBELT intervention showed that it was effective in reducing belt restraint usage without increasing the use of other physical restraints, falls and fall-related injury, or psychoactive drug use immediately after its implementation. ${ }^{11}$ EXBELT also prevented the use of belt restraints in newly admitted residents.

Previous studies have limited their follow-up data to no more than 12 months following a restraint reduction intervention. ${ }^{13}$, 16-21 Similarly, the original EXBELT study only followed study participants for eight months. With additional funding we had the opportunity to investigate the effects of EXBELT intervention two years following our baseline assessment in the original study. We focused on two groups in the current study: 1) the panel group, which was comprised of all residents who were present at both baseline and 24 months after baseline and who gave informed consent for the original study, and 2) the survey group, consisting of all residents in the same nursing homes at 24 months after baseline, including the members of the panel group.

The aim of the present study is to describe the effects of the EXBELT intervention program on primary (belt restraint use) and secondary outcomes (other types of physical restraints) 24 months following the initiation of the EXBELT study. 


\section{Methods}

\section{Design}

Data were collected in a quasi-experimental longitudinal study, with measurements at baseline, and 24 months after baseline. The primary focus of this paper is to present the data comparing restraint use at baseline to that at 24 months after baseline in the panel group. In addition, we assessed the restraint use of the survey group in order to check whether the frequency in restraint use was comparable in both groups. Details of the design and results of the original study can be found in the articles regarding the design and the effectiveness of the EXBELT program. ${ }^{11}, 15$ Data of physical restraint use, gender, age, psychoactive drug use, and falls and fall-related injuries in the preceding three months were collected at baseline and four and eight months after baseline. Twenty-four months after baseline, only data on physical restraint use were collected.

\section{Sample}

In 2009 we recruited 13 nursing homes from various regions in the Netherlands, for a total of 26 psychogeriatric wards with at least $10 \%$ prevalence of belt use. A total of 714 residents were eligible for participation in the original study. Complete data were available for 405 residents. ${ }^{11}$ Of these, 225 residents continued to reside in the nursing homes 24 months after baseline (panel group; $n=91$ and $n=134$ in the control and intervention groups, respectively). For this study we also examined restraint use in a group of residents present in the nursing homes at 24 months after baseline (survey group; $n=315$ and $n=374$ in the control and intervention groups, respectively). Twenty-four months after baseline 25 wards were left form the original sample; one of the intervention wards was closed due to extensive renovation.

\section{Ethical Considerations}

The medical ethics committee of the University Hospital Maastricht and Maastricht University and the ethical committees from four nursing home associations that represent the 13 nursing homes approved the original study design and protocol. Since the original study protocol did not include data collection at 24 months after baseline additional approval was obtained. For the original study we obtained informed consent form the legal representatives of the residents since we collected data on physical restraint use, gender, age, psychoactive drug use, falls and fall-related injuries in the preceding three months. For 
the current study we only focused on the use of physical restraints 24 months after baseline in both the panel and the survey group. Therefore no informed consent for the residents in the survey group was obtained.

\section{Intervention}

EXBELT comprises four key components:

1. A policy change by the nursing home management: new use of belts was prohibited and current use had to be reduced;

2. An intensive educational program offered by two nurse specialists (registered nurses with extensive experience in physical restraint reduction) to the nursing home staff;

3. Consultation from the two nurse specialists (who delivered the educational program) to individual nurses on the intervention wards;

4. Availability of alternative interventions: nursing home managers in the intervention group provided resident-centered alternative interventions, such as sensor mats, balance training, exercise, and low-height adjustable beds. These alternatives intend to promote safe mobility.

Implementation of the interventions started after baseline, and was approved by the nursing home management governing each facility. The intervention is described in more detail elsewhere. ${ }^{11}, 15$ After the completion of the original study, the intensive educational part of the EXBELT program was provided to all control wards participating in the original study.

\section{Measurements}

Physical restraints are defined as any limitation in an individual's freedom of movement.22 A belt restraint (primary outcome) is a device or material attached to the waist. Observational data of physical restraint use were collected on all residents present within the control and intervention wards 24 months after baseline.

Restraint use was measured using an observation tool developed by Huizing and colleagues. ${ }^{12,13}$ Belt and other restraint use, listed as present or absent, was recorded by a single trained observer, blinded to the group assignment, four times during a 24-hour period (morning, afternoon, evening, and night). The participating nursing homes were informed shortly before the additional measurement that it would occur, but the day and timing of measurements was unannounced to the wards to prevent any temporary removal of physical restraints. If a restraint was observed on a resident one or more times during the four observation periods, the restraint was noted as used. 


\section{Data Analysis}

Data from residents were used and analyzed according to the intention-to-treat principle. Only complete data sets were analyzed. Differences at baseline between the intervention and control groups in the panel group with regard to belt use, psychoactive drug use, falls, and resident characteristics (age and sex) were investigated. Chi-square tests were used for categorical variables, independent samples t-test for continuous variables, and generalized estimating equation (GEE) techniques to estimate the effect on the main outcome variable (belts use), adjusting for baseline characteristics and dependence between measurements (age, sex, psychoactive drug use, falls, and nursing home). SPSS software version 19 and STATA 11 were used to perform these analyses (SPSS, Inc., Chicago, IL). Results are presented with odds ratios (ORs) and 95\% confidence intervals (CIs). In order to examine any differences between the two groups, $\mathrm{p} \leq 0.05$ was considered statistically significant.

\section{Results}

Table 1 shows the baseline characteristics of the panel group. Baseline belt restraint use, gender, falls in the preceding 3 months, and psychoactive drug use did not differ between the two groups. The mean age of the control group was higher (83.9 versus $80.9, \mathrm{p}=.003$ ).

Table 1. Panel Group Background Characteristics and Measures at Baseline

\begin{tabular}{llll}
\hline & Control & Intervention & \\
\cline { 2 - 3 } Measured variables & $(\mathrm{n}=91)$ & $(\mathrm{n}=134)$ & p-value \\
\hline Background characteristics & $76(84)$ & $98(73)$ & .068 \\
$\quad$ Female, $\mathrm{n}(\%)$ & $83.9 \pm 6.6$ & $80.9 \pm 8.0$ & .003 \\
$\quad$ Age, mean \pm SD $^{*}$ & & & .802 \\
Measures & $14(15)$ & $19(14)$ & .320 \\
$\quad$ Belt restraints, n (\%) & $13(14)$ & $26(19)$ & .685 \\
$\quad$ Falls, n (\%) & $65(71)$ & $99(74)$ & \\
$\quad$ Psychoactive drug use, $\mathrm{n}(\%)$ & 65 &
\end{tabular}

*SD = Standard Deviation

\section{Belt restraints use}

In the panel group $(n=225)$ at baseline, belts were used for $15 \%$ of the residents in the control group and $14 \%$ in the intervention group. Twenty-four months after baseline, belt use had decreased nearly $65 \%$ from $14 \%$ to $5 \%$ in the intervention group, whereas the proportion of residents using belts in the 
control group was similar to baseline (Table 2). The adjusted difference between the groups tested by using chi-square analyses was significant $(p=.019)$. GEE resulted in a significant difference between the intervention and control groups in the panel group regarding the use of belts (OR $=0.35,95 \%$ CI $(0.13$ 0.93); $\mathrm{p}=.036$ ). In the survey group the proportion of residents using belts in the control and intervention groups was respectively $13 \%$ and $3 \%(\mathrm{p}<.001)$.

\section{Belt restraint use in the panel and survey group}

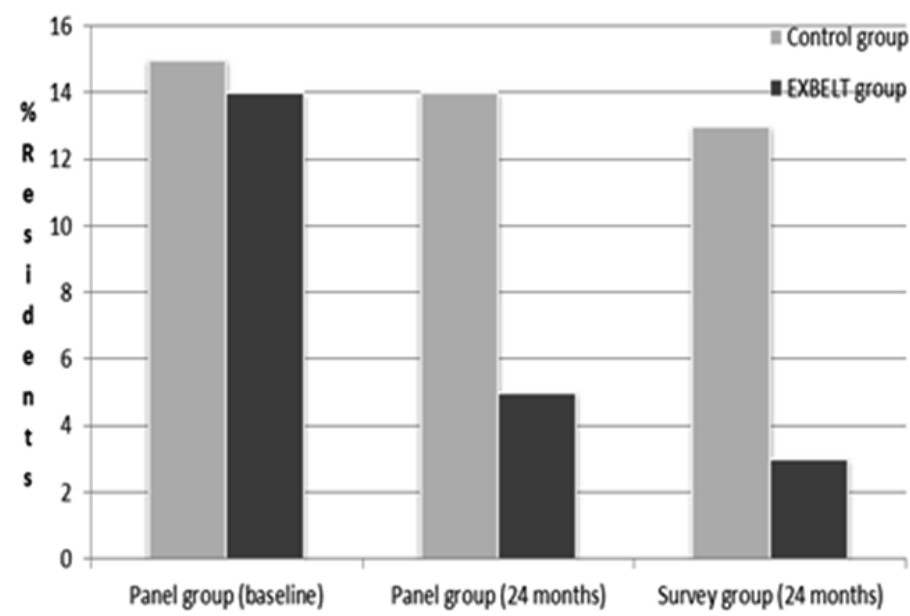

Figure 1. Belt restraint use over 24 months in the panel group $(n=225)$ and a point measurement of the survey group $(n=689)$ at 24 months after baseline. The panel group comprised all residents who were present at both baseline and 24 months after baseline and who gave informed consent for the original study. The survey group consists of all residents in the same nursing homes at 24 months after baseline, including the members of the panel group

\section{Use of other physical restraints}

A significant difference was found in the panel group between the control and intervention groups 24 months after baseline, with regard to the number of residents who were restrained with any kind of physical restraint. In the control group, restraint devices were used on $75 \%$ of the residents, compared to $60 \%$ of the residents in the intervention group ( $\mathrm{p}=.026)$. The use of (wheel) chairs with a locked table and full-enclosure bedrails was less in the intervention group ( $\mathrm{p}=.035$ and $\mathrm{p}=.001$, respectively, Table 2$)$.

In the survey group, 24 months after baseline, at least one physical restraint device was used in 58\% of the residents of the control group and $51 \%$ of those in the intervention group $(\mathrm{p}=.054)$. Furthermore, the largest differences 
between the groups were found in the use of (wheel) chairs with a locked table and full-enclosure bedrails, which were significantly less in the intervention group ( $\mathrm{p}=.005$ and $\mathrm{p}=.001$, respectively, Table 2 ).

Table 2. Physical restraint use at baseline (panel group) and after 24 months (panel group and survey group)

\begin{tabular}{|c|c|c|c|c|c|c|c|c|c|}
\hline \multirow[b]{4}{*}{ Outcome Measure } & \multicolumn{9}{|c|}{ Follow-up period } \\
\hline & \multicolumn{3}{|c|}{$\begin{array}{l}\text { Baseline } \\
\left(\text { Panel^}^{\wedge}\right)\end{array}$} & \multicolumn{3}{|c|}{$\begin{array}{l}24 \text { months after baseline } \\
\left(\text { Panel }^{\wedge}\right)\end{array}$} & \multicolumn{3}{|c|}{$\begin{array}{l}24 \text { months after baseline } \\
\left(\text { Survey }{ }^{\wedge}\right)\end{array}$} \\
\hline & $\begin{array}{l}\text { Control } \\
(n=91)\end{array}$ & $\begin{array}{l}\text { Intervention } \\
(\mathrm{n}=134)\end{array}$ & & $\begin{array}{l}\text { Control } \\
(n=91)\end{array}$ & $\begin{array}{l}\text { Intervention } \\
(\mathrm{n}=134)\end{array}$ & & $\begin{array}{l}\text { Control } \\
(n=315)\end{array}$ & $\begin{array}{l}\text { Intervention } \\
(\mathrm{n}=374)\end{array}$ & \\
\hline & $\%$ & $\%$ & p-value & $\%$ & $\%$ & p-value & $\%$ & $\%$ & p-value \\
\hline \multicolumn{10}{|l|}{ Primary* } \\
\hline Belt restraints & 15 & 14 & .80 & 14 & 5 & .019 & 13 & 3 & $<.001$ \\
\hline \multicolumn{10}{|l|}{ Secondary* } \\
\hline $\begin{array}{l}\text { (Wheel)chair with a } \\
\text { locked table }\end{array}$ & 12 & 10 & .57 & 14 & 6 & .035 & 9 & 5 & .05 \\
\hline Special sheet & 4 & 7 & .47 & 2 & 2 & .69 & 1 & 1 & .81 \\
\hline $\begin{array}{l}\text { Full enclosure } \\
\text { bedrails }\end{array}$ & 58 & 40 & .008 & 65 & 42 & $<.001$ & 48 & 32 & $<.001$ \\
\hline Chair on a board & 0 & 2 & .24 & 0 & 1 & .41 & 0 & 0 & .90 \\
\hline $\begin{array}{l}\text { Deep and/or over- } \\
\text { turned (wheel) chair }\end{array}$ & 10 & 8 & .52 & 13 & 9 & .31 & 11 & 8 & .27 \\
\hline Sleep suits $* *$ & 10 & 7 & .39 & 11 & 16 & .32 & 9 & 10 & .63 \\
\hline $\begin{array}{l}\text { At least one physical } \\
\text { restraint device }\end{array}$ & 62 & 49 & .054 & 75 & 60 & .026 & 58 & 51 & .054 \\
\hline
\end{tabular}

* Effects were assessed by means of chi-square analyses; ${ }^{* *}$ Clothing that deters a person from undressing; ^ The panel group comprised all residents who were present at both baseline and 24 months after baseline and who gave informed consent for the original study; ${ }^{\wedge} \wedge$ The survey group consists of all residents in the same nursing homes at 24 months after baseline, including the members of the panel group

\section{Discussion}

The significant association between those wards that participated in the EXBELT intervention and reduced restraint use, compared to a control group, persisted 16 months following the completion of all the components of the intervention. ${ }^{11}$ In the panel group $(n=225)$, there was a significant reduction in belt restraint use in favor of the intervention group. In the survey group ( $\mathrm{n}=$ 689) we saw nearly the same effects in belt and other physical restraint use as in the panel group. The use of the most restrictive types of restraints, such as the use of belt restraints, (wheel) chairs with a locked table, and full enclosure 
bedrails, were statistically significantly lower in the intervention group, both in the panel group and in the survey group.

The effect in the panel group is somewhat weaker compared to the survey group. This could be a result of differences between these groups regarding the resident's length of stay. Residents in the panel group have been residing in the nursing home for at least two years and were already admitted at the start of the EXBELT study. By contrast, about $45 \%$ of the survey group was newly admitted in the past two years, and it is assumed that it is easier to prevent the use of physical restraints in newly admitted residents than to reduce their use in individuals who are already restrained. ${ }^{11}$ Furthermore, residents who are residing in a nursing home for a longer time may be more physically and cognitively impaired compared to newly admitted residents. Impaired cognitive status, increased physical dependency and a lower mobility level are the most important determinants for the use of physical restraints. ${ }^{1,7}$ Therefore the length of stay in the nursing home might have influenced the degree of physical restraints use and the difference in restraint use between the panel and the survey group 24 months after baseline.

In various studies, with the interventions restricted to education, and sometimes consultation, inconsistent effects of reducing the use of physical restraints were reported.12, 18 The introduction of two additional components in the EXBELT study - policy change and availability of alternative interventions may have had an important influence on the results. In addition, the comprehensive multi-component EXBELT intervention may have resulted in a change in the perceptions and behaviors of the nursing home staff regarding the use of physical restraints, resulting in an attitude shift towards reducing the use of physical restraints.

The overall use of physical restraints increased in both the control and intervention groups of the panel group comparing baseline and 24 months after baseline. This indicates that after the implementation of EXBELT in the intervention group, in both the intervention and control groups the use of some kind of physical restraint was newly initiated. However, in the intervention group the use of the most restrictive physical restraints (e.g., belt restraints and (wheel)chairs with a locked table) decreased drastically.

There are limitations in this study. First, generalization of the results may be limited by the small sample size $(n=225)$ of the panel group 24 months after baseline. Second, the use of physical restraints (especially belt restraints) in both the intervention and control groups could be affected by other interventions which were introduced in the period after the original study (up to 24 months after baseline). However, no new national guidelines and/or policies were introduced to reduce the use of physical restraints. After the original study, the educational part of EXBELT was delivered to the control group of the 
participating nursing home associations. This could have affected the results presented in the current study, but considering the fact that we found almost no reduction of belt restraint use in the control group this seems to not be the case. These findings, similar to others 13,23 , indicate that offering an educational program alone is insufficient for a reduction of physical restraint use. For this reason, the availability of alternative interventions 12, 14 and legislation and related regulatory mandates 24,25 were considered to be essential for restraint reduction and added to the EXBELT intervention program. Third, for most of the residents represented in the survey group we only collected data on the use of physical restraints. Data on age, gender, falls, fall-related injuries, and psychoactive drugs use were only gathered at baseline for a subgroup of the survey group (panel group). Therefore it is uncertain whether the control and intervention groups in the survey group are comparable. However, to be admitted to a psychogeriatric nursing home, residents have to meet certain criteria. For this reason we assume that those within the survey group intervention and control groups are comparable. In addition, table 1 shows that the intervention and control groups within the panel group, which is a subgroup of the survey group, are comparable apart from age. Furthermore, including panel subjects in the survey group may have resulted in a weakening of effects found, especially regarding the differences in prevalence numbers. Fifth, since we do not have data available on length of stay and other demographic data from both the panel and survey groups 24 months after baseline, we cannot compare these data. This is another limitation of the current study. However, one might assume that the health status of participants in the panel group is worse, partly due to a longer length of stay, resulting in higher prevalence rates of physical restraints in the panel group. Sixth, the quasi-experimental longitudinal study design could have introduced bias. However, since control and intervention groups were comparable at baseline we do not believe that this has affected our results substantially. In addition, in order to avoid contamination bias from nursing homes that were situated in close proximity, these were assigned to the same group by the research team. Finally, the study was limited to psychogeriatric nursing homes; it is not clear if the results can be obtained in other healthcare settings.

In conclusion, this study is, to the best of our knowledge, the first in which physical restraint use was measured over a follow-up period of 24 months after baseline. The use of belts and other very restrictive restraints (such as a (wheel) chair with a locked table and full enclosure bedrails) decreased over 24 months between the groups, in favor of the intervention group. Therefore, we can conclude that the EXBELT intervention is suitable for reducing belt restraint use over the long term in psychogeriatric nursing homes. 


\section{References}

[1] Capezuti E. Minimizing the use of restrictive devices in dementia patients at risk for falling. Nursing Clinics of North America. 2004;39: 625-647.

[2] Castle NG, Fogel B, Mor V. Risk factors for physical restraint use in nursing homes: pre- and post-implementation of the Nursing Home Reform Act. Gerontologist. 1997;37: 737-747.

[3] Evans D, Wood J, Lambert L. Patient injury and physical restraint devices: a systematic review. Journal of Advanced Nursing. 2003;41: 274-282.

[4] Miles SH, Irvine P. Deaths caused by physical restraints. The Gerontologist. 1992;32: 762-766.

[5] Hamers JPH, Gulpers MJM. Reducing physical restraints in nursing homes: results of a pilot study. Journal of Nutrition, Health \& Aging 2009;suppl.: S17.

[6] Meyer G, Kopke S, Haastert B, Muhlhauser I. Restraint use among nursing home residents: cross-sectional study and prospective cohort study. Journal of Clinical Nursing. 2009;18: 981990.

[7] Hamers JP, Gulpers MJ, Strik W. Use of physical restraints with cognitively impaired nursing home residents. Journal of Advanced Nursing. 2004;45: 246-251.

[8] Sullivan-Marx. Achieving restraint-free care of acutely confused older adults. Journal of Gerontological Nursing. 20014

[9] Schols JMGA, Crebolder HF. Nursing home and nursing home physician: The Dutch experience. J Am Med Dir Assoc. 2004;207-212.

[10] Verbeek H, van Rossum E, Zwakhalen SM, Ambergen T, Kempen GI, Hamers JP. The effects of small-scale, homelike facilities for older people with dementia on residents, family caregivers and staff: design of a longitudinal, quasi-experimental study. BMC geriatrics. 2009;9: 3.

[11] Gulpers MJ, Bleijlevens MH, Ambergen T, Capezuti E, van Rossum E, Hamers JP. Belt restraint reduction in nursing homes: effects of a multicomponent intervention program. J Am Geriatr Soc. 2011;59: 2029-2036.

[12] Huizing AR, Hamers JP, Gulpers MJ, Berger MP. Short-term effects of an educational intervention on physical restraint use: a cluster randomized trial. BMC Geriatr. 2006;6: 17.

[13] Huizing AR, Hamers JP, Gulpers MJ, Berger MP. A cluster-randomized trial of an educational intervention to reduce the use of physical restraints with psychogeriatric nursing home residents. J Am Geriatr Soc. 2009;57: 1139-1148.

[14] Hamers JP, Meyer G, Kopke S, Lindenmann R, Groven R, Huizing AR. Attitudes of Dutch, German and Swiss nursing staff towards physical restraint use in nursing home residents, a crosssectional study. Int J Nurs Stud. 2009;46: 248-255.

[15] Gulpers MJ, Bleijlevens MH, van Rossum E, Capezuti E, Hamers JP. Belt restraint reduction in nursing homes: design of a quasi-experimental study. BMC Geriatr. 2010;10: 11.

[16] Capezuti E, Maislin G, Strumpf N, Evans LK. Side rail use and bed-related fall outcomes among nursing home residents. Journal of the American Geriatrics Society. 2002;50: 90-96.

[17] Capezuti E, Wagner LM, Brush BL, Boltz M, Renz S, Talerico KA. Consequences of an intervention to reduce restrictive side rail use in nursing homes. Journal of the American Geriatrics Society. 2007;55: 334-341.

[18] Evans LK, Strumpf NE, Allen-Taylor SL, Capezuti E, Maislin G, Jacobsen B. A clinical trial to reduce restraints in nursing homes. Journal of the American Geriatrics Society. 1997;45: 675681.

[19] Huizing AR, Hamers JP, Gulpers MJ, Berger MP. Preventing the use of physical restraints on residents newly admitted to psycho-geriatric nursing home wards: a cluster-randomized trial. Int J Nurs Stud. 2009;46: 459-469.

[20] Testad I, Aasland AM, Aarsland D. The effect of staff training on the use of restraint in dementia: a single-blind randomised controlled trial. International Journal of Geriatric Psychiatry. 2005;20: 587-590. 
[21] Mohler R, Richter T, Kopke S, Meyer G. Interventions for preventing and reducing the use of physical restraints in long-term geriatric care. Cochrane Database Syst Rev. 2011: CD007546.

[22] Hantikainen V. Physical restraint: a descriptive study in Swiss nursing homes. Nursing Ethics. 1998;5: 330-346.

[23] Pellfolk TJ, Gustafson Y, Bucht G, Karlsson S. Effects of a restraint minimization program on staff knowledge, attitudes, and practice: a cluster randomized trial. J Am Geriatr Soc. 2010;58: 62-69.

[24] Dunn KS. The effect of physical restraints on fall rates in older adults who are institutionalized. Journal of Gerontological Nursing. 2001;27: 40-48.

[25] Marek KD, Rantz MJ, Fagin CM, Krejci JW. OBRA '87: has it resulted in better quality of care? Journal of Gerontological Nursing. 1996;22: 28-36. 
Chapter 7

General discussion 


\section{Introduction}

According to the (Dutch) Quality Framework Responsible Care (2007 and 2010) responsible care is good quality care that, at any rate, is given in an effective, efficient, safe and patient-oriented manner and that is attuned to the client's real needs. ${ }^{1,2}$ Applying physical restraints does not fit the definition of responsible care. In this light, the use of physical restraints in the Netherlands should be reduced to an absolute minimum. This is confirmed in the recently released "Quality Document 2012: Nursing, Care and Home Care". ${ }^{3}$ Nevertheless, physical restraint use is common practice in nursing homes. Therefore, reduction and prevention of the use of these devices is recommended. ${ }^{4-7}$ The number of studies on the reduction of physical restraints has increased over the past two decades. The most frequently used intervention is nursing-staff education and consultation. However, the effects of this intervention were conflicting between care settings and countries. ${ }^{8-12}$ Also, findings indicated that education and consultation were not sufficient.9,13 Therefore we developed a comprehensive approach, "EXBELT", with additional interventions (a policy change and availability of alternative interventions). We tested this program over the last five years. 5 The program's primary aim was to reduce and prevent belt restraint use in psychogeriatric nursing home residents. In addition, it aimed to reduce the use of other types of physical restraints, without increasing psychoactive drugs use and falls and fall-related injuries.

This general discussion starts with an overview of the main findings of the EXBELT study. Then, some methodological issues are discussed, followed by theoretical considerations regarding the interpretation of our results. This chapter ends with a brief report on the societal impact of this study, and recommendations for practice and future research.

\section{Main findings}

The EXBELT intervention turned out to be effective on the primary (belt restraint reduction and prevention) and secondary outcomes (reduction of other physical restraint use), without increasing psychoactive drug use, falls, and fallrelated injuries.

More specifically:

- EXBELT resulted in a substantial reduction in the use of belt restraints, fullenclosure bedrails, and sleep suits, without increasing the use of other physical restraints, psychoactive drugs, or falls and fall-related injuries (Chapter 3); 
- Prevention of belt restraint use and other types of physical restraints in newly admitted residents in nursing homes is attainable without causing an increase in psychoactive drug use, falls, and fall-related injuries (Chapter 4);

- The implementation of the EXBELT study was successful, and was found to be a feasible approach in psychogeriatric nursing homes (Chapter 5);

- In the long-term (24 months follow-up) the use of belts restraints and other very restrictive restraints (such as (wheel) chairs with a locked table and full-enclosure bedrails) continued to be lower in the intervention group compared to the control group (Chapter 6).

\section{Methodological considerations}

A quasi-experimental design was used to test EXBELTs effectiveness. As EXBELT is a comprehensive approach at the level of the nursing home, allocation to the intervention or control group had to be conducted on this level. Random allocation may had 'helped' to promote comparable study groups at baseline, but large numbers of nursing homes would have been needed to benefit from randomization. However, we did not have the resources to include a large number of nursing homes in our study. We therefore chose for nonrandom allocation of the participating (13) homes. This gave us the opportunity to avoid contamination bias by preventing overlap of nursing home staff between intervention and control homes. In addition, nursing homes in close proximity of each other are assigned to the same group in order to keep the study feasible and avoid excessive travel time for the nurse specialists who delivered the educational and consultation part of the intervention. Except for non-random allocation we incorporated key design elements of a randomized controlled trial in our study, such as a control group, baseline measurements in both study groups and blinding of outcome measurements.

Still, some choices regarding the design of our study may have introduced bias, especially selection bias. Although the resident characteristics that we measured at baseline were overall quite comparable (except for age) in both study groups, no information is available on the distribution of other relevant characteristics, e.g. cognitive level and functional status. This also applies to nursing staff characteristics (e.g. work load, educational level, and motivation to reduce belts) or ward culture. Although we have no indications for large differences between the groups in this respect, one has to rely on an equal distribution of these characteristics and adjustment of (small) baseline differences in multivariate data analyses. 
In regard to the study design, the contrast between the two study groups is an important methodological issue in this study. Although some intervention parts were accomplished later than planned (policy change) or less often used than expected (alternative interventions), the four EXBELT interventions were largely implemented according to protocol. There are no indications that interventions or components of interventions were implemented in any of the control wards. They received only usual care. We therefore think that problems regarding the contrast between the groups did not bias the results.

\section{Theoretical considerations}

The studies described in the current thesis reveal convincing effects of the EXBELT intervention regarding both the reduction and prevention of belt restraint usage in Dutch psychogeriatric nursing homes. How can the efficacy of EXBELT be explained and did a specific part of the EXBELT intervention cause the positive effects? Answers to these questions are not easy to find, since EXBELT is a complex and multicomponent intervention. Such interventions are characterized by interacting components; the number and difficulty of behaviors required by those delivering or receiving the intervention; the number of groups or organizational levels targeted by the intervention; the number and variability of outcomes; and the degree of flexibility or tailoring of the intervention. ${ }^{14}$ As all these aspects interact with each other, it would be a rather artificial exercise to try to distinguish the effectiveness of the individual intervention parts. However, looking closer to these different parts may give us a better understanding of why EXBELT was successful.

As described in detail earlier, EXBELT consist of an educational intervention, consultation by a nurse specialist, availability of alternative measures and a policy change. The combination of an educational intervention and the consultation of a nurse specialist has been reported to be effective in the USA. ${ }^{8}$ In an earlier controlled study that was conducted by our group ${ }^{10}, 13$, such an approach did not result in any change in restraint use. This finding has been (indirectly) confirmed in our present studies. After completion of the educational part of the intervention (T2; first post test after 4 months) we found no substantial decrease in the use of belt restraints and other restraints in the intervention group in comparison with the control group. ${ }^{15} \mathrm{After}$ the completion of the EXBELT study, the educational program was offered to all control wards. Again, this did not result in a reduction of belt usage. ${ }^{16}$ However, we have indications that the educational parts of EXBELT were conditional for the effectiveness of the approach, since we found significant positive changes regarding participants' attitudes about restraint use, measured with the Maastricht Atti- 
tude Questionnaire (not reported in this thesis). ${ }^{17,} 18$ Participants reported transfer of new knowledge and awareness of consequences of restraint use and alternative interventions. The change in attitude towards the use of restraints likely influenced the successful implementation of the EXBELT intervention.

We further believe that the availability of alternative interventions also seems to be a necessary component of the EXBELT intervention, as participants of the study by Huizing et al 10,13 reported that the lack of these alternatives (such as lower beds, infrared warning systems) were put forth as explanations for the lack of effect of that educational intervention. However, we have seen that in $50 \%$ of the cases in which the usage of belt restraints was stopped, no alternative interventions were reported. ${ }^{15}$ The effect of EXBELT can therefore not be explained by the use of alternative interventions without the other components.

The last part of the EXBELT intervention was the policy change. Participating nursing homes had to implement the new policy on belt restraints (prohibition of the use of belt restraint for newly admitted residents, initiating belt restraint use for already admitted residents and overall reduction of current use of belt restraint) within 4 months after the start of study. We think that this policy change demonstrated the importance of a clear administrative perspective regarding the use of restraints, and the importance of supporting clinical staff by involvement of management. However, we do not think that EXBELT can be restricted to the policy change. The other intervention parts need to be in place prior to the policy change. As a result we conclude that the success of EXBELT's lies in the combination of the different parts of the intervention.

Two other elements also seem to have contributed substantially to EXBELT's success: communication and leadership. It has been our experience that clear communication is a major facilitator to enable change processes such as EXBELT. Communication with nursing home residents, their relatives and nursing home staff (nursing assistants, registered nurses, physicians, physiotherapists, psychologist, managers etc.) is necessary for support and cooperation. Communication increases commitment and enables change processes. To start and guide these processes (nursing) leadership is required. Gopee and Galloway ${ }^{19}$ describe leadership as "being visionary, showing the way forward, anticipating change, innovating, seeing the bigger picture, inspiring, motivating and focusing on the development of individuals". Leadership is needed to facilitate change processes, to support nursing home staff in using creative and innovative approaches, and serve as role models. It is also necessary to be clear what is expected from the leader.

In addition there is convincing evidence that increasing the level and quality of nursing staff in nursing homes results in improved resident outcomes, including residents' functional abilities, mobility and resident satisfaction .20 
The studies presented in this thesis demonstrate that nurse specialists (Registered Nurse (RN) with extensive experience in physical restraint reduction), who delivered the education and consultation, have influenced the attitudes of the nursing home staff. In addition, both nursing home administrators and ward managers had an important role in the implementation of the policy change. This is consistent with the nursing home workforce literature that has documented that a higher number of RN and leadership can improve the implementation of evidence based practice and the quality of care in nursing homes. ${ }^{21,22}$

\section{Societal impact}

In 2000, the appeal to reduce the use of physical restraints in nursing homes, and especially the use of belts, was sharply criticized by nurses and physicians in the Netherlands. At that time, most nurses, physicians, and other nursing home staff attending conferences argued that the use of belts and other measures of physical restraints were needed for safe care and prevention of falls and fall-related injuries. Currently these attitudes have changed in that most nursing home staff does not perceive the use of restrictive physical restraints as adequate and safe care anymore. This dramatic change in the opinions of professional caregivers and policymakers is partly due to the dissemination of nursing research studies such as EXBELT. Our research group at Maastricht University started their studies on physical restraints in 1999, with a study on the prevalence and determinants of physical restraint use in psychogeriatric nursing homes. The results of this study, presented in 2002, received much attention in the Dutch media. ${ }^{4}$ This study was followed by a randomized controlled trial (RCT), however, after four years of research the conclusion was that the prevalence of restraint use remained the same. ${ }^{9,10,13}$ In 2009 we started with the EXBELT study in which we have found significant positive outcomes. The Dutch restraint studies have resulted in scientific publications, $\mathrm{PhD}$ theses, many presentations at scientific conferences, and new grants to take further extend the work of this successful intervention. There was a lot of 'other output' as well, e.g. articles in clinical professional journals in the fields of nursing, medicine and welfare; numerous presentations about the research results and its meaning for clinical practice at professional conferences; the development of educational materials (video's/DVD's/written materials) for various nursing programs; on site consultation by specialized nurses; numerous articles regarding the research results in newspapers (at a national and regional level) and interviews for radio and television (national and regional level). Furthermore, a declaration of intent was signed in 2008 by all relevant stakehold- 
ers (e.g., client organizations, caregivers, Dutch Nursing Association, Dutch Association of Old Age Medicine, health insurance companies and the Health Care Inspectorate) to ban the use of belts in nursing homes in 2011. Next, the Secretary of State brought a bill into the Dutch parliament in 2009, stating that the use of belts would be prohibited to prevent falls in nursing homes that includes reference to our research results. Finally, the Dutch Health Care Inspectorate recommended that all nursing homes should implement the evidencebased EXBELT intervention, and announced that they would visit nursing homes at the end of 2011 to assess how they dealt with the new restraint policy. ${ }^{23}$ According to an evaluation committee of the Research School CAPHRI at Maastricht University the restraint studies reflect "a classic example of societal impact" and the research work was awarded the Crebolder Award for Societal Impact in 2011.

The successful implementation of the EXBELT intervention has contributed to the much needed attention to the quality of life for psychogeriatric nursinghome residents.

\section{Implications for clinical practice and research}

\section{Clinical practice}

The common use of physical restraints in nursing homes and the known adverse consequences of their use, in addition to the available evidence that physical restraint usage is not associated with a decrease in falls and fall-related injuries, warrants the further development and implementation of an effective program aimed at reducing and preventing the use of physical restraints in healthcare. In general, the availability of such programs is limited ${ }^{8,24}$ and in The Netherlands such a program was lacking. The results of the studies presented in this thesis show that decreasing and preventing the use of belt restraints and other physical restraints is an attainable goal. Furthermore, it shows that the EXBELT program is acceptable for nursing home staff and feasible in daily Dutch nursing home practice. For this reasons EXBELT is a valuable addition to current healthcare services in The Netherlands and it is recommended to implement the EXBELT program in all Dutch nursing homes. This widespread implementation is also supported by the Dutch Health Care Inspectorate. ${ }^{23}$ However, our studies also demonstrated that there is no guarantee that the use of restrictive physical restraints will be reduced automatically. The EXBELT intervention is an important step in reduction and prevention of restraint use in nursing homes. As the study on long-term effects shows (chapter 6 ), it is evident that persistent attention to restraint reduction and the imple- 
mentation of effective interventions is needed to really make a difference in clinical practice. In addition, the continued focus on the reduction and prevention of restraint usage should be emphasized since many restraints are still used in nursing homes but also in other health care sectors.

Nursing home organizations interested in implementing the multicomponent EXBELT intervention should consider some essential preconditions which need to be addressed prior to implementation. First, the management has to embrace a position of restraint minimization. Second, this message should be clearly and consistently communicated to all stakeholders (both nursing home staff as well as residents' representatives). The message can be delivered in several ways, e.g. written information in a formal letter and announcements in internal newspapers and oral in groups meetings and during educational programs. In addition, it should be emphasized that EXBELT comprises a comprehensive package of four interventions, all of which must be implemented. EXBELT is successfully implemented when the education, consultation, availability of alternative interventions are delivered and the use of belts is prohibited. If these preconditions are met the multidisciplinary nursing home staff is empowered to facilitate the decision making process concerning the use of physical restraints with the resident's representatives.

Finally, it could be argued that introducing such a comprehensive intervention like EXBELT is accompanied by extra costs. ${ }^{25}$ The current process evaluation revealed that there were no indications that costs of the intervention hampered its implementation.

\section{Future research}

It is remarkable that the implementation of EXBELT (despite the documented positive effects of restraint reduction and the known negative consequences of restraint use for residents) is currently limited to about $10 \%$ of the psychogeriatric nursing homes in the Netherlands, but it is possible that this is because the results have been distributed relatively recently. Research examining why distribution of EXBELT is limited and how implementation can be stimulated seems desirable.

New studies are needed to evaluate whether the EXBELT intervention would be effective in reducing and preventing the use of physical restraints in other health care settings such as acute hospitals and institutions for the care for people with an intellectual disability. Considering the different institutional milieu of these institutions, it would be likely, as in other countries, that prior adaptations to the implementation protocol would be necessary. ${ }^{26}$

The EXBELT intervention is an approach that in a modified form may also result in desirable changes regarding other clinical practices with known ad- 
verse consequences. For example, psychoactive drugs in psychogeriatric nursing homes residents are often used although their usefulness in reducing behavioral symptoms is doubtful and there are known negative side effects such as somnolence and impaired balance. Practice change would require the same four elements as used in the EXBELT intervention. First, nursing home staff should have sufficient knowledge about psychoactive drugs. Nursing home administrators should support a clear policy regarding the use of psychoactive drugs. A pro-active consultation by nurse clinicians would facilitate staff decision making regarding the use of alternative resources. The EXBELT intervention protocol should be tailored to address this and other problems in clinical practice. Subsequently, pilot testing of these protocols that are adapted for specific issues would be needed first, prior to implementing larger clinical trials.

Finally, the need for restraint reduction is not only a Dutch issue. In many countries, researchers and clinicians have been working on interventions and approaches aiming to safely reduce the use of restraints in nursing homes and other settings such as hospitals. ${ }^{8,24,27-30}$ Of importance is that we can all learn from these interventions, knowing that there is no general approach for reducing physical restraints, but that interventions should be tailored to countries and settings. However, to enable valid and reliable comparisons it is important to speak the same language. For this reason, our group is now working on an international research definition on physical restraints. In this project we are collaborating with 48 international experts from 14 different countries. ${ }^{31}$ It is important that this process results in an internationally accepted definition about physical restraint that will support and facilitate the interpretation and comparison of studies regardless of setting or country. Furthermore, based on this definition we might gain more insight into the "black box" of cultural differences among countries regarding restraint use and thus facilitate tailored approaches to reduce and prevent their usage internationally. 


\section{References}

[1] Van Veen JAH. Quality Framework Responsible Care. Report. 2007.

[2] Van Veen JAH. Zichtbare zorg: Kwaliteits kader verantwoorde zorg. Report. 2010.

[3] Raad voor de Volksgezondheid en Zorg. Kwaliteisdocument 2012: Verpleging, Verzorging en Zorg Thuis Report. 2012.

[4] Hamers JP, Gulpers MJ, Strik W. Use of physical restraints with cognitively impaired nursing home residents. Journal of Advanced Nursing. 2004;45: 246-251.

[5] Hamers JPH, Gulpers MJM. Reducing physical restraints in nursing homes: results of a pilot study. Journal of Nutrition, Health \& Aging 2009;suppl.: S17.

[6] Meyer G, Kopke S, Haastert B, Muhlhauser I. Restraint use among nursing home residents: cross-sectional study and prospective cohort study. Journal of Clinical Nursing. 2009;18: 981990.

[7] Sullivan-Marx. Achieving restraint-free care of acutely confused older adults. Journal of Gerontological Nursing. 20014

[8] Evans LK, Strumpf NE, Allen-Taylor SL, Capezuti E, Maislin G, Jacobsen B. A clinical trial to reduce restraints in nursing homes. Journal of the American Geriatrics Society. 1997;45: 675681.

[9] Huizing AR, Hamers JP, Gulpers MJ, Berger MP. Short-term effects of an educational intervention on physical restraint use: a cluster randomized trial. BMC Geriatr. 2006;6: 17.

[10] Huizing AR, Hamers JP, Gulpers MJ, Berger MP. Preventing the use of physical restraints on residents newly admitted to psycho-geriatric nursing home wards: a cluster-randomized trial. Int J Nurs Stud. 2009;46: 459-469.

[11] Lai CKY, Chan MH, Szeto SSL, et al. A retrospective study on the outcomes of a collaborative restraint reduction project by a residential home for older people and a hospital-based community geriatric assessment service. Hong Kong Nursing Journal. 2006;42: 23-30.

[12] Mac Dermaid L, Byrne C. Restraint reduction education. Canadian Nursing Home. 2006;17: 1014.

[13] Huizing AR, Hamers JP, Gulpers MJ, Berger MP. A cluster-randomized trial of an educational intervention to reduce the use of physical restraints with psychogeriatric nursing home residents. J Am Geriatr Soc. 2009;57: 1139-1148.

[14] Craig P, Dieppe P, Macintyre S, Michie S, Nazareth I, Petticrew M. Developing and evaluating complex interventions: the new Medical Research Council guidance. BMJ. 2008;337: a1655.

[15] Gulpers MJ, Bleijlevens MH, Ambergen T, Capezuti E, van Rossum E, Hamers JP. Belt restraint reduction in nursing homes: effects of a multicomponent intervention program. J Am Geriatr Soc. 2011;59: 2029-2036.

[16] Gulpers MJ, Bleijlevens MH, Ambergen T, Capezuti E, Van Rossum E, Hamers JP. Reduction of belt restraint use: Long-term effects of the EXBELT intervention. JAGS. 2012: accepted for publication.

[17] Gulpers MJ, Bleijlevens MH, Capezuti E, Van Rossum E, Hamers JP. EXBELT; Impact of a restraint reduction program on nursing home staff attitudes. GSA Gerontological Society of America. 2011

[18] Hamers JP, Meyer G, Kopke S, Lindenmann R, Groven R, Huizing AR. Attitudes of Dutch, German and Swiss nursing staff towards physical restraint use in nursing home residents, a crosssectional study. Int J Nurs Stud. 2009;46: 248-255.

[19] Gopee N, Galloway J. Leadership in Practice settings. Sage. 2008: 19.

[20] Hyer K, Thomas KS, Branch LG, Harman JS, Johnson CE, Weech-Maldonado R. The influence of Nursing Staffing Levels on Quality of Care in Nursing Homes. The Gerontologist. 2011.

[21] Harrington C, Choiniere J, Goldmann M, et al. Nursing home staffing standards and staffing levels in six countries. J Nurs Scholarsh. 2012;44: 88-98. 
[22] Kim H, Kovner C, Harrington C, Greene W, Mezey M. A panel data analysis of the relationships of nursing home staffing levels and standards to regulatory deficiencies. J Gerontol B Psychol Sci Soc Sci. 2009;64: 269-278.

[23] IGZ. Cultuuromslag terugdringen vrijheidsbeperking bij kwetsbare groepen in langdurige zorg volop gaande: Duidelijke ambities voor 2011 nodig. Den Haag: IGZ, 2010.

[24] Koczy P, Becker C, Rapp K, et al. Effectiveness of a multifactorial intervention to reduce physical restraints in nursing home residents. J Am Geriatr Soc. 2011;59: 333-339.

[25] Grol R, Wensing M, Eccles M. Improving Patient Care. The Implementation of Change in clinical Practice. London: Elsevier, 2005.

[26] Mion LC, Sandhu SK, Khan RH, et al. Effect of situational and clinical variables on the likelihood of physicians ordering physical restraints. J Am Geriatr Soc. 2010;58: 1279-1288.

[27] Kopke S, Mühlhauser I, Gerlach A, et al. Effect of a Guideline-Based Multicomponent Intervention on Use of Physical Restraints in Nursing Homes. JAMA. 2012;307: 7.

[28] Kwok T, Bai X, Chui MY, et al. Effect of physical restraint reduction on older patients' hospital length of stay. J Am Med Dir Assoc. 2012;13: 645-650.

[29] Pellfolk TJ, Gustafson Y, Bucht G, Karlsson S. Effects of a restraint minimization program on staff knowledge, attitudes, and practice: a cluster randomized trial. J Am Geriatr Soc. 2010;58: 62-69.

[30] Testad I, Ballard C, Bronnick K, Aarsland D. The effect of staff training on agitation and use of restraint in nursing home residents with dementia: a single-blind, randomized controlled trial. J Clin Psychiatry. 2010;71: 80-86.

[31] Bleijlevens MH, Wagner LM, Capezuti E, Hamers JP. A Delpi consensus study to determine an internationally accepted definition on physical restraints. Abstractbook Annual Meeting of the GSA, San Diego, USA.2012. 



\section{Summary}

There are almost 40,000 residents in psycho-geriatric nursing homes in the Netherlands, and it is estimated that physical restraints are used in nearly half of them. Physical restraints are defined as any limitations in an individual's freedom of movement by the use of devices. Examples of restraint measures are the use of belts, full enclosure bedrails, geriatric chairs and locked doors. The use of belts is seen as one of the most restrictive measures. In 2008, the prevalence of belt restraint usage in Dutch psychogeriatric nursing homes was about $12 \%$, and these were predominantly used to prevent falls and (severe) injuries as a result of falls. However, research has shown that injuries resulting from falls is not reduced by the use of these measures. In addition, the use of physical restraints also has negative consequences (e.g. pressure ulcers, loss of muscle strength and endurance, incontinence, and aggression) for residents, and can even be harmful; several older people die yearly as a result of the use of belt restraints and bed rails. Therefore, reduction of the use restrictive physical restraints in nursing homes is clearly needed.

This thesis reports on the development, implementation and evaluation of an integrated approach aimed at reducing and preventing the use of belts and other physical restraints in psycho-geriatric nursing home residents.

The first chapter (introduction) provides background information about psycho-geriatric nursing home care in the Netherlands, the use of physical restraints, and research on the use and reduction of restraints. The aim of the present study is to test the effectiveness of EXBELT intervention on belt restraint reduction in Dutch psychogeriatric nursing homes. Furthermore, the EXBELT intervention is explained. EXBELT is a multi-component intervention which consists of the following elements: (1) a policy change, whereby the use of belts restraint is prohibited; (2) intensive education consisting of three 3 hour sessions over a period of 3 weeks and an additional 90-minute session summarizing the content to staff members who could not attend the educational program; (3) consultation by a specialized nurse and director; and (4) the availability of alternative interventions such as hip protectors, infrared alarm systems, balance training and adjustable low-height beds.

In chapter 2 the design of the main study is presented. We employed a quasi-experimental study including residents living on 26 wards of 13 psychogeriatric nursing homes. Measurements were conducted at baseline and after 4 and 
8 months. Restraint use was measured by a trained observer, who was 'blinded' to group assignment. Falls and fall-related injuries were recorded using an incident reporting system that Dutch nursing homes are required to maintain and data on psychoactive drug use were collected from the residents' medical records.

The effect evaluation (Chapter 3) shows that the use of belts restraint was reduced from $17 \%$ at baseline to $9 \%$ after 8 months in the intervention group, whilst for the control group the use of belts restraint was 19\%, both at baseline and after 8 months. This reduction of belt restraints in the intervention group did not lead to an increase of psychoactive drug use, falls and fall-related injuries.

Chapter 4 reports on the preventive effect of the EXBELT intervention in newly admitted nursing home residents. Participation was limited to residents who were admitted to the participating wards between baseline and 4 months later and who were still present 8 months after baseline. The data obtained demonstrated a preventive EXBELT effect: fewer belt restraint and other restraints were used in the intervention wards without an increase in the psychoactive drug use, falls and fall-related injuries. However, the findings have to be interpreted with caution since the sample size in this study was limited.

The process evaluation (chapter 5) reveals that the EXBELT intervention was largely implemented according to protocol and very well received by nursing home staff and resident's representatives. We learned that the EXBELT intervention could be improved by introducing examples how to communicate the policy change to staff and families, and by more pro-actively utilizing of available consultants to assist staff.

Chapter 6 presents additional data on the use of belt and other restraints 24 months after the start of the EXBELT study. In the residents included in the study at baseline, EXBELT resulted in a $65 \%$ decrease in belt use between baseline and 24 months after baseline. Observation of all residents still present on the intervention and control wards 24 months after baseline, found that the proportion of residents using belts was $13 \%$ on the control wards and $3 \%$ on the intervention wards. Furthermore, the use of the most restrictive types of restraints was significantly lower in the intervention wards than the control wards.

The final chapter (Chapter 7) is the general discussion. The main findings of the study are described. In addition, the societal impact of the study is addressed. Finally, implications for clinical practice and future research are presented. 


\section{Nederlandse samenvatting}

In de Nederlandse psychogeriatrische verpleeghuizen wonen ongeveer 40.000 bewoners en naar schatting worden bij bijna de helft van deze bewoners fysieke vrijheidsbeperkende middelen toegepast. Deze middelen omvatten alle middelen die de bewegingsvrijheid van mensen beperken. Voorbeelden hiervan zijn: het gebruik van fixatiebanden, bedhekken die het bed geheel omsluiten, diepe stoelen en gesloten deuren.

Het gebruik van fixatiebanden wordt gezien als een van de meest restrictieve middelen. In 2008 werden bij ongeveer $12 \%$ van de bewoners in Nederlandse psychogeriatrische verpleeghuizen fixatiebanden gebruikt. Deze werden vooral preventief ingezet om vallen en ernstige letsels als gevolg van vallen te voorkomen. Echter, onderzoek laat zien dat letsel door vallen niet verminderd wordt door het gebruik van fixatiebanden. Daarnaast blijkt dat het gebruik van fysieke vrijheidsbeperking negatieve gevolgen heeft voor de bewoners (bijvoorbeeld: drukplekken, verlies van spierkracht en conditie, incontinentie en agressie) en gevaarlijk kan zijn: een aantal oudere mensen overlijdt elk jaar ten gevolge van gebruik van banden en/of bedhekken. Daarom is vermindering van het gebruik van restrictieve fysieke vrijheidsbeperkingen in verpleeghuizen noodzakelijk.

Dit proefschrift beschrifft de ontwikkeling, implementatie en evaluatie van een integrale aanpak om het gebruik van fixatiebanden en andere vrijheidsbeperkende middelen te verminderen bij bewoners van psychogeriatrische verpleeghuizen.

Het eerste hoofdstuk (introductie) geeft achtergrondinformatie over de psychogeriatrische verpleeghuiszorg in Nederland, het gebruik van fysieke vrijheidsbeperkende middelen en onderzoek naar het gebruik en het reduceren van deze middelen. Bovendien wordt in dit hoofdstuk de EXBELT interventie geïntroduceerd, die gericht is op de reductie en preventie van het gebruik van fixatiebanden en andere fysieke vrijheidsbeperkende middelen. EXBELT is een multi-component interventie die bestaat uit de volgende elementen: (1) beleidswijziging, waarbij het gebruik van fixatiebanden verboden is; (2) scholing van drie dagdelen in een periode van drie weken en aanvullend een 90minutensessie met een samenvatting van de inhoud voor de medewerkers die niet aanwezig konden zijn bij het scholingsprogramma; (3) consultatie door 
gespecialiseerde verpleegkundigen en een directeur; (4) de beschikbaarheid van alternatieve interventies zoals heupbeschermers, infrarood alarmsystemen, balanstraining en verstelbare hoog-laagbedden. De ontwikkelde EXBELT interventie is in deze studie getest op effectiviteit in het verminderen van het gebruik van fixatiebanden in Nederlandse psychogeriatrische verpleeghuizen.

Het design van het onderzoek wordt beschreven in hoofdstuk 2. Het betreft een quasi-experimentele studie waaraan bewoners van 26 afdelingen van 13 psychogeriatrische verpleeghuizen deelnamen. Zeven verpleeghuizen werden toegewezen aan de controlegroep en zes aan de interventiegroep. Data werden verzameld vóór de start van de interventie (nulmeting), na 4 en na 8 maanden. Het gebruik van vrijheidsbeperkende middelen werd per bewoner geregistreerd door een getrainde observator die niet bekend was met de groepstoewijzing (controle- versus interventiegroep). Vallen en val-gerelateerde letsels werden geregistreerd op basis van het Melding Incidenten Cliënten (MIC) systeem dat standaard in Nederlandse verpleeghuizen gebruikt wordt. Het gebruik van psychofarmaca van bewoners werd verkregen uit de medische dossiers.

De effectevaluatie in hoofdstuk 3 laat zien dat in de controlegroep 8 maanden na de nulmeting het percentage bewoners met een fixatieband onveranderd $19 \%$ bleef, terwijl het percentage in de interventiegroep verminderde van $17 \%$ bij de nulmeting naar $9 \%$ na 8 maanden. De gevonden effecten zijn statisch significant en bleven ook significant $(\mathrm{P}=.01)$ na correctie voor variabelen als leeftijd, geslacht, psychofarmaca-gebruik en verpleeghuis. De vermindering van het gebruik van fixatiebanden in de interventiegroep leidde niet tot een verhoogd gebruik van psychofarmaca of een toename van valpartijen dan wel valgerelateerde verwondingen.

Het preventieve effect van de EXBELT-interventie bij nieuw in het verpleeghuis opgenomen bewoners wordt in hoofdstuk 4 beschreven. Dit onderzoek is beperkt tot de bewoners die kort na de start van het EXBELT-onderzoek werden opgenomen (tot 4 maanden na de nulmeting) en die tevens op de tweede nameting (8 maanden na de nulmeting) aanwezig waren. De data laten een preventief effect van EXBELT zien: er werden in de interventiegroep minder fixatiebanden en andere vrijheidsbeperkende middelen gebruikt, zonder een toename van psychofarmacagebruik, vallen en val-gerelateerde verwondingen. Deze bevindingen moeten overigens voorzichtig worden geïnterpreteerd omdat het aantal deelnemers in deze studie gering was.

De procesevaluatie in hoofdstuk 5 toont dat de EXBELT-interventie in ruime mate volgens protocol is geïmplementeerd en heel goed is ontvangen door de medewerkers van de verpleeghuizen en de vertegenwoordigers van de bewo- 
ners. Van de procesevaluatie hebben wij geleerd dat de EXBELT- interventie verbeterd kan worden door aan de leidinggevenden van de verpleeghuizen voorbeelden aan te reiken met betrekking tot het communiceren van de beleidsverandering - het niet meer toepassen van fixatiebanden - naar medewerkers en familie van de bewoners. Daarnaast wordt aanbevolen om beschikbare consultants (gespecialiseerde verpleegkundigen) meer proactief in te zetten om medewerkers op de werkplek te ondersteunen bij het zoeken naar alternatieven voor het gebruik van vrijheidsbeperkende middelen.

In hoofdstuk 6 worden de resultaten gepresenteerd van een aanvullende meting, 24 maanden na de start van de EXBELT-studie. De centrale vraag in deze studie is of de gevonden resultaten - reductie van het gebruik van fixatiebanden en overige vrijheidsbeperkende middelen - blijven aanhouden op de lange termijn. Eerst werd gekeken naar alle 225 bewoners die zowel bij de nulmeting als na 24 maanden in het verpleeghuis verbleven. Bij de bewoners in de interventiegroep verminderde in die periode het gebruik van fixatiebanden met $65 \%$, terwijl dat in de controlegroep bij slechts $7 \%$ het geval was. Daarna werd bij alle bewoners $(n=689)$ van de controle- en interventieafdelingen die 24 maanden na de nulmeting aanwezig waren, het gebruik van vrijheidbeperkende middelen geregistreerd. Bij 13\% van de bewoners op de controle-afdelingen werden fixatiebanden gebruikt, terwijl het gebruik op de interventieafdelingen slechts 3\% was. Daarnaast was ook het gebruik van de meeste andere vrijheidsbeperkende middelen significant lager in de interventie- dan in de controlegroep.

Het laatste hoofdstuk (hoofdstuk 7) betreft de algemene discussie van het gehele onderzoekstraject. Eerst worden de belangrijkste bevindingen samengevat: de EXBELT-interventie leidt tot een wezenlijke vermindering en preventie van het gebruik van fixatiebanden. Daarnaast is het gebruik van overige vrijheidsbeperkende middelen verminderd. Het gebruik van psychofarmaca is niet toegenomen en er is geen toename van vallen of val-gerelateerde letsels. Vervolgens wordt in dit hoofdstuk ingegaan op het maatschappelijke belang van de EXBELT-studie en het belang van het verminderen van vrijheidsbeperkende middelen voor de kwaliteit van leven voor bewoners van psychogeriatrische verpleeghuizen. Tot slot worden de implicaties voor de dagelijkse praktijk en toekomstig onderzoek beschreven. Er moet aandacht voor de vermindering en preventie van vrijheidsbeperking blijven omdat er nog steeds te veel vrijheidsbeperkende middelen in verpleeghuizen en andere sectoren van de gezondheidszorg worden toegepast. 



\section{Dankwoord}

Promoveren doe je samen met anderen die naast dank ook felicitaties verdienen.

Als eerste gaat mijn dank uit naar de bewoners met hun vertegenwoordigers, medewerkers, leidinggevenden en bestuurders van de zorgorganisaties Sevagram, Vivre, Land van Horne en Florence. Hartelijk dank voor de samenwerking en het vertrouwen tijdens de onderzoeksperiode.

Het promotieteam bestaande uit Jan Hamers, Liz Capezuti, Erik van Rossum en Michel Bleijlevens was in elke fase van het EXBELT onderzoek mijn steun en toeverlaat. Steeds was het mogelijk om hulp te vragen en ontzettend veel heb ik van jullie mogen leren.

Beste Jan, aan jou heb ik het te danken dat ik aan dit proces beginnen kon. De wijze waarop jij mij in deze periode ondersteund hebt, is voor mij onmisbaar geweest.

Dear Liz, from the very outset of my studies, you had a very positive influence on me and my doctoral work. I knew that I would be able to fall back on your support, which at times was sorely needed. When writing the articles, you knew how to convey a clearer and more powerful message by leaving out a few words here and adding a word or two there. Many thanks for you encouragement and positive support.

Beste Erik, in alle rust heb je op het juiste moment de aanwijzingen gegeven zodat ik verder kon en steeds opnieuw heb jij hulp aangeboden. Alleen al het weten dat er hulp is als dat nodig is, heeft mij zeer geholpen. Dank voor de ontzettend prettige wijze van ondersteunen.

Beste Michel, ongeveer vier jaar hebben wij de kamer gedeeld en wij hebben de mogelijkheid gehad om uitvoerig onderwerpen te bespreken die veelal met het onderzoek van doen hadden. Het waren zeer zinvolle gesprekken waarbij jij mij hebt geholpen om zaken van uit verschillende, voor mij soms nieuwe, invalshoeken te bekijken. Het was bijzonder en goed voor mij. Michel, dank daarvoor.

Ton Ambergen dank ik voor de begeleiding en hulp bij het analyseren van de verzamelde data. Jouw geduld bij het verhelderen van de gevonden resultaten was voor mij waardevol. 
De leden van de beoordelingscommissie onder voorzitterschap van Prof. dr. Frans Verhey dank ik voor het lezen en beoordelen van het proefschrift.

De begeleidingsgroep van het EXBELT onderzoek was vooral tijdens het eerste jaar van het onderzoek actief en gaf in die periode zeer bruikbare adviezen. Hiervoor wil ik de leden van de begeleidingsgroep hartelijk danken. De leden waren: Terry Brouwers, Stefanie Linssen, Ine Smeets, Martijn Berger en Thijs Melchior.

Bij de uitvoering van het onderzoek zijn Ine Smeets en Terry Brouwers als gespecialiseerde verpleegkundigen actief betrokken geweest als ondersteuning bij scholing en consultancy die als interventies aangeboden werden. Yvonne Dolman en Stefanie Linssen hebben bij de individuele bewoners de observaties naar het gebruik van vrijheidsbeperkende middelen uitgevoerd en de resultaten geregistreerd. Sandra Stoffelen heeft deze duizenden gegevens op perfecte wijze ingevoerd. Ik dank deze dames zeer voor de werkzaamheden en de enthousiaste inzet voor het onderzoek.

De collega's van de vakgroep wil ik graag danken voor de fijne contacten, de leerzame gesprekken en de mooie momenten tijdens congressen. Het is moeilijk om hier namen te noemen en volgens mij hoeft dat ook niet.

De Raad van Bestuur van de MeanderGroep Zuid Limburg, Jos Meijerink en Roger Ruijters, ben ik zeer erkentelijk dat ze mij de ruimte hebben gegeven om naast mijn werk met onderzoek bezig te zijn en te kunnen promoveren. De collega-directeuren en veel anderen werkzaam bij de MeanderGroep hebben mij de noodzakelijke steun gegeven. Speciaal wil ik de leidinggevenden, medewerkers, vrijwilligers en Cliëntenraad van Verpleeghuis Lückerheide noemen, omdat zij vaak met mijn programma rekening hebben moeten houden.

Mijn familie, vooral mijn dochters Marieke en Anne, maar zeker mijn vrouw Anita, hebben soms even mijn aandacht moeten missen. Mijn excuus daarvoor, maar ik zal proberen dit in te halen. Anita heeft mij steeds aangespoord en nooit belemmerd om door te gaan. Deze steun was voor mij onmisbaar.

Helaas zijn er ook mensen die ik niet meer via deze letters kan bereiken en danken, aan hen denk ik op mijn manier.

Ik ben dankbaar dat ik de kans heb gekregen om te promoveren en dat jullie mij geholpen hebben om het waar te kunnen maken. 


\section{About the author}

Math Gulpers was born in Schaesberg, the Netherlands in 1951. After finishing school, he attended technical college where he trained to become a metalworker and car mechanic.

In 1972, he started studying for qualifications in care work and from 1975 onwards, combined this training with studies to qualify as a registered nurse. In 1980 he qualified as a registered psychiatric nurse. From 1980 to 1994 he worked as a training coordinator in a nursing home, and this included a period of study to become a second grade qualified nursing teacher, for which he qualified in 1990. In the same year he started a master's program in nursing science, which he successfully completed in 1995. From 1994 to 1999, he was administrator on a number of different wards in a nursing home. From October 2008 to 2013, he conducted the research which is presented in this PhD thesis. Whilst studying for his PhD, he attended EANS Summer Schools for Doctoral Studies in Witten Herdecke, Germany; Lund, Sweden; and Leuven, Belgium respectively over a three-year period (from 2010 to 2012) .

Since 1999 he has been a director at MeanderGroep Zuid-Limburg and is responsible for a psycho-geriatric nursing home, day-care for patients suffering from dementia, a day centre for visually impaired elderly persons, palliative night care at home and a hospice. 



\section{List of publications}

\section{International journal articles}

Hamers JP, Gulpers MJ, Strik W. Use of physical restraints with cognitively impaired nursing home residents. J Adv Nurs. 2004;45: 246-251.

Huizing AR, Hamers JP, Gulpers MJ, et al. Short-term effects of an educational intervention on physical restraint use: a cluster randomized trial. $B M C \mathrm{Ge}$ riatr. 2006;6: 17.

Huizing AR, Hamers JP, Gulpers MJ, et al. A cluster-randomized trial of an educational intervention to reduce the use of physical restraints with psychogeriatric nursing home residents. J Am Geriatr Soc. 2009;57: 1139-1148.

Huizing AR, Hamers JP, Gulpers MJ, et al. Preventing the use of physical restraints on residents newly admitted to psycho-geriatric nursing home wards: a cluster-randomized trial. Int J Nurs Stud. 2009;46: 459-469.

Gulpers MJ, Bleijlevens MH, van Rossum E, et al. Belt restraint reduction in nursing homes: design of a quasi-experimental study. BMC Geriatr 2010;10: 11.

Gulpers MJ, Bleijlevens MH, Ambergen T, et al. Belt restraint reduction in nursing homes: effects of a multicomponent intervention program. J Am Geriatr Soc 2011;59: 2029-2036.

Gulpers MJ, Bleijlevens MH, Capezuti E, et al. Preventing belt restraint use in newly admitted residents in nursing homes: a quasi-experimental study. Int J Nurs Stud 2012;49: 1473-1479.

Gulpers MJ, Bleijlevens MH, Ambergen T, et al. Reduction of belt restraint use: long-term effects of the EXBELT intervention. J Am Geriatr Soc 2013;61: 107-112.

Bleijlevens MH, Gulpers MJ, Capezuti E, et al. Process Evaluation of a multicomponent intervention program (EXBELT) to reduce belt restraints in nursing homes. Accept for publication 5 March 2013 in J Am Med Dir Asscoc 


\section{National journal articles}

Hamers JP, Gulpers MJ, Bleijlevens $\mathrm{MH}$, et al. Het reduceren van vrijheidsbeperking in verpleeghuizen. Tijdschrift voor Ouderengeneeskunde. 2009;5: 156-9.

\section{Conference abstracts}

Gulpers MJ, Bleijlevens MH, van Rossum E, et al. Effects of an intervention program on belt restraint reduction in nursing homes after 24 months. The Gerontologist, 2012;52(s1): 136. The Gerontological Society of America: 65th Annual Scientific Meeting, San Diego (CA), USA, November 14-18, 2012.

Gulpers MJ, Bleijlevens MH, van Rossum E, et al. Exbelt: the impact of a restraint reduction program on nursing staff attitudes. The Gerontologist, 2011;51(suppl 2): 539. The Gerontological Society of America: 64th Annual Scientific Meeting, Boston (MA), USA, November 18-22, 2011.

van Rossum E, Gulpers MJ, Bleijlevens $\mathbf{M H}$, et al. Belt restraint reduction in nursing homes: Design of an intervention study. The Gerontologist. 2010;50(suppl 1): 333. The Gerontological Society of America: 63rd Annual Scientific Meeting, New Orleans (LA), USA, November 19-23, 2010.

Gulpers MJ, Bleijlevens MH, van Rossum E, et al. Effectiveness of an intervention program on belt restraint reduction in Dutch nursing homes. The Gerontologist. 2010;50(suppl 1): 333. The Gerontological Society of America: 63rd Annual Scientific Meeting, New Orleans (LA), USA, November 19-23, 2010.

Bleijlevens MH, Gulpers MJ, van Rossum E, et al. Process evaluation of an intervention program on belt restraint reduction in Dutch nursing homes. The Gerontologist. 2010;50(suppl 1): 333. The Gerontological Society of America: 63rd Annual Scientific Meeting, New Orleans (LA), USA, November 19-23, 2010.

Gulpers MJ, Bleijlevens MH, van Rossum E, et al. Reducing the use of physical restraints in Dutch nursing homes: a pilot study. $J$ Clin Nurs. 2010;19(s1): 58. Fourth European Nursing Congress Older Persons: the Future of Care, Rotterdam, the Netherlands, October 4-7, 2010.

Gulpers MJ, Bleijlevens MH, van Rossum E, et al. Reducing belts from nursing homes: a pilot study. The Gerontologist, 2009;49(suppl 2): 459. The Geron- 
tological Society of America: 62nd Annual Scientific Meeting, Atlanta (GA), USA, November 18-22, 2009.

Hamers JP, Gulpers MJ. Reducing physical restraints in nursing homes: results of a pilot study. J Nutr Health Aging. 2009;13(Issue 1 Supplement): S17. The 20th IAGG World Congress, Paris, France, July 5-9, 2009.

\section{Awards}

Awarded with the Crebolder Award for Societal Impact (May 2011). Maastricht University/CAPHRI School for Public Health and Primary Care

Awarded with the first price for 'Best Presentation Gerontology' (February 2012) at the Geriatric Days (Geriatriedagen) in Den Bosch entitled "Reduceren van onrustbanden in verpleeghuizen: de effecten van de EXBELT interventie". 